\title{
The English resultative
}

by

\author{
Elizabeth Christie
}

A thesis submitted to the Faculty of Graduate and Postdoctoral Affairs in partial fulfillment of the requirements for the degree of

Doctor of Philosophy

in Cognitive Science

Carleton University

Ottawa, Ontario

(C) 2015

Elizabeth Christie 


\begin{abstract}
The purpose of this thesis is to augment our empirical knowledge of the English resultative and to provide a theoretical treatment of the syntax and semantics of the resultative using current linguistic tools. This involves using both theoretical and experimental methods to ensure that the model reflects human usage of natural language and follows the principles required for formal language modelling.

The main questions addressed are 1) Is the result phrase an argument, an adjunct, or something else (an added/derived argument, sometimes called an argumentadjunct)? 2) How do we best capture the properties of the resultative in a formal model? In order to address these questions, it must be determined what falls into the overall category of the resultative and how the resultative can be sub-classified into further sub-categories to best reflect the potentially distinctive properties of related resultative constructions. These divisions are then tested for fit with the theoretical categories of argument, adjunct and added/derived argument. Lastly, an analysis is provided using Lexical-Functional Grammar and Glue Semantics.
\end{abstract}




\section{Acknowledgements}

The work of writing a thesis is never a singular effort. Many people become important partners in the project over the time it takes to complete, and my journey was no different. Without the tireless efforts of those around me, the work that I did would have just been one person sitting at a desk typing, and would never have become a complete project in the end. To begin with, I would like to thank the scholarships and funding bodies which made my PhD possible, including the 2010 President's Doctoral Fellowship, the Kevin Sampson Scholarship, and the Wargaret Wade Labarge Fund. Without their generous support, this project would have never begun, let alone come to fruition in the form that it is now.

Next, I would like to thank the administrative team within my department: Colleen Fulton, May Hyde, Liane Dubreiul, Georgina Henderson, and, more recently, John Tracey. Your helpful knowledge and friendly smiles have made being in the department for the last five years much easier and more enjoyable.

To the members of the Logic, Language and Information Lab: thank you for all of your helpful comments and feedback, as well as the opportunity to share my ideas in a small group environment.

To my committee members, Kumiko Murasugi and John Logan, thank you for your support in designing and interpreting my emperiment. Without the many hours Kumiko dedicated to my study, I know I would still be sitting at my desk trying to decide how to get the type of information I needed from speakers.

Of course, this thesis would not have happened without the support of my family and friends. Bryan, my loving husband, you picked me up when things got difficult, and helped me concentrate when my mind would wander. I do not know how I would 
have faced the sheer volume of effort this took if I had not had your unwavering support. To my mother, father and sister, you endlessly fielded questions about whether or not a given sentence was still considered "Englsih" or not, and you did so without thinking (or at least without saying) how weird my questions were becoming. You kept me grounded and never let me forget what the world was like outside of of academia. And, Deirdre, my best friend, you reminded me that my struggles were normal, that I could handle whatever life threw at me, and, most importantly, you always gave me the boost I needed to feel confident about myself and my ideas.

Finally, and most important in the process of writing a thesis, my supervisors: Ash Asudeh and Ida Toivonen. Ash, your constant honesty and keen eye for the theoretical implications of my work kept me balanced and on track (no matter what speed I may, or may not, have been going). I could always count on your advice when things weren't at their best. Ida, although we didn't always see eye-to-eye on theory in our meetings, I always knew that you were there to support me and to make sure that I also enjoyed the social side of grad school. I know I could not have succeeded in completing my thesis without the two of you there to guide and support me. 


\section{Contents}

Abstract ........................... ii

Acknowledgements ............................ iii

1 Introduction 1

1.1 Defining the resultative . . . . . . . . . . . . 2

1.2 Arguments and adjuncts .................... 5

1.3 A note about terminology . . . . . . . . . . . . . . 7

1.4 Structure of the thesis . . . . . . . . . . . . . . . 8

2 Background $\quad 9$

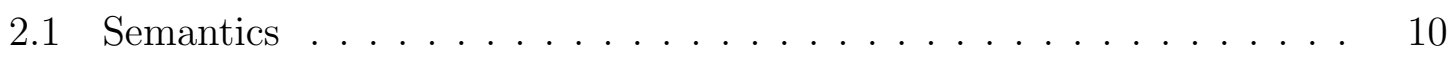

2.1.1 Pieces of the resultative . . . . . . . . . . . 10

2.1 .2 Telicity and the resultative .................. 23

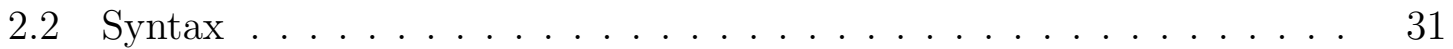

2.3 Conclusion . . . . . . . . . . . . . . . . . . . 37

3 The resultative and the argument/adjunct distinction 38

3.1 Introduction . . . . . . . . . . . . . . . 38

3.2 Tests for argumenthood . . . . . . . . . . . . . . 42 
3.2.1 Core participants (semantic selection) . . . . . . . . . 43

3.2.2 Syntactic obligatoriness . . . . . . . . . . . . . 44

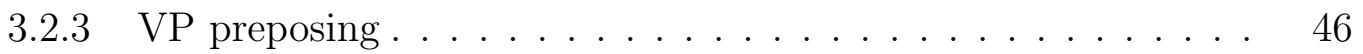

3.2.4 VP anaphora $($ do so $) \ldots \ldots \ldots \ldots$. . . . . . . . . . 47

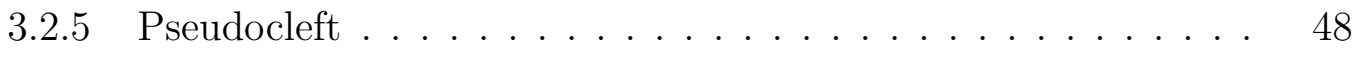

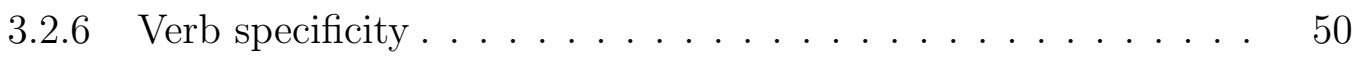

3.2.7 Fixed preposition . . . . . . . . . . . . . . . . 51

3.2 .8 Prepositional content . . . . . . . . . . . . . . . 52

3.2 .9 Uniqueness/iterativity ...................... 54

3.3 Testing the result phrase . . . . . . . . . . . 55

3.3.1 Semantic distinctions . . . . . . . . . . . . . 56

3.3.2 Argument structure distinctions . . . . . . . . . . . . 64

3.3.3 Lexical category distinctions . . . . . . . . . . . . . . 72

3.4 Conclusion . . . . . . . . . . . . . . . . . 80

4 Experimental results $\quad 81$

4.1 Introduction . . . . . . . . . . . . . . . . 81

4.2 Experiment 1: Transitive resultatives . . . . . . . . . . 83

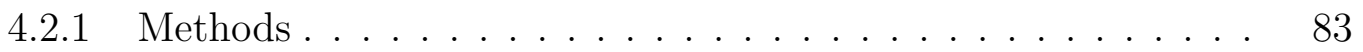

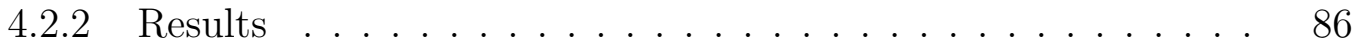

4.2.3 Discussion of experiment $1 \ldots \ldots \ldots$. . . . . . . . 88

4.3 Experiment 2: Unaccusative resultatives . . . . . . . . . . . . 89

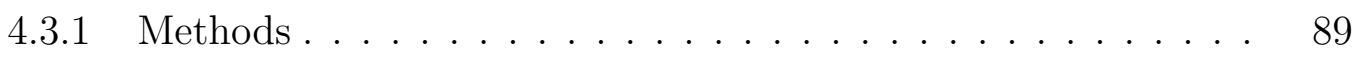

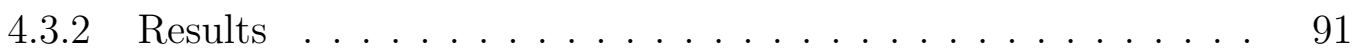

4.3 .3 Discussion of experiment $2 \ldots \ldots \ldots$. . . . . . . . . 92 
4.4 Experiment 3: Unergative resultatives . . . . . . . . . . . . . . 93

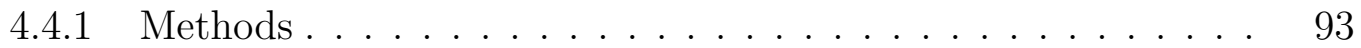

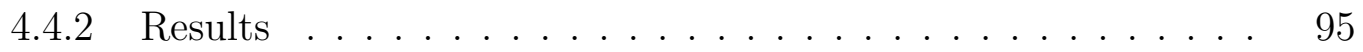

4.4.3 Discussion of experiment $3 \ldots \ldots \ldots 7$

4.5 General discussion . . . . . . . . . . . . . . . . 97

$\begin{array}{lll}5 & \text { Analysis } & 100\end{array}$

5.1 Introduction . . . . . . . . . . . . . . . . . . . . 100

5.2 Proposed resultative construction . . . . . . . . . . . . . . 100

5.3 Resultative templates . . . . . . . . . . . . . . . . 104

5.3.1 Resultative c- and f-Structures . . . . . . . . . . . 105

5.3 .2 Target semantics for the resultative . . . . . . . . . . . 113

5.3 .3 Proposed templates . . . . . . . . . . . . . . . . 115

5.4 Walking through the proofs . . . . . . . . . . . . . 124

5.4.1 Transitive property resultative . . . . . . . . . . . . 124

5.4 .2 Unaccusative path resultative . . . . . . . . . . . . . 134

5.4 .3 Fake reflexive property resultative . . . . . . . . . . . . . 141

5.5 Conclusions . . . . . . . . . . . . . . . . . 150

6 Conclusions and future work $\quad 152$

6.1 Conclusions . . . . . . . . . . . . . . . . . 152

6.2 Future work . . . . . . . . . . . . . . . . 154

$\begin{array}{ll}\text { Appendices } & 156\end{array}$

A Stimuli for experiment 1: Transitive resultatives 157 
B Stimuli for experiment 2: Unaccusative resultatives

C Stimuli for experiment 3: Unergative resultatives

D Participant Means and Standard Deviations 


\section{List of Tables}

2.1 Event Classes . . . . . . . . . . . . . . . . . . . . . 25

3.1 Argument/adjunct test results by semantic type . . . . . . . . 65

3.2 Argument/adjunct test results by argument structure type . . . . . . 72

3.3 Argument/adjunct test results by lexical category of result phrase . . 80

4.1 Single stimulus item for experiment $1 \ldots \ldots \ldots \ldots$

4.2 Single stimulus item for experiment $2 \ldots \ldots \ldots \ldots$

4.3 Single stimulus item for experiment $3 \ldots \ldots \ldots$

D.1 Participant means and standard deviations per condition for experiment $1 \ldots \ldots \ldots \ldots \ldots \ldots \ldots \ldots \ldots \ldots \ldots$

D.2 Participant means and standard deviations per condition for experiment $2 \ldots \ldots \ldots \ldots \ldots \ldots \ldots \ldots \ldots$

D.3 Participant means and standard deviations per condition for experiment $3 \ldots \ldots \ldots \ldots \ldots \ldots \ldots \ldots \ldots \ldots \ldots$ 


\section{List of Figures}

4.1 Mean response by result phrase type $($ Expt 1) . . . . . . . . 86

4.2 Mean response by target phrase location $($ Expt 1$) \ldots \ldots$. . . . 88

4.3 Mean responses by result phrase type $($ Expt 2) . . . . . . . . . . 91

4.4 Mean response by target phrase location (Expt 2) . . . . . . . 93

4.5 Mean response by result phrase type $($ Expt 3) $\ldots \ldots$. . . . . . 96

5.1 LFG templates for the resultative . . . . . . . . . . . . . 116

5.2 Logical proof for the sentence Kim hammered the metal flat . . . . . . 133

5.3 Logical proof for the sentence The syrup flowed down the tubes . . . . 140

5.4 Logical proof for the sentence Kim laughed herself silly . . . . . . . . . 148 


\section{Chapter 1}

\section{Introduction}

Sentences like (1) are referred to as resultatives:

(1) Kim hammered the metal flat.

In (1), Kim hammers the metal, and as a result, the metal becomes flat. This interpretation is what gives the construction its name: the final phrase of the sentence describes the result of the action of the sentence.

Resultatives have many interesting characteristics and have thus received considerable attention in the literature for nearly fifty years of syntactic research. However, there is still disagreement about the exact specifications a resultative sentence must meet to be considered part of the construction. This includes which phrase types are possible in the final phrase (the result phrase); what the formal semantic interpretation of a resultative sentence should be; and what kinds of result to consider.

The purpose of this thesis is to augment our empirical knowledge of the English resultative and to address the question of how to treat the resultative in a modern grammatical framework. This will include both theoretical and experimental methods 
to ensure that my model reflects human usage of natural language and follows the principles required for formal language modelling.

The questions to be addressed are 1) Is the result phrase an argument, an adjunct, or something else? 2) How do we accurately capture the properties of the resultative in a formal model? In order to address these questions, I will first try to determine what falls into the category of the resultative and how it can be divided to best reflect the potentially distinctive properties. Then I will see how those divisions stand up against the categories of argument, adjunct and added/derived argument. Finally, I will demonstrate how those resultatives can best be treated in a modern formal grammar.

This process will allow me to clarify the terminology from the literature to ensure that the resultative can be identified and treated in all of its guises. Additionally, I will be bringing the treatment of the resultative in Lexical Functional Grammar (LFG) in line with a more modern version of the formalism and adding more evidence in favour of using templates as more than just a computational shorthand in LFG.

\section{$1.1 \quad$ Defining the resultative}

The English resultative has been defined in many different ways in the literature. For the sake of clarity, I will begin by defining what I mean by the resultative construction, stating its key aspects, and laying out the key terminology which will be used in this thesis. The resultative is typically introduced as a transitive verb and an adjective phrase (2). However, the resultative can take many forms, with both transitive and intransitive verbs, combined with adjective, noun or preposition phrases. In his corpus research on the resultative, Boas (2003) gives two potential resultative sentence forms 
(3), which together show how varied the form of the resultative can be. From these two potential forms, we can pick out sentences which either contain or do not contain a postverbal noun phrase (NP) as well as any sentence which uses an adjective phrase $(\mathrm{x}=\mathrm{A})$, noun phrase $(\mathrm{x}=\mathrm{N})$, or preposition phrase $(\mathrm{x}=\mathrm{P})$ for the final element. These descriptions are obviously too broad for any formal definition of the resultative, as they would equally recognize (2) and (4) as resultatives, despite their meaning differences discussed below.

(2) Kevin hammered the metal flat.

(3) $\quad[\mathrm{NP} \text { V NP XP }]^{1}$ or $\left[\mathrm{NP}\right.$ V XP]: $:^{2}$ where $\mathrm{X}$ can be A, N or P

One key aspect of the resultative is its semantic interpretation: the action of the sentence causes the result state or location (the XP in (3)) to come about (Halliday, 1967). Thus, the basic meaning of (2) is "the action of Kevin hammering the metal caused the metal to become flat." This causative meaning distinguishes the resultative from the similar depictive construction (4). Although the depictive has the same form as (3), its meaning does not denote causation, but rather a co-temporal link between the action of the main verb and the state described by the XP. Thus, the interpretation of (4) would be "when Kevin served the soup, it was cold."

(4) Kevin served the soup cold.

There are different types of the resultatives including the transitive resultative (2), (8) and (9), the unaccusative resultative (5), the fake object resultative (6), and the fake reflexive resultative (7).

\footnotetext{
${ }^{1}$ Boas, 2003, (1.2)

2 Boas, 2003, footnote 2
} 
(5) The river froze solid.

(6) Sam ran her shoes threadbare.

(7) Kim danced herself dizzy.

(8) Kelly smashed the vase to pieces.

(9) Riley dyed her pants a bright red.

Another way to classify the resultative refers to the syntactic category of the head of the result phrase. Using the same sentences, we can also describe the adjectival resultative $((2),(5)-(7))$, the prepositional resultative (8), and the nominal resultative (9).

The results in (5)-(9) are all properties. However, similar examples can be given using path results: transitive (10), unaccusative (11), fake object (12), and fake reflexive (13). For all path resultatives, the head of the result phrase is a preposition, as that is how English encodes information about paths.

(10) Rory rolled the ball down the hill.

(11) The ball rolled down the hill.

(12) The boat owner jumped into the water and swam the boat to shore. http://sheltonherald.com/23452/boat-accident-reported/ (Retrieved Nov 20, 2013)

(13) William took out this barbell thing and had her hold on to it while she swam herself across the pool.

https: //cadycupcake.wordpress.com/2011/06/17/first-swim-lesson/ 
(Retrieved Nov 20, 2013)

With such a large variety of potential sentences for the resultative construction, there is a great risk of terminological confusion. For example, in some works on the resultative (Boas, 2003; Goldberg and Jackendoff, 2004), intransitive resultative refers to only those resultatives without a postverbal NP (5) and (11), while in others (Simpson, 1983b; Carrier and Randall, 1992; Goldberg, 1995; Washio, 1997; Kratzer, 2005; MacGregor, 2009; Randall, 2010, among others) it refers to any resultative sentence formed with a verb which is normally intransitive ((5), (6), (7), (11), (12), and (13)).

\subsection{Arguments and adjuncts}

Arguments and adjuncts are broad classes of phrases within formal grammar. Arguments are elements which are usually defined as being central to the action denoted by the verb (Haegeman, 1994; Tallerman, 2005; Williams, 2015, among others). They are frequenltly tied to the verb through some form of argument-structure relationship, for example, the linking theories of Jackendoff (1990), Goldberg (1995), Goldberg and Jackendoff (2004) and Randall (2010) or the a-structure level of abstraction in Lexical Functional Grammar (Bresnan and Zaenen, 1990; Dalrymple, 2001, among others). A common example of an argument is the postverbal noun phrase that is typically referred to as an object (or direct object) of the verb, the ball in (14).

(14) Kelly kicked the ball on Tuesday.

Adjuncts, on the other hand, are additional information that can be added to any event, and which are frequently left unspecified in a discourse. They are seen as 
optional, additional information that can be incorporated into a description of an event. A common example of an adjunct is a phrase which denotes the time or location of the event being described, like the temporal marker on Tuesday in (14).

This binary distinction is not without its controversy, and many researchers have pointed out that this distinction lacks the ability to properly convey the relationship between certain types of phrases and the verbs that govern them, including directional arguments (into the store in (15)) (Hall, 1965; Dowty, 2003; Van Luven, 2014), instrument phrases (with a key in (16)) (Van Valin and LaPolla, 1997) and benefactives (for Kim in (17)) (Toivonen, 2013b).

(16) Kelly opened the door with a key.

(17) Kelly baked a cake for Kim.

These types of arguments have been called added or derived arguments in the literature and have been the subject of recent research. Prototypical arguments and adjuncts both exhibit distinctive syntactic and semantic characteristics. The behaviour of a given phrase with respect to these distinctive characteristics allow researchers to separate arguments from adjuncts, and when the phrase in question does not pattern consistently in one direction or the other, it can be seen as an added argument. Chapter 3 will discuss both the tests from the literature and how the resultative patterns with respect to those tests. 


\subsection{A note about terminology}

In this thesis, I will try to be consistent with my use of terminology. To assist with this consistency, I will lay out the major divisions of what I will refer to with specific terms here. First, the resultative (or an indefinite use of that noun phrase) will refer to the entire structure as a whole, usually a sentence. The result phrase will refer just to the XP in (3) which contains the result predicate: flat in (18), across the room in (19) and solid in (20).

(18) Kim hammered the metal flat.

(19) Tony danced himself across the room.

(20) The river froze solid.

Transitive resultative will refer to resultatives formed with transitive verbs as the main predicate (18). Unaccusative resultative will refer to resultatives which contain a main predicate that is an intransitive unaccusative verb (20), a discussion of which will take place in section 2.1.1. Unergative resultative will refer to resultatives which contain a main predicate that is an intransitive unergative verb (again, further discussion in section 2.1.1), and must contain either a non-subcategorized object or a fake reflexive pronoun (19). Finally, property resultative will refer to all resultative sentences which denote a final state as a result of the main verbal action; and path resultative will refer to all resultative sentences which denote a transition to a new location as a result of the main verbal action. 


\subsection{Structure of the thesis}

The thesis will be structured as follows: Chapter 2 will review the resultative literature, including the various ways in which the resultative has been divided in previous resultative treatments, as well as the major components which mark the resultative as a construction unto itself; Chapter 3 will discuss tests for argumenthood from the literature and apply those tests to three different ways of sub-dividing the resultative in order to determine how to divide the resultative for a formal analysis; Chapter 4 will discuss an acceptability judgement task which measures the status of the result phrase according to one of tests discussed in Chapter 3; Chapter 5 will propose a formal treatment for the resultative with the formal architecture of Lexical Functional Grammar and Glue Semantics in light of both the theoretical conclusions of Chapter 3 and the experimental conclusions of Chapter 4; finally, Chapter 6 will provide some final conclusions for the thesis. 


\section{Chapter 2}

\section{Background}

The resultative has a long history of research, and thus there is much to introduce for the background of this thesis. To get a good understanding of the resultative before we evaluate its features in the following chapters, we will first need to review the structure, its history in the literature, its syntax, its semantics, and the ways that it intersects other important areas of research, including the structure of events. The chapter will be structured as follows: Section 2.1 will describe the semantic properties of the resultative including a description of the resultative interpretation (2.1.1) as well as describing how telicity interacts with the resultative (2.1.2). Section 2.2 will describe the syntactic properties of the resultative. 


\section{$2.1 \quad$ Semantics}

\subsubsection{Pieces of the resultative}

\section{The resultative interpretation}

In order to infer the major components of the resultative interpretation, I will compare semantic representations of resultative sentences and non-resultative sentences which contain the same main verb and object. I will then look at the semantic representation for each type of resultative in turn, and see which conjuncts are common to all types to determine what belongs in the resultative as a whole.

Sentence (21-a) can be interpreted informally as "Kim beat the metal and because of that the metal became flat". From that, we can propose the simplified semantic representation in (21-b) ${ }^{1}$ setting aside tense, aspect and the structure of definite noun phrases.

a. Kim beat the metal flat.

b. $\quad \exists s \exists e$. beat $(e) \wedge \operatorname{agent}(e)=\operatorname{Kim} \wedge \operatorname{patient}(e)=$ the.metal $\wedge$ flat $(s) \wedge$ $\operatorname{patient}(s)=$ the. metal $\wedge$ cause $(s)=e$

This simple interpretation includes two event variables, $e$ and $s$, which are related to each other via a causal chain stating that event $e$ causes state $s$. Additionally, there are semantic roles listed for the event participants, namely an agent and a patient for $e$ and a patient for $s$, which is the same entity as the patient in $e$. These filled roles come together to give us the interpretation that Kim beat the metal and, because of this action, the metal became flat.

\footnotetext{
${ }^{1}$ The formula in (21-b) has been adapted from (3.24) in MacGregor (2009).
} 
Let us now compare (21) to the corresponding non-resultative sentence.
a. Kim beat the metal.
b. $\quad \exists e$. beat $(e) \wedge \operatorname{agent}(e)=\operatorname{Kim} \wedge$ patient $(e)=$ the.metal

A comparison of the semantic representations of resultative sentences and their nonresultative counter-parts reveals the information which is contributed by the presence of the result phrase. For the transitive property resultative, we can compare (21-b) and (22-b) to note the existence of three additional conjuncts: an existentially bound event argument $s$ (which is specified by the predicate flat), a patient role for that event (the metal), and a causal link between the two events.

The same comparison can be made with the unaccusative property resultative to determine the information attributable to the result phrase in this type of sentence. Below I have an unaccusative property resultative sentence (23-a) and its semantic representation (23-b).

a. The river froze solid.

b. $\exists s \exists e . f r e e z e(e) \wedge$ patient $(e)=$ the.river $\wedge$ solid $(s) \wedge$ patient $(s)=$ the.river $\wedge$ $\operatorname{cause}(s)=e$

The non-resultative counterpart of (23-a) is given in (24-a), and the semantic representation is given in (24-b).
a. The river froze.
b. $\quad \exists$ e.freeze $(e) \wedge$ patient $(e)=$ the.river

These two examples and their semantic interpretations differ in that the representation of the resultative sentence (23-b) includes three conjuncts which are not present 
in the representation of the non-resultative sentence (24-b): an existentially bound event argument $s$ (which is specified by the predicate solid in this instance), a patient role for that event (the river), and a causal link between the two events. These are the same three additional conjuncts that occur in the transitive property resultative, and, as we will see, they will occur in the unergative resultative as well.

Finally, I will look at the unergative property resultative and its non-resultative counterpart. First, I will look at the resultative sentence (25-a) and its associated representation (25-b) to complete our inventory of resultative interpretations.
a. Kim danced herself breathless.
b. $\quad \exists s \exists e . \operatorname{dance}(e) \wedge \operatorname{agent}(e)=\operatorname{Kim} \wedge \operatorname{patient}(e)=\operatorname{Kim} \wedge \operatorname{breathless}(s) \wedge$ $\operatorname{patient}(s)=\operatorname{Kim} \wedge \operatorname{cause}(s)=e$

Next we can compare that to the non-resultative sentence (26-a) and its associated representation (26-b).
a. Kim danced.
b. $\quad \exists e$ dance $(e) \wedge \operatorname{agent}(e)=\operatorname{Kim}$

As with the other types of resultatives, three logical conjuncts were present in the representation of the unergative property resultative sentence (25-b) that are not present in the representation of the non-resultative sentence (26-b): an existentially bound event argument $s$ (which is specified by the predicate breathless in this instance), a patient role for that event (Kim), and a causal link between the two events. Additionally, the semantic representation of the resultative sentence has a patient role for the main predicate's event $e$ which is not present in the semantic representation of the non-resultative sentence, and is a specific addition for the unergative resultative. 
Thus, we have now seen three pieces of information present in the representation of all types of resultative sentences which are not present in the representation of the non-resultative versions of the sentences: an existentially bound event argument $s$, a patient role for that event, and a causal link between the two events. These three pieces of information, then, represent the resultative interpretation, as they are what set resultative sentences apart from non-resultative sentences. Additionally, the unergative resultative adds a patient argument to the main verb, an addition which is specific to that formulation of the resultative.

In order to describe something as secondary predication, there must be at least the first two of my described pieces of information (a second predicate, and an argument for that predicate), and the third piece of information (a causal link between the main and added events) is what marks the resultative as its own construction and makes it different from the similar depictive construction.

These observations have been made previously. Halliday (1967) noted the causal link between the two events, stating that because the second action results from the first, we refer to these sentences as resultatives, and others as depictives (pp. 6263). Simpson (1983a b) used a lexical rule to add a predicate and give that predicate a subject (which is semantically a patient). Jackendoff's (1990) AP resultative adjunct, and spatial resultative linking rules as well as Goldberg's (1992) resultative construction incorporated both the added event and the causal link between the two predicates. Napoli (1992) described all three in her comparison of English and Italian resultatives. Verspoor (1997) stressed the importance of the causal link between the main and secondary predicate by setting aside any so-called resultatives which do not contain that link. Kratzer (2005) discussed the causal link at length, stressing 
that there can be no intervening causal states for a resultative interpretation to be appropriate. Beavers (2012) describes all of these features in his comprehensive handbook chapter. For more discussion of these properties, see also Bresnan and Zaenen (1990); Carrier and Randall (1992); Goldberg (1995); Levin and Rappaport Hovav (1995); Bowers (1997); Washio (1997); Rappaport Hovav and Levin (2001); Boas (2003); Broccais (2003); Goldberg and Jackendoff (2004); Irimia (2005); Wechsler (2005); Iwata (2006); MacGregor (2009); Thepkanjana and Uehara (2009); Christie (2010); Whelpton (2010); Mateu (2011); Christie and Toivonen (2013); Grône (2014); Wechsler (2015), and Williams (2015).

\section{The shared argument}

In addition to noting the basic elements of meaning contributed by the presence of a result phrase, we can also look at how the resultative interacts with both the main verb and the shared argument. We can begin by looking at the following examples:

(27) Kim hammered the metal flat.

(28) Josephine danced herself silly.

(29) The river froze solid.

These examples show that the result phrase can be predicated of the object of a transitive verb (27), a fake reflexive pronoun in object position (28), or the subject of an intransitive verb which falls into a class traditionally referred to as unaccusative.

Starting with Perlmutter (1977), the subject of an unaccusative verb has been treated as the "original" or "underlying" object of that verb. This status as an underlying object has been captured in different ways in a variety of frameworks; see 
Perlmutter (1977) for Relational Grammar, Burzio (1986) for Government and Binding, and Simpson (1983b) for classical Lexical Functional Grammar. Assuming the underlying object status of unaccusative subjects, a generalization appears: the result phrase is predicated of objects, both surface and underlying. This generalization was first noted by Simpson (1983b), and was coined as the Direct Object Restriction or DOR by Levin and Rappaport Hovav (1995).

Previous LFG analyses of the resultative have dealt with the underlying object status of the subject of an unaccusative in various ways. Simpson (1983a b) posits a lexical rule which applies to unaccusatives and states that the object of the verb becomes the new subject, which she states is "equivalent to the passive rule" (Simpson, 1983b, p. 157).

Bresnan and Zaenen (1990) recast Simpson's analysis in Lexical Mapping Theory. In their analysis, the unaccusative subject is not an underlying object. Instead, it is a [- r] argument, and Bresnan and Zaenen (1990) assume that result phrases are always predicated of $[-\mathrm{r}]$ arguments. See Chapter 5 for more details on Bresnan and Zaenen's (1990) analysis.

\section{Unaccusative and unergative}

At this point, it is prudent to note that there are at least two ways of defining the distinction between unaccusative and unergative verbs: through the underlying configuration (where the object originates in the structure) and location of the patient argument (following authors like Perlmutter (1977); Perlmutter and Postal (1984); Baker $(1988,1996)$, among others); and through the telicity of the intransitive verb (following authors like Tenny (1994); van Hout (2004), among others). 
In order to decide which method of classifying unaccusative and unergative better matches the resultative data, we can look at a series of intransitive resultatives of both types and determine if the similarities between the groups come from an agent or patient subject; or from an event which would be telic without the result phrase.

It will be assumed here that whether a resultative which is formed with an intransitive verb requires a fake reflexive is tied to the distinction between unaccusative and unergative verbs: unergative resultatives require a fake reflexive object, and unaccusatives do not. Of course, it is possible that the appearance of a fake reflexive object can be independently motivated. However, I will stick with the traditional assumption that a fake reflexive object is a marker of unergativity. To ensure that this assumption will not introduce errors into my treatment, the next section will investigate the following question: Do intransitive verbs with agent subjects require a fake reflexive object and intransitive verbs with patient subjects disallow fake reflexives; or, do inherently atelic verbs take a fake reflexive object and inherently telic verbs disallow a fake reflexive?

A close look at the resultative shows that many of the unaccusative and unergative examples do not show a difference between the telicity and patient-as-subject explanations. Where the two types differ, more examples follow the predictions of the patient-as-subject model than follow the predictions of the telicity model, but examples of both do exist. For example, in (30-a) the verb is atelic, so the telicity model would predict that the resultative version would require a fake reflexive, while the subject is a patient, so the patient-as-subject model would predict no post verbal object. Example (30-b) indicates that the patient-as-subject model made the right predictions. 

a. The window banged.
b. The window banged shut.

On the other hand, the telicity model would predict no post-verbal object for the telic bolting event in (31-a), while the patient-as-subject model would predict a fake reflexive for the agentive action. Example (31-b) shows that in this instance the telicity model is correct and there is no post-verbal object.

a. Five hostages bolted.

b. Five hostages bolted to safety from gunman. (Twitter post by @Independent, Dec 15, 2014)

Examples also exist which fit neither of the models of the unaccusative as well as both of them. But, I will argue that the patient-as-subject model better fits these examples. Where the post-verbal object is optional ${ }^{2}$ for an intransitive resultative, adding it imbues a sense of volitionality to the subject of the sentence which implies that subject is seen as an agent in the action, whether they are animate or not. To begin with, we can compare (30-b) to (32). Intuition tells us that the addition of the reflexive imposes an agentive interpretation which is unavailable without it.

The window banged itself shut.

The same agentive imposition can be seen in the corpus examples (33)-(36). A robot can be seen as simply performing the action it was designed to do and wheel into a given location (33), but when a reflexive pronoun is added, the robot must be acting on its own (34). Similarly, the bottle in (35) is seen as simply doing what gravity

\footnotetext{
${ }^{2}$ Levin and Rappaport Hovav (2005) note examples with a similarly optional fake reflexive, but do not discuss the volitionality added by the reflexive pronoun.
} 
would force it to do, while in (36) it is describing a self-propelled action in a short film.

(33) [They] watched intently as the robot wheeled across the table, angled to the right, came to a halt and tried to lift a "weight" built from Legos. (Pasco Tribune, Dec 1, 2012 http://tbo.com/pasco-county/rushe-middle-schoolhosts-student-robotics-competition-today-578632)

(34) After the demo was done, the robot wheeled itself off stage. (BostInno, Jan 22, 2015 http://bostinno. streetwise.co/2015/01/22/boston-robotics-companies-jibo-irobot-googles-boston-dynamics-make-news/)

(35) "We're sinking into a deep sea crevasse! Davy Jones's locker, here we come!" cried Jake as the bottle rolled over the edge and plunged toward the concrete sidewalk. (Battle in a Bottle by Frank Asch, page 52)

(36) Dollar bill buys drink with someone drinking and throwing bottle on ground. Bottle rolls itself to recycle can and throws itself away. (Video description for Recycle Stop Motion video, uploaded by a teacher user http://www . schooltube.com/video/069dff50462346bda803/Recycle)

Thus, even though there is evidence in favour of both models of unaccusativity, I will be following the patient-as-subject model for my treatment of resultatives for two main reasons: many existing resultative treatments utilize the patient-as-subject model; and where minimal pairs exist, the addition of the pronoun gives a sense of volitionality or agentivity to the action denoted by the main verb, which is consistent 
with the patient-as-subject model. ${ }^{3}$

\section{Subject-directed resultatives}

Both the DOR and the use of the resultative as a test for unaccusativity in English, stem from the resultative necessarily being predicated of an object (which, in turn, assumes that the unaccusative subject must be an underlying object). However, subject-directed resultatives formed from transitive verbs have been noted in the literature (Verspoor, 1997; Toivonen, 1999, 2002, 2003; Wechsler, 1997, 2000, 2005; Grône, 2014). Goldberg and Jackendoff (2004) give the examples in (37)-(40): ${ }^{4}$ which all take the subject of the main clause as the host of the resultative action.

(37) Bill followed the road into the forest.

(38) We drove Highway 5 from S[and] D[iego] to S[an] F[rancisco].

(39) The sailors rode the breeze clear of the rocks.

(40) John danced mazurkas across the room.

${ }^{3}$ Levin and Rappaport Hovav (1995) (section 5.1.1) give evidence of manner-of-motion verbs which can be seen in both the unaccusative and unergative patterns, including swim (i) and dance (ii) (from their examples (15)-(16)).

(i) a. They slowly swam apart.

b. Don't expect to swim/jog yourself sober!

(ii) a. She danced/swam free of her captors.

b. He danced his feet sore.

However, they additionally note that these examples cannot change patterns with the same phrases as their dependants, stating that they may be of different classes.

${ }^{4}$ Examples (37)-(40) are from Goldberg and Jackendoff (2004) examples (11a)-(11e). 
Wechsler $(1997,2000)$ points out the following additional subject-directed path resultatives in $(41)-(42) .^{5}$

(41) The wise men followed the star out of Bethlehem.

(42) He followed Lassie free of his captors.

Verspoor (1997) gives examples (43)-(45), which show that subject-directed resultatives are available to both property and path resultatives. However, subject-directed path resultatives seem to be more common. Toivonen $(2003,2006)$ allows both subject-predicated and object-predicated transitive resultatives by allowing the subject of the result phrase to be any CORE GRAMMATICAL FUNCTION, which includes SUBJECT, OBJECT and OBJECT .

(43) John danced Mazurkas across the room.

(44) John swam laps to exhaustion. (property resultative)

(45) The children played leapfrog across the park.

All of these examples show that the resultative can be predicated of a transitive subject, and thus the assumption that the result phrase can only be predicated of an object (underlying or otherwise) does not hold. However, the generalization seems to be that the result phrase is usually predicated of the patient of the main predicate, except in a minority of examples (most of which are path resultatives). Verspoor (1997) claims that the subject-directed examples are not problematic for the resultative as a whole by pointing out that they "differ enormously" from other resultatives in four ways: (1) there is no element of causation, (2) the goal phrase is restricted

\footnotetext{
${ }^{5}$ Examples (41)-(42) are from Wechsler (1997), (15a) and (15c), respectively.
} 
by the semantics of the verb, (3) the meaning shift in these cases (from manner of motion to directed motion) can be induced by context, and (4) the end-point for the change of state is non-specific (Verspoor, 1997, p. 151). She additionally notes that subject-directed resultatives must encode transition along a path, and gives (46) as evidence, since exercise is a manner-of-motion verb which does not entail motion along a path. ${ }^{6}$ This example does improve if the reflexive is used (47), but with that addition, it is no longer subject-directed, and thus whether or not it entails motion along a path is not relevant to Verspoor's (1997) argument.

*Mildred exercised into the room.

Mildred exercised herself into the room.

However, Verspoor's reasoning doesn't seem to work for all of her points. Firstly, it is not clear that the element of causation is missing completely from these examples, as the "John danced Mazurkas and because of this he ended up across the room." interpretation is still available for these examples. So, there must be some form of causation between the main event and secondary predicate event, it just may not be the direct causation needed for most resultatives (as the dancing caused motion and the motion caused traversal). Secondly, there are many resultative verbs which have a change in meaning induced by the context of the resultative, including the repetitive action interpretation in (48).

(48) The dog barked itself hoarse.

\footnotetext{
${ }^{6}(46)$ is from Verspoor (1997), (4.110)
} 
Finally, not all of the end-points in the subject-directed resultatives are non-specific. In fact, the end-point in (38) is specific, and can be achieved the moment one crosses into San Francisco.

Beavers (2012) deals with subject-directed resultatives by stating that the examples are still being predicated of a patient-like argument (emphasis mine), and thus can be treated in a similar manner to object-directed examples. He states this is possible in one of two ways: either by using Wechsler's (1997) expansion of the concept of patient to include some arguments of V's that do not change but could; or by utilizing Rappaport Hovav and Levin's (2001) expanded category of "force recipient" which includes patients as well as the arguments picked out by the What $X$ did to $Y$ diagnostic from Jackendoff (1990) (Beavers, 2012, p. 913). Beavers, however, does not weigh in on which method of resolving this issue would be the better solution, stating only that both are viable options to conserve the generalization that resultatives are normally predicated of an object while dismissing the DOR.

As I will discuss in Chapter 3, path resultatives are different from property resultatives in several ways. In order to account for the full range of resultatives, the two types of resultatives will need to be considered as separate phenomena, even though they share similar properties. Given that I will be treating property and path resultatives differently for independent reasons, the fact that the majority of the anomalous examples here come from a category of resultatives which exhibit other non-standard properties only adds to the evidence that these two phenomena are related but distinct constructions in English.

In conclusion, the resultative interpretation consists of three key pieces of information in all of its forms: an existentially bound argument, a patient role for 
that event/state argument, and a causal link between the main predicate and the added (or secondary) predicate. Additionally, the unergative resultative also adds a patient/object to the main predicate. The resultative is usually predicated of the object of a transitive verb, the fake object of an unergative verb or the subject of an unaccusative verb. As such, it has been used as a test for unaccusativity in English as this group of arguments has classically been seen as objects, either surface or underlying. However, that generalization does not stand when subject-directed resultatives are included in the analysis. Thus, a complete analysis of the resultative should capture all of these features.

\subsubsection{Telicity and the resultative}

Telicity is a property of verb phrases which is based on whether the event that is being described has an end-point (delimited events), or not (non-delimited events) (Vendler, 1967; Dowty, 1979; Tenny, 1992, 1994). Delimited events have an end-point, whereas non-delimited events do not. Citing tests devised by Dowty (1979), Krifka (1989, 1992) terms the verbal expressions of these two types of events as telic and atelic, stating "a verbal expression is atelic if its denotation has no terminal point, and it is telic if it includes a terminal point" (Krifka, 1992, p.30). Kearns (2006) gives six tests

for telicity: the ability to combine with in-adverbials; the "take time" expression; the ability to combine with for-adverbials; the sub-interval property; the entailment of the progressive (or the imperfective paradox); and, the intersection of event duration and the progressive.

The resultative as a whole is often described as definitionally having an end-point (Simpson, 1983b; Van Valin, 1990; Napoli, 1992; Tenny, 1994; Levin and Rappa- 
port Hovav, 1995; Wechsler, 2000; Rappaport Hovav and Levin, 2001; Boas, 2003; Christie, 2011). In fact, it is so commonly assumed that the resultative is telic that Boas (2003) states that the telic status of the resultative is uncontroversial (p. 134). Indeed, the telicity of the resultative is assumed in several resultative descriptions including Napoli (1992); Wechsler (1997); Kratzer (2005); van Egmond (2009), and MacGregor (2009); both Beavers $(2002,2008)$ and Wechsler $(2000,2005)$ discuss why the resultative must be telic; and, Levin and Rappaport Hovav (1995) call the resultative a delimiter when describing its aspectual properties (Levin and Rappaport Hovav, 1995, pp. 56-58). To explore the telicity of the resultative, we can look at (49). In this example, the event ends when the table reaches a clean state, and the table must have reached a state which the speaker is satisfied to characterize it as completely clean for the sentence to be true, making (50) odd (or perhaps interpretable only as a scathing remark on Kathy's table-wiping abilities). Resultatives, then, "describe events with a definite end-point ... they are accomplishments or achievements" (Wechsler, 2000, p. 4).

(49) Kathy wiped the table clean.

(50) ?Kathy wiped the table clean, but it's still dirty.

According to Vendler (1967), events can be broken down into four different categories (state, achievement, activity/process and accomplishment) according to three criteria: (1) whether the event in question entails a change; (2) whether the event takes place over time; and, (3) whether the event is bounded in time (summarized in Table 2.1). Additionally, Smith (1991) describes the category of semelfactives (added as a final line in Table 2.1), which are events that reset themselves to their starting 


\begin{tabular}{l|ccc} 
& Denotes a change & Has a duration & $\begin{array}{c}\text { Bound in time } \\
\text { (has a telos) }\end{array}$ \\
\hline State & - & + & - \\
Achievement & + & - & + \\
Activity/Process & + & + & - \\
Accomplishment & + & + & + \\
Semelfactive & + & - & -
\end{tabular}

Table 2.1: Classes of events according to Vendler (1967) and Smith (1991)

states upon completion (like cough, or tap). According to this classification system, Wechsler's assertion that resultatives are accomplishments or achievements means that resultatives necessarily have end-points and denote a change, but may differ in their duration.

However, the telic status of the result phrase has come into question in recent years. Goldberg and Jackendoff (2004) specifically argue that resultative sentences can be atelic, citing examples like (51)-(55). ${ }^{7}$

(51) For hours, Bill heated the mixture hotter and hotter.

(52) For hours, Bill hammered the metal ever flatter.

(53) For years, Penelope wove the shawl longer and longer.

(54) Bill floated down the river (for hours).

(55) Bill pushed Harry along the trail (for hours).

Additionally, Folli and Harley (2006) argue extensively for the existence of atelic resultatives with manner-of-motion verbs, including (56)-(59), and suggest, following Borer (2005), that the notion of end-point telicity be relaxed for the resultative to

\footnotetext{
${ }^{7}$ Examples (51)-(55) are Goldberg and Jackendoff's (2004) examples (23a-c), and (24c-d), respectively.
} 
the more general "threshold telicity" (Folli and Harley, 2006, pp.127-128).

(56) John waltzed Matilda around and around the room for hours.

(57) John walked Mary along the river all afternoon.

(58) John ran the dog up and down the path for hours.

(59) John jumped the horse back and forth across the ditch for 30 minutes.

Beavers (2008) specifically dismisses the Goldberg and Jackendoff (2004) examples, stating that those examples have "highly particular morphology [and are] not indicative of the larger tendency of resultatives towards telicity. In a later paper, Beavers (2012) states that telicity may be a default for resultatives (Beavers, 2012, p. 926), adding that "the semantics of change has outpaced work on resultatives for the last ten years" (Beavers, 2012, p. 927), leaving it as an open question for research to explore whether the understanding of resultatives as necessarily telic should be revised in light of recent work on the semantics of change.

However, the existence of atelic examples must be addressed in some way, and some of these examples may be optionally telic (60-62).

(60) Bill heated the mixture hotter (than it was before).

(61) Bill hammered the metal flatter (than it was before).

(62) Penelope wove the shawl longer (than it was before).

First, they can freely occur with both for 3 hours (the atelic marker) and in three hours (the telic marker) (63-a)--(63-b). 
a. Bill heated the mixture hotter (than it was before) in three hours / for three hours.

b. Bill hammered the metal flatter (than it was before) in three hours / for three hours.

c. Penelope wove the shawl longer (than it was before) in three hours / for three hours.

Additionally, according to Kearns, finishing an event requires both a duration and an end-point (Kearns, 2000, p. 214). So, if an event can be finished, it must have an end-point: ${ }^{8}$
a. Bill finished heating the mixture hotter.
b. Bill finished hammering the metal flatter.
c. Penelope finished weaving the shawl longer.

Thus, according to these two tests, these apparently atelic resultatives must have telic interpretations, as they can both take place in a specific period of time, and can be described as a finished event. So we must conclude that there is more than just atelicity going on in these examples.

According to Beavers's (2012) notion of incremental theme, specific end-points are those which are obviously bound on one, or both, ends of a scale (which normally occur in the resultative). Non-specific end-points are those which achieve a goal, but that goal can iteratively change. Wechsler (2005) also notes that "iterative aspect" is possible in the resultative, and that "it is not sentence telicity per se that this

\footnotetext{
${ }^{8}$ Kearns is using this data to discuss the difference between telicity and boundedness. However, for my purposes I will treat these two concepts as the same thing. For more discussion of boundedness and telicity, see Depraetere (1995).
} 
construction requires" (Wechsler, 2005, p. 269), in light of (65).

$$
\text { John hammered metal flat for hours. }{ }^{9}
$$

We can apply Beavers' notion of specific versus non-specific end-points to the resultative in that most result phrases are specific, like flat, breathless or, clean in (66-a)-(66-c), but the atelic examples (51)-(64-c) can be seen as non-specific end-points, as demonstrated by the addition of the phrase than it was before which specifies an intermediate end-point in (60)-(62). For example, each time Bill heats the mixture to a point which could be described as hotter than the previous temperature in (60), that mixture has crossed a lower threshold, and the action of increasing the temperature can be iterated. We do not have to specify when the mixture should be considered as being past the threshold of "hotter", but there is a threshold which must be crossed.
a. Jane hammered the metal flat.
b. Kim danced herself breathless.
c. Pam wiped the table clean.

Beavers (2008) notes that the telicity of the main verb in the sentence and the secondary predicate must match for a given sentence to be grammatical. Specifically, he states that the events must be matched in complexity: delimited events must have telic result phrases. Since Kennedy and McNally (2005) note that the resultative must take an adjective with a partially-closed scale, we can see this matching of complexity: regular telic resultatives are paired with bounded adjectives. Kennedy and McNally state that adjectives like open are lower-bounded and adjectives like flat are upper-bounded (Kennedy and McNally, 2005, p. 356), thus these partially-closed

\footnotetext{
${ }^{9}(65)$ is from Wechsler $(2005,(29))$.
} 
adjectives are acceptable with a result phrase.

One way we can resolve the issue of whether these examples have iterative aspect or not is to investigate them using the tests for telicity from Kearns (2006). These include combination with in and for adverbials, the take time expression, the sub-interval property, the entailment of the progressive, and the interaction between duration and the progressive. We can take each of the examples in (60)-(62) and apply them to the first four of the six tests (the fifth and sixth tests are meant to distinguish between accomplishments and achievements, a distinction that is not relevant for the resultative, as both are possible resultative events). We can begin by looking at the first two tests: combination with in and for adverbials (67-a)--(67-c).
a. Bill heated the mixture hotter $\{$ in / for $\}$ three hours.
b. Bill hammered the metal flatter $\{$ in / for $\}$ three hours.
c. Penelope wove the shawl longer $\{$ in / for $\}$ three hours.

In these examples both in three hours and for three hours are acceptable adverbials depending on if you are evaluating the interpretation on a continual or iterative basis. If you choose the continual interpretation, then in three hours is the better option. However, if you choose the iterative interpretation, where the event takes place in stages and the base threshold can be passed multiple times, then for three hours is the better option.

Next we can look at the third test, the take time expression. For this test, accomplishments and achievements are both able to combine with the take time expression, and only differ on their interpretation. Since we are only interested in the existence of an end-point, we do not have to worry about the interpretation, as accomplishments and achievements are all and only those event classes with a telos. For this test we 
can look at the examples in (68-a)-(68-c).
a. It took three hours for Bill to heat the mixture hotter.
b. It took three hours for Bill to hammer the metal flatter.
c. It took three hours for Penelope to weave the shawl longer.

As each of these examples is grammatical, there must be an end-point which the take time expression can pick out. Thus, the iterative interpretation is acceptable in this case as well.

Finally, we can look at the sub-interval property test, in which telic events do not have equivalent sub-intervals, while atelic events do. For example, for the sentence Kim ate apples, each sub-interval of that event is still an event of eating apples. Conversely, for the sentence Kim ate six apples, each sub-interval is not the same: in the first sub-interval she could be on her first apple, and in the third sub-interval she could be eating apples three and four. For the resultative examples we can look at $(69-\mathrm{a})-(69-\mathrm{c})$
a. Bill heated the mixture hotter.
b. Bill hammered the metal flatter.
c. Penelope wove the shawl longer.

In each of these examples, the sub-intervals are distinct: at each interval the item acted upon (the mixture, the metal or the shawl), begins at one level and increases to the next, and the following interval begins at the second level and increases to a third. For example, in (69-a) during the first interval, the mixture could begin at $32^{\circ} \mathrm{C}$, and end at $35^{\circ} \mathrm{C}$; and during the second interval the mixture starts at $35^{\circ} \mathrm{C}$ and ends at $39^{\circ} \mathrm{C}$. Thus, the sub-intervals are not homogeneous, and the events can 
be considered telic.

Thus, we can conclude that the resultative is in general telic, but that there are some counter examples. However, these counter examples have specific characteristics, as described by Beavers (2012), and many examples that seem atelic at first glance may, in fact, be optionally telic and pattern with telic verb phases when scrutinized more closely. For these reasons, I will continue the tradition of assuming that resultatives are telic. However, the potential counter-examples are very interesting for further study.

\subsection{Syntax}

The resultative is a sentence of the form [NP V NP XP] where the $\mathrm{X}$ can stand for A, $\mathrm{P}$ or $\mathrm{N}$ (Boas, 2003, p. 2). The internal structure of the resultative has been a topic of debate within the literature. In this section, I will briefly review three proposed structures for the resultative: a binary-branching, small clause structure with the post-verbal NP inside the resultative XP; a ternary-branching small clause structure; and, a ternary-branching flat structure. I will then investigate the key factors which determine the structure within the formalism of LFG, and state which of these structures is best suited for such an analysis.

The first structure is a small clause structure with the post-verbal NP inside the resultative XP (70). 


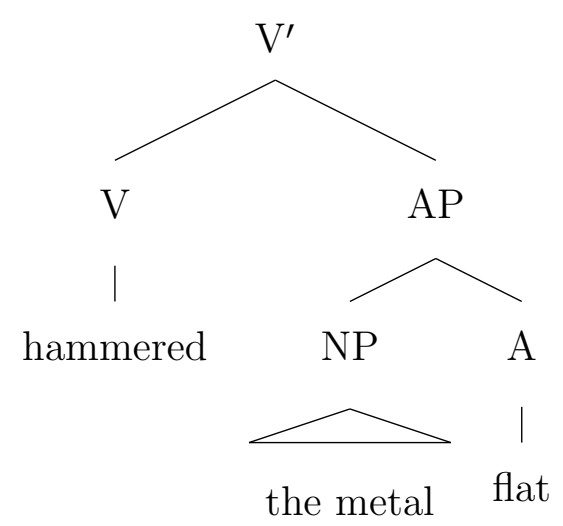

This structure has been presented in many works on the resultative including Broccais (2003); Embick (2004); Kratzer (2005); Irimia (2005); Folli and Harley (2006); Mateu (2011), and Beavers (2012).

The first ternary-branching structure that I will discuss is a ternary small clause structure (71), which is a simplified version of the treatment put forth by Hoekstra (1988). For this structure, the post-verbal NP is still a sister of V, while the subject of the resultative XP is not the post-verbal NP, but rather an unpronounced big PRO, which can potentially be co-referential with the post-verbal NP.

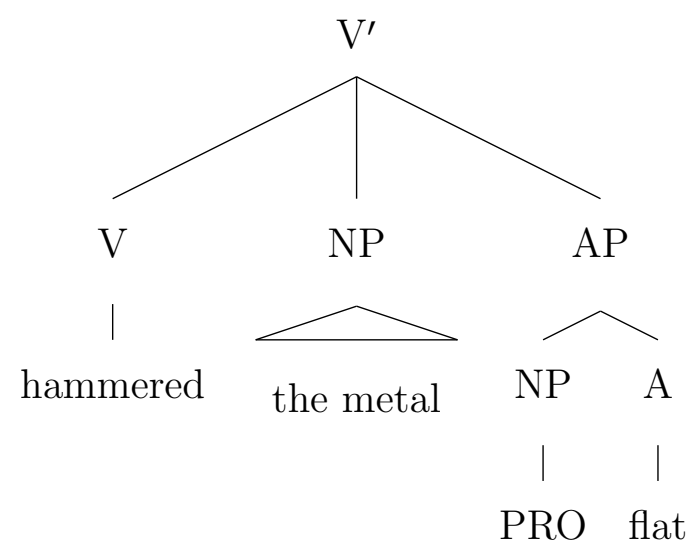

This structure captures the secondary predicate nature of the resultative, with the metal as the subject of the predicate flat. However, in LFG, this information is 
not captured in the c-structure, and the generalizations captured in (70)-(71) are captured elsewhere in the grammar. For this reason, I will be positing a simpler structure for the resultative.

The second ternary-branching structure is a completely flat structure (72). Structures like (72) have been put forth by many researchers, including Simpson (1983b); Jackendoff (1990); Carrier and Randall (1992); Goldberg (1992); Wechsler (1997); Goldberg and Jackendoff (2004); Iwata (2006); MacGregor (2009) and Christie (2010). In this structure, both the post-verbal NP and the resultative XP are sisters of the $\mathrm{V}$, and are located in an argument position in the tree. This type of structure was argued extensively for in Carrier and Randall (1992) based on the status of the postverbal NP as a direct internal argument of the verb, which they demonstrate through the use of five different tests for internal argument status: selectional restrictions, long distance extraction, middle formation, adjectival passive formation and process nominal formation. However, these arguments are not strictly relevant to an LFG analysis, so I will not discuss them here. Instead, I will discuss the most important factor for LFG c-structures: constituency.

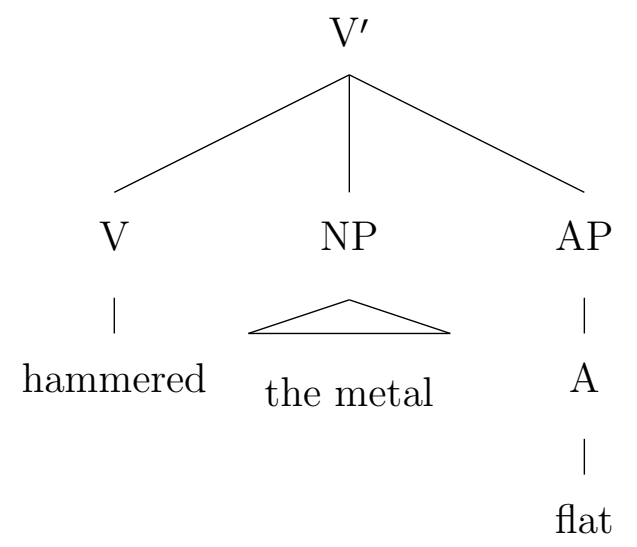

According to Radford (1981), one way to identify a constituent is that constituents 
"behave distributionally as a single unit" (Radford, 1981, p. 69). Thus, if we can split up the result phrase, post-verbal NP and verb, then they should not be a single constituent, but if we cannot split them up, then they should be considered a single constituent. Using one of the alternative sentence structures from Radford we see that when the VP hammer the metal flat is displaced and occurs before the subject, the object and the result phrase cannot appear separately (73) (see also the discussion of the VP preposing test in both Chapter 3 and Chapter 4).

a. I said I will hammer the metal flat, and hammer the metal flat I will. ${ }^{10}$

b. *I said I will hammer the metal flat, and hammer I will the metal flat.

c. *I said I will hammer the metal flat, and hammer the metal I will flat.

Another test for constituency that Radford (1981) puts forth is that individual constituents do not "readily permit the intrusion of parenthetical elements" and that parenthetical elements are usually only permitted at the boundaries of phrasal constituents (Radford, 1981, p. 69). Thus, we can test to see if the result phrase, post-verbal NP and verb act as a single constituent using the sentences in (74).
a. Jane certainly hammered the metal flat.
b. *Jane hammered certainly the metal flat.
c. *Jane hammered the metal certainly flat.
d. Jane hammered the metal flat certainly.

Since the parenthetical comment certainly is not allowed to occur between any of our key elements, we can conclude that they must be a single constituent.

Thus, according to the two constituency tests put forth here, all three elements

${ }^{10}(73)$ is based on Radford's (1981) example (109). 
(the result phrase, post-verbal NP and verb) are a single constituent. This disfavours the structure in (70), and leaves us with a choice between the structures in (72) or (71).

Given that unexpressed elements do not appear in c-structure trees in LFG, we can also rule out the structure in (71), as the PRO and the relationship between it and other elements of the sentence would be addressed in $\mathrm{f}$ (unctional)-structure.

This leaves us with the ternary-branching structure in (72) for the transitive resultative. This structure is preferred because it captures the constituency facts discussed above, while also complying with the Principle of Economy of Expression (Bresnan, 2001, Chapter 6).

We must also look at the constituency facts for the unaccusative resultative to determine the best structure for it. We can again run the tests from Radford (1981). First, we can look to see if the result phrase can be stranded when the VP is preposed (75).
a. *I said the river will freeze solid, and freeze it will solid.
b. I said the river will freeze solid, and freeze solid it will.

These two examples show us that the result phase and verb act as a single unit as far as VP preposing is concerned. Another structure from Radford which could shed light on this structure is (76):

a. There is one thing the river will not do: freeze solid.

b. There is one thing the river will not do: freeze. (Not the same meaning)

Here the meaning changes when the result phrase is present. In fact, there is a difference that can be teased out between the two sentences: a river that is frozen 
may not be safe to skate on, as the ice may be thin, but a river that is frozen solid is safe for skating, as the ice must be solid. Finally, we can look at the insertion of a parenthetical between the verb and result phrase (77):
a. The river certainly froze solid.
b. $\quad *$ The river froze certainly solid.
c. The river froze solid certainly.

Here we can see that a parenthetical cannot be inserted between the verb and result phrase, so they must be acting as a single constituent. These facts show us that the unaccusative result phrase forms a single constituent with the verb, and we can conclude that the best c-structure for this type of resultative is (78).

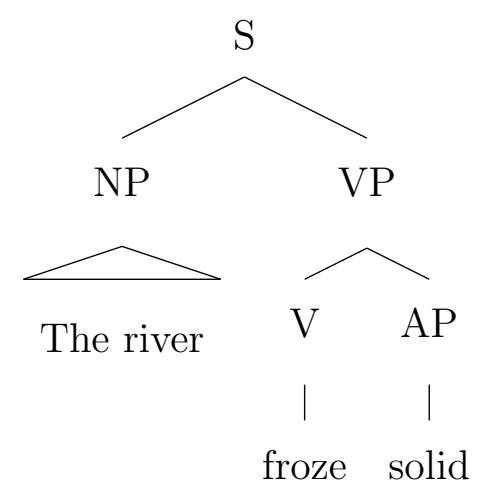

In conclusion, despite much discussion in the literature about what type of tree structure is best suited for the resultative, many of the arguments for a specific structure are not relevant to an LFG c-structure, as the information those tests utilize to categorize the data is incorporated into the language model at other levels of representation. Thus, at the one level which is most important for determining the shape of a c-structure tree, that of constituency, and the facts show that a ternary-branching structure is best suited for an LFG treatment of the transitive and unergative resul- 
tative and a binary-branching structure is best for the unaccusative.

\subsection{Conclusion}

In conclusion, this chapter has shown that the resultative has the following major properties to be accounted for in a formal model. First, there are three basic pieces of information which it adds to a sentence: an existentially bound predicate variable, a patient role for that predicate, and a causal link between the main predicate and the added (secondary) predicate. Second, there is a class of verbs which are known as the unaccusative which can occur with the resultative without a post-verbal NP. This class of verbs may be defined by their use of a patient role for their only argument, or by their status as normally telic predicates, but the existence of a patient role seems to be the best predictor for use in the resultative. Third, the resultative can be assumed to be telic, although counter examples do exist which require further study. Fourth, and finally, the resultative should be given a ternary-branching flat structure in an LFG treatment.

These major properties will have to be accounted for in the model proposed in Chapter 5. Additionally, the conclusions drawn in Chapters 3 and 4 (namely, the difference between property and path resultatives, noted in both chapters; and the differences which mark the unaccusative noted in Chapter 3) will also have to be accounted for, and may provide feedback and guidance as to how to best account for

all of the properties of the resultative without over-generalizing or over-specifying the construction. 


\section{Chapter 3}

\section{The resultative and the}

\section{argument/adjunct distinction}

\subsection{Introduction}

In this chapter, I will introduce nine different tests for argumenthood from the literature, and then investigate the resultative in its various formulations with respect to these tests. As each test is introduced, I will discuss how it classifies the category of added arguments in order to give a reference point for this category of phrase. Investigating the result phrase with respect to the tests I will introduce will allow me to determine which divisions within the resultative result in meaningful distinctions between categories with respect to their argumenthood. This, in turn, will allow me to create the most effective model of the construction in Chapter 5.

I will begin by discussing the pre-existing tests for determining which phrases in a sentence should be considered arguments and which should be considered adjuncts. However, before we can discuss the tests, we must first discuss what is meant by the 
terms argument and adjunct. These two terms have been discussed at length in the literature, however, no consensus has been reached as to the exact formal definition. For example, given the textbook definitions below, we could define arguments (a subset of which are termed complements) as the frequently obligatory elements which are selected by the head (79):

"Adjuncts are always optional, whereas complements are frequently obligatory. The difference between them is that a complement is a phrase which is selected by the head, and therefore has an especially close relationship with the head; adjuncts, on the other hand, are more like bolt-on extra pieces of information and don't have a particularly close relationship with the head." (Tallerman, 2005, p. 98)

Or, the elements which are closely associated with the main predicate (80):

(80) "This distinction between arguments and adjuncts is important, but not always easy to make. The basic difference is that arguments are closely associated with the meaning of the predicate itself, while adjuncts are not." (Kroeger, 2004, p.10)

Or the minimally involved elements (81):

(81) "The arguments are the participants minimally involved in the activity or state expressed by the predicate." (Haegeman, 1994, p.44)

Or the elements which have the properties the predicate describes (82):

(82) "Verbs and adjectives, and some nouns, express properties of things [...] or relationships between things [...]. The arguments are the phrases that denote 
the things that have such properties or are involved in such relationships." (Culicover, 1997, p.16)

Or the elements which participate in the predicate relation (83):

(83) "The entities (which can be abstract) participating in the [predicate] relation are called arguments." (Carnie, 2007, p.51)

Or the elements which are directly involved in the predicate (84):

(84) "From a semantic perspective, subjects and complements share in common the fact that they generally represent entities directly involved in the particular action or event described by the predicate: to use the relevant semantic terminology, we can say that subjects and complements are arguments of the predicate with which they are associated. [...] An expression which serves to provide (optional) additional information about the time or place (or manner, or purpose etc.) of an activity or event is said to serve as an adjunct." (Radford, 2004, pp.3-4)

On the opposite side of the coin, according to these definitions adjuncts could be defined as the obligatorily optional elements not selected by the verb (79), the elements which are not closely associated with the main predicate (80), the elements added to a predicate (81), the elements which are not involved in the predicate (82) and (84), or the elements which don't participate in the predicate relation (83). All of these definitions essentially mean "anything which isn't an argument," but, there are some phrases which aren't considered arguments by the above definitions, but also do not necessarily behave like adjuncts according to the above descriptions. For example, 
passive agents, like Kim in (85):

(85) The window was broken by Kim.

One could argue that these descriptions present a theme in which some phrases are clear arguments, and the rest should be considered adjuncts. However, the group of "non-arguments" which would be considered adjuncts under this classification do not form a coherent class. Thus, researchers have noted that another category of phrase exists, one that is not exactly an argument, but also not exactly an adjunct (Jackendoff, 2002; Kay, 2005; Zaenen and Crouch, 2009; Needham and Toivonen, 2011; Asudeh et al., 2014). This category is usually either optional or not normally or necessarily associated with the predicate, but nonetheless behave like arguments where other syntactic or semantic behaviour is considered. Examples of this category include the passive agent mentioned above, as well as benefactive noun phrases like Laura in (86) Toivonen (2013a).

Kelly baked Laura a cake.

According to the definitions I discussed above, Laura could be considered both an argument and an adjunct. It's optional, so according to Tallerman (2005) and Radford (2004) it is probably an adjunct. However, it's also highly relevant to the action in question, the cake would probably not exist if not for Laura's participation in the event and so would be considered an argument according to the definitions from Culicover (1997), Carnie (2007) and Radford (2004).

It is for this reason that some researchers have come to propose a third category, one that allows for the non-trivial connection to the description of the event, but also recognizes that the phrase in question may not be normally associated with that verb. 
Needham and Toivonen (2011) dub this category derived arguments and Kay (2005) calls it added arguments, a label which I will also utilize. This new category gives us a three-way distinction instead of the strict dichotomy of argument versus adjunct. This will allow me to account for the difference between the things which are seen as basic to an event no matter when it is described (for example the agent and patient in an event like kick), and the things that behave syntactically or semantically like an argument, but which may not be present every time that the verb is used (like Laura in (86)).

Before we begin, however, I will define what I mean by "other syntactic and semantic behaviour". One of the major differences between arguments and adjuncts is not just their relation to the predicate, but also how they interact with the other parts of the sentence when syntactic operations like fronting, questioning, and coordinating take place. The ways in which phrases group together as either arguments, adjuncts or added arguments can be seen in how they pattern with respect to these tests of argumenthood, nine of which I will discuss below.

\subsection{Tests for argumenthood}

This section will introduce the argumenthood tests which are used in my thesis and show how the tests can be used to identify the status of a given phrase. It should be noted, however, that the tests themselves have been taken at face value from the literature, and they may not be honing in on the exact properties of arguments and adjuncts. A careful study of these tests would be an excellent addition to the literature, but is beyond the scope of this project. As such, I will apply the tests discussed here at face value to show that differences exist between the categories of 
argument, adjunct and added argument.

\subsubsection{Core participants (semantic selection)}

As mentioned above, the core participants (or semantic selection) test is one test which is used to define in general terms what an argument or adjunct is in textbooks (Dalrymple, 2001; Carnie, 2002; Koenig et al., 2003; Kroeger, 2004). The test investigates the basic intuition of the speaker as to whether or not something is an argument and is often used hand-in-hand with the syntactic obligatoriness test (see section 3.2.2). For this test, a native speaker decides what elements of an event are semantically required by, or core to the meaning of, the verb (Dowty, 1982; Levin and Rappaport Hovav, 1995; Carnie, 2002, pp. 166-167; Boland and Blodgett, 2006; Tutunjian and Boland, 2008; Needham and Toivonen, 2011, pp. 4-5). For instance, in the event described by (87) the verb kiss takes two elements to describe a complete event: an agent (or "kisser") and a patient (or "kissee"). These two things are considered the arguments of the verb.

$$
\text { Sam kissed Rory on Tuesday in the park. }
$$

The time and location in (87) are not specifically required by the verb kiss to describe a complete event, and are thus considered adjuncts. Since all events take place at some time and in some location, they are a part of all events. This means that time and location are not required by verbs and specifying them is considered added information, making them adjuncts.

However, this test is not sufficient on its own to define what should be considered an argument or adjunct, as it can sometimes be too generous. For example, all events 
take place at some time and in some place, so one could make the argument that these things are core to the meaning of any event. However, time and location are usually considered to be adjuncts, as they perform differently on all of the other syntactic and semantic tests for argumenthood discussed below.

Another problem with this test is that opinions can differ on what is "core" to the event, based on what criteria linguists prioritize in their testing. For example, Barbu (2015) shows that instrument phrases (with a needle in (88)) have been multiply defined in the literature as arguments, adjuncts, both arguments and adjuncts depending on the head of the phrase, and as a gradient property of the sentence (Barbu, 2015, p. 37).

(88) The granny sewed the pillow case with a needle. ${ }^{1}$

Thus, this test should always be taken as only one part of the investigation into argumenthood for a given element, and never as the single method to determining a phrase's status.

\subsubsection{Syntactic obligatoriness}

Syntactic obligatoriness, along with the core participants test (see section 3.2.1), is one of the most cited ways to distinguish arguments from adjuncts in syntax textbooks (Dalrymple, 2001; Carnie, 2002; Kroeger, 2004). These two tests form the backbone of the introductory definition of what an argument or an adjunct can be. The intuition behind these two tests forms our basic distinction between arguments and adjuncts: the notion of something being more closely tied to an individual action as having a

\footnotetext{
${ }^{1}(88)$ is from Barbu (2015), Chapter 5, example (7).
} 
higher status in that action's verbal instantiation.

The syntactic obligatoriness test (Jackendoff, 1990; Dalrymple, 2001; Carnie 2002, pp. 166-170; Kroeger, 2004; Needham and Toivonen, 2011, p. 4; Asudeh and Giorgolo, 2012; Barbu 2015; Williams 2015) states that the arguments of a verb are only those elements which are syntactically required, with all optional elements being adjuncts. Given the example in (89), the sentence is grammatical if on Tuesday is removed (90), but becomes ungrammatical if Sam is removed (91). This suggests that Sam is an argument and on Tuesday is an adjunct.

(89) Kelly prodded Sam on Tuesday.

(90) Kelly prodded Sam.

(91) *Kelly prodded on Tuesday.

However, there is a potential problem with this test. If we look at (92), we can see an inconsistency between this test and the previous one.
a. Kelly ate a sandwich.
b. Kelly ate.

In these examples, according to the semantic selection test, a sandwich should be considered an argument, as every eating event requires something to be eaten. However, according to the syntactic obligatoriness test, a sandwich should be considered an adjunct, as it can be omitted without affecting the grammaticality of the sentence.

We can also look at a passive agent for this test, by Kim in (93), one type of added/derived argument introduced earlier.

(93) The window was broken by Kim. 
For this type of phrase, the agent is central to the action, and thus a core participant, but it is syntactically optional. So, again we have conflicting behaviour on the first two tests.

Thus, there are phrases which fail this test, but still behave on other tests in the same manner as the phrases which pass this test. This means that a third category is required to account for both the data from this test and the data from the other tests I will discuss below. Asserting that there are only arguments or adjuncts may lead us to ignore treatments which otherwise would be effective at describing the language. Any treatment of arguments and adjuncts that sticks rigidly to a dichotomy between the two categories will inevitably not be able to account for the entire range of phrases possible.

\subsubsection{VP preposing}

The VP preposing test states that an argument must always be moved with a preposed verb, but adjuncts can be left behind (Emonds, 1970; Baltin, 2006; Needham and Toivonen, 2011; Toivonen, 2012). For example, (94) is ungrammatical because the verb draw is preposed (or fronted) without its argument a picture, while (95) is grammatical because the verb run is preposed, leaving behind only the adjunct on Tuesday.

(94) *Kylie wanted to draw a picture, and draw she did a picture.

(95) Kelly wanted to run on Tuesday, and run she did on Tuesday.

So, here we can see that the VP preposing test does show a difference between the syntactic behaviour of arguments and the syntactic behaviour of adjuncts. When VP 
preposing is used, any and all arguments must be preposed with the verb, while the adjunct(s) are not required to be preposed with the verb.

For the category of added arguments, we can look at the benefactive NP Laura in (96).

(96) *Kelly wanted to bake Laura a cake, and bake she did Laura a cake.

For this test, the benefactive NP is more argument-like, as it cannot be stranded when the VP is fronted. This means that the category of added argument should be more argument-like when the behaviour of VP preposing is considered.

\subsubsection{VP anaphora (do so)}

The VP-anaphora, or "do so," test states that argument phrases cannot be added to VP anaphoric "do so" clauses, while adjuncts can (Lakoff and Ross, 1966; Baker, 1978; Radford, 1988; Hedberg and DeArmond, 2009; Needham and Toivonen, 2011; Williams, 2015). For example, if we attempt to add the wall to the VP anaphor in (97-b) the sentence is ungrammatical, and we can conclude that the ball is an argument in (97-a). However, if the test phrase is acceptable with the VP anaphor, as in on Wednesday in (98-b), and we can conclude that on Tuesday is an adjunct in $(98-\mathrm{a})$.

a. Cathy kicked the ball.

b. *Cathy kicked the ball and Kelly did so the wall.

(98) a. Kelly swam on Tuesday.

b. Kelly swam on Tuesday and Rory did so on Wednesday. 
According to Hedberg and DeArmond (2009), both the VP anaphora and pseudocleft tests are an effective means of getting clear naive judgements from participants. However, the judgements become less clear when we consider phrases which aren't straightforwardly arguments or adjuncts, adding to evidence for the introduced third category of added or derived arguments.

a. Kim loaded the trailer with hay.

b. ?Kim loaded the trailer with hay and Kelly did so with straw.

a. Katie baked a cake for Laura.

b. ?Katie baked a cake for Laura and Mike did so for Kevin.

For the transfered object of a verb like load, the VP anaphoric sentence which attempts to add another object (in this case, straw) is not fully ungrammatical, but is rather difficult to interpret (99-b). The same thing happens when a new recipient of the benefactive PP is added (100-b), with the resulting sentence not completely ungrammatical as with a prototypical argument (97-b), but still somewhat odd. This varied behaviour adds to the evidence for the category of added argument, as their behaviour matches with neither the prototypical argument nor the prototypical adjunct.

\subsubsection{Pseudocleft}

The pseudocleft test posits that adjuncts, but not arguments, can appear after do in a VP-focused pseudocleft (Hedberg and DeArmond, 2009; Needham and Toivonen, 2011). For example, the phrase on Rory cannot appear after do (101-b), marking it as an argument, while the phrase at the side of the road can appear after do (102-b), 
marking it as an adjunct.

a. Kim relies on Rory.

b. *What Kim does on Rory is rely.
a. Kelly stands at the side of the road.
b. What Kelly does at the side of the road is stand.

This test has been noted to elicit strong intuitions from speakers (Hedberg and DeArmond, 2009, p. 11), unlike some of the previous tests, which can rely on the interpretation of contributing factors rather than a direct judgement of a sample phrase. For example, before a lay-person can give a judgement on the core meaning of a preposition or the core elements in a verbal predicate, one must first coach them on what constitutes "core" to the meaning of a given word or phrase. The lay-person would be expected to interpret the contributing meaning of the preposition, rather than giving a gut reaction to the sentence as a whole. This means that the pseudocleft test can provide clean and consistent data from fewer judgements, allowing for faster and more consistent data collection. However, the test also seems to break things along the same lines as the syntactic obligatoriness and semantic selection tests when in-between status phrases like the goal in a sentence involving load (103-b) or the benefactive (104-b) are considered.
a. Kim loaded the trailer with hay.
b. \# What Kim did with hay was load the trailer.
a. Kim baked a cake for Sarah.
b. What Kim did for Sarah was bake a cake. 
Thus, this test is well suited to give clear intuitions about how phrases can be divided, but like other tests, is one part of a larger investigation. If we utilize a three-way distinction, then this test can help us to lay out one of the two boundaries that are needed, but more tests are needed to flesh out the third dimension.

\subsubsection{Verb specificity}

The verb specificity test states that verbs place certain restrictions on their arguments, but not on adjuncts (Jackendoff, 2002; Koenig et al., 2003; Needham and Toivonen, 2011; Asudeh and Giorgolo, 2012). For example, agent arguments can only occur with verbs of action which assign an aspect of volition, specifically transitive and unergative verbs, and patients can only occur with transitive or unaccusative verbs. This can be seen in (105) with the unaccusative verb freeze resulting in ungrammaticality when active volitionality is enforced by the verb try, while the unergative swim remains grammatical.

$$
\text { Kim tried to swim } / * \text { freeze. }
$$

However, verbs do not place restrictions on their adjuncts. Thus, in (106), the locational phrase in the car is able to be used with any of the verbs in the set: transitive eat and write, unergative laugh and unaccusative freeze.

(106) Tom ate pizza/froze/wrote a letter/laughed in the car.

Although information like the time and place an event took place could be seen as central to the meaning of an event, because they are part of every event, they are seen as too general to be considered arguments. The verb specificity test relies on the fact 
that general information is not seen as intrinsic to a given event. Thus, if a phrase in question cannot be seen as specific to the event it is a part of, then it should be considered an adjunct, and if the verb that describes the event can place restrictions on the phrase (like its animacy, what lexical category it can be headed by, etc.), then it should be considered an argument.

\subsubsection{Fixed preposition}

The fixed preposition test posits that argument phrases are more likely to have a fixed preposition, and adjunct phrases are more likely to allow for any number of prepositions to head the phrase (Pollard and Sag, 1987, pp. 136-137; Wechsler, 1991, pp. 85-86; Carnie, 2002, p. 119; Tutunjian and Boland, 2008; Needham and Toivonen, 2011). For instance, the PP in (107) must be headed by on, marking the phrase as an argument, while the PP in (108) can be headed by any of several prepositions, marking it as more likely to be an adjunct phrase.

(107) Kim relies on $/ *^{*}$ near/*over/*along Kelly.

(108) Kim jogs on/near/over/along the hill.

However, there are exceptions to this test, like the locative phrase the verbs put (Tutunjian and Boland, 2008, p. 2). For instance, in (109), we would expect the locative phrase to be an argument, as it is both a core participant (semantically selected) and syntactically required (the two most basic argumenthood diagnostics). However, according to this test, it would be considered less likely to be an argument, as the preposition is not fixed. 
(109) Kelly put the book in/on/beside the box.

For the category of added aguments, the behaviour is difficult to pin down. Some added arguments have a fixed preposition (110), (111), but many do not even contain a preposition to be analyzed by this test (like the benefactive NP or intstrumental subject).

(110) Kelly baked a cake for/*from/?onto/?over Laura.

(111) The window was broken by/*from/*into Tim.

In conclusion, this test can be helpful for separating arguments from adjuncts, but does not give clear criteria for determining if a phrase is an argument or an adjunct. Although having a fixed preposition is a hallmark of argumenthood for those phrases which contain a preposition, not having one does not mean that the phrase in question should be considered an adjunct. Thus, this test can only act as one measure among many that are needed to determine the status of a given phrase.

\subsubsection{Prepositional content}

The prepositional content test posits that argument phrases are less likely to use the core or basic meaning of the preposition (Pollard and Sag, 1987, p. 136; Wechsler 1991, Needham and Toivonen 2011, p. 5). For instance, the preposition on in (112) can be seen as a place holder which does not denote a relationship of being located physically on top of another thing, thus marking on Kelly as an argument phrase. While the preposition on in (113) does denote being physically on top of something, namely the hill, so the phrase on the hill would be considered an adjunct phrase. 
(112) Kim relies on Kelly. ${ }^{2}$

(113) Kim jogs on the hill.

However, like the fixed preposition test, this test is difficult to apply consistently. This is because determining what the core or basic meaning of a preposition is can be a problematic endeavour. For instance, according to the Oxford English Dictionary, the preposition into could be defined in many ways, two of which being "in the process of being placed inside of another object" (114), and "in the process of being transformed" (115) ("into", 2013). However, if those phrases which use the core or basic meaning for their preposition should be considered adjuncts, then we would expect either that both into the box and into a butterfly are adjuncts, because they use defined meanings of into; or that only into the box should be considered an adjunct as the location changing meaning of into is listed earlier in the dictionary entry, and thus could be considered "more core" to the meaning of the preposition.

(114) Kim put the book into the box.

(115) Kelly turned into a butterfly.

However, neither of those two options are consistent with the semantic selection or syntactic obligatoriness tests, as the PP is required both syntactically and semantically in these two examples. So, the prepositional content test, much like the others I have discussed, does not yield a clear and consistent division between arguments and adjuncts and can only be taken as part of a larger investigation into a phrase's status. It is not able to determine clearly if something should be considered an argument or

\footnotetext{
${ }^{2}$ Examples (112) and (113) are from (Pollard and Sag, 1987, 256a-d).
} 
an adjunct, but only if the phrase in question is more likely to be an argument or an adjunct. The prepositional content test can aid us in our search for a refined division between arguments and adjuncts, but it is by no means a single measure with which we can mark things in either category.

\subsubsection{Uniqueness/iterativity}

The uniqueness/iterativity test posits that argument positions must be filled by one and only one phrase, while adjuncts can be iterated multiple times (Fillmore, 1968; Bresnan, 1982; Pollard and Sag, 1987; Dalrymple, 2001; Carnie, 2002; Zaenen and Crouch, 2009; Needham and Toivonen, 2011; Williams, 2015). For example, the object argument position cannot be filled by two phrases (the boy and the girl) (117), but the locative adjunct position in (118) can be filled by multiple phrases (in the park and on the red bench).

(116) Kelly kissed the boy.

(117) *Kelly kissed the boy the girl.

(118) Kelly kissed the boy in the park on the red bench.

One formal application of this test is the Principle of Coherence in Lexical Functional Grammar (LFG) (Kaplan and Bresnan, 1982). In LFG, a f(unctional)-structure is coherent if and only if only those grammatical functions which are in the f-structure are required by the predicate (Kaplan and Bresnan, 1982, p. 211-212). F-structures in LFG must be both complete and coherent. An f-structure is complete if and only if all of the grammatical functions required by the predicate are present in the f-structure 
(Kaplan and Bresnan, 1982, p. 211-212). The two principles together means that there can be no spare parts and no empty spaces; there must be one and only one of each of the grammatical functions called for in the predicate. Since the grammatical functions required by the predicate are the arguments of that predicate, coherence requires that each argument position can only be filled once, which is just what the uniqueness test looks for.

For the category of added arguments, the behaviour is more arguement-like. Two examples of this are the passive agent (119) and the benefactive NP (120), neither of which can be multiply specified.

*The window was broken by Kelly by Tim.

*Kelly baked Laura Tim a cake.

Thus, the uniqueness/iterativity test does separate arguments from adjuncts, and also categorizes added arguments as arguments. This test is a powerful tool in determining the status of a given phrase, but as will be discussed later, there may be an issue in determining whether a role is being multiply specified, or further specified.

\subsection{Argument/adjunct tests and resultative clas- sifications}

This section will utilize the argumenthood tests discussed in the previous section as a metric to determine which type of resultative classification system discussed in Chapter 2 yields the most meaningful distinctions between classes. By determining how the different sets of resultatives perform, we can see if a classification system provides 
useful distinctions between types of resultatives, or if that systems provides inconsistent divisions between the categories it uses. The section will progress as follows: first I will discuss the semantic distinctions from Goldberg and Jackendoff (2004), then, in light of that discussion, I will address the syntactic and lexical divisions from the literature. For the sake of consistency, each subsection will proceed as follows: a summary of the results of the tests, a set of examples for each type of test in the order the tests were presented in the previous section, and finally, a discussion of what these results tell us.

Additionally, it should be noted that the judgements provided in this section are those of myself and a small number of native speakers with whom I consulted to confirm my judgements. Psycholinguistic judgement data is presented for one of the discussed tests in Chapter 4.

\subsubsection{Semantic distinctions}

When the semantic divisions of the resultative (property versus path and causative versus non-causative or agentive versus non-agentive) are investigated using the tests discussed above, we can see a definite difference between property and path resultatives, and no difference between agentive and non-agentive resultatives. For this type of distinction, the tests pattern into four different categories: one which provides inconsistent results (core participants), one which classifies all resultatives as adjuncts (syntactic obligatoriness), those which classify all result phrases as arguments (VP preposing, VP anaphora, pseudocleft, verb specificity, and uniqueness/iterativity) and those which classify property and path resultatives differently (fixed preposition, and prepositional content). 
Unergative examples (121) will be set aside for the rest of this subsection, as the fake object/fake reflexive pronoun adds complication that will not be relevant here. However, unergatives will be discussed in 3.3.2.

Kim danced herself silly.

The first type of test that we will discuss is the one which gives mixed results for the result phrase: the CORE PARTICIPANTS, or semantic selection, test. For this test, we are looking to see if the result phrase is entailed by the verb. To find out, we will look at example pairs to determine if there is always an understood or expressed result when the main event takes place. Examples will be shown with one verb that entails a change even when the result phrase is absent, and one that does not entail a change without the result phrase for three of the four categories: agentive property (122) and (123), agentive path (124) and (125), and non-agentive path (126) and (127) resultatives.

(122) a. Kim hammered the metal flat. (agentive property)

b. Kim hammered the metal for hours, but it remained a big useless lump.

(123) a. Kim broke the vase into pieces. (agentive property)

b. *Sam broke the vase, but it remained whole.

(124) a. Bill rolled the ball down the hill. (agentive path)

b. *Bill rolled the ball, but it stayed put.

(125) a. Bill pushed the rock up the hill. (agentive path)

b. Bill pushed the rock, but it stayed put.

(126) a. The truck rolled into the garage. (non-agentive path) 
b. *The truck rolled, but it stayed put.

a. Kelly floated down the river. (non-agentive path)

b. Kelly floated, but remained in one spot.

Examples (122)-(127) showed that agentive property, agentive path, and non-agentive path result phrases can occur with both verbs whose events entail a change and verbs whose events do not. Only the non-agentive property resultatives (128)-(129) seem to be the exception to this rule.

a. The river froze solid. (non-agentive property)

b. *The river froze, but it remained a slushy mess.

a. The tower collapsed into a ruin.

b. *The tower collapsed, but it remained upright.

In these examples, the verbs hammer, push and float do not entail a resulting state or location without the result phrase, thus marking the associated result phrases as more adjunct-like. Conversely, the verbs roll, break, collapse and freeze do entail an end state or location without the result phrase, thus marking the associated result phrases as more argument-like. The only result phrase which seems to pattern consistently is the unaccusative. The reason for this is unclear, but it may have to do with the class of unaccusative verbs used in the resultative all being change-of-state verbs: ${ }^{3}$ which necessarily encode a change.

The next test to be discussed classifies the resultative in all of its forms as an adjunct: SYNTACTIC OBLIGATORINESS. Since I argue that the resultative is an added

\footnotetext{
${ }^{3}$ See Simpson (1983b) and Levin (1993) for discussion of the resultative and the change of state class of verbs.
} 
argument, it is unsurprising that it would be syntactically optional. If an element is being added to an argument structure, then the fact that the sentence is acceptable without that element is an artefact of this addition. Thus, the optionality of the result phrase is an artefact of its addition to the sentence and does not hold bearing on its argumenthood, but rather marks it as a potential added argument.

Two types of test results remain to be discussed for this classification of the resultative: those which always classify the result phrase as an argument (VP preposing, VP anaphora, pseudocleft, verb specificity, and uniqueness/iterativity), and those which mark a difference between property and path resultatives (fixed preposition, prepositional content).

The tests which classify all types of result phrases as an argument all share the property of having been shown to be the most comprehensive at identifying added or derived arguments (Needham and Toivonen, 2011), a category to which the resultative belongs. For the VP PREPOSING TEST, the test sentence is ungrammatical if the result phrase is not fronted with the verbs for all semantic types of the resultative $(130-134)$.

a. Kim hammered the metal flat. (agentive property)

b. *Kim wanted to hammer the metal flat, and hammer the metal she did flat.

a. Kim broke the vase into pieces. (agentive property)

b. *Kim wanted to break a pot into pieces, and break a pot she did into pieces. 
(132) a. The river froze solid. (non-agentive property)

b. *The river needed to freeze solid, and freeze it did solid.

(133) a. Bill kicked the ball into the net. (agentive path)

b. *Bill wanted to kick the ball into the net, and kick the ball he did into the net.

(134) a. The truck rolled into the garage. (non-agentive path)

b. *The truck needed to roll into the garage, and roll it did into the garage.

For the VP ANAPHORA, or do-so, test, when a result phrase is added after do so the sentence is ungrammatical, just as is found with proto-typical arguments. This is true of all four forms: agentive property (135) and (136), non-agentive property (137), agentive path (138) and non-agentive path (139). Similar results were found by Larson (1990), who stated that you cannot strand a secondary predicate when you create a gapping structure.

(135) a. Kim wiped the counter clean and Sam wiped the counter dry. (agentive property)

b. *Kim wiped the counter clean and Sam did so dry.

(136) a. Kim broke his cup into shards and Sam broke his cup in half. (agentive property)

b. *Kim broke his cup into shards and Sam did so in half.

(137) a. The vase broke into pieces and the pot broke in half. (non-agentive property)

b. *The vase broke into pieces and the pot did so in half. 
(138) a. Bill pushed a friend into the house and Sammy pushed a friend into the garage. (agentive path)

b. *Bill pushed a friend into the house and Sammy did so into the garage.

(139) a. The truck rolled into the garage and the bus rolled down the street. (non-agentive path)

b. *The truck rolled into the garage and the bus did so down the street.

For the VERB SPECIFICITY TEST, the result phrase also patterns like an argument. The resultative can only occur with certain kinds of verbs, specifically "verbs of contact and verbs denoting some change of state" (Simpson, 1983b, p. 150). This means that, unlike adjunct phrases, the resultative is not able to freely combine with any event, making it more argument-like.

The next test to be discussed is the PSEUdOCLEFT test. When the result phrase is placed after do in a VP-focused pseudocleft, the sentence becomes ungrammatical, no matter which type of result phrase is under consideration: agentive property (140) and (141), non-agentive property (142), agentive path (143) and non-agentive path (144).

(140) a. Kim hammered the metal flat. (agentive property)

b. *What Kim did flat was hammer the metal.

(141) a. Kim broke the vase into pieces. (agentive property)

b. *What Kim did into pieces was break the vase.

(142) a. The river froze solid. (non-agentive property)

b. *What the river did solid was freeze. 
a. Bill kicked the ball into the goal. (agentive path)

b. *What Bill did into the goal was kick the ball.

(144) a. The truck rolled into the garage. (non-agentive path)

b. *What the truck did into the garage was roll.

The last test which classifies all semantic types of the resultative as an argument is the UNIQUENESS test. For this test, we can see that neither properties nor paths can be multiply specified. At first glance, it seems that paths are able to be multiply specified (145) while properties are not (146). However, this is misleading, as the multiple specification in (145) is actually the continuation of a single path. If we change the result phrases so that the property result phrase has a description which can be further specified (148), and the path result phrase describes two separate paths (147), then the result is the same: multiple specification is not allowed, and continuous specification is allowed. Thus, according to the uniqueness test, the result phrase is argument-like.

(145) We had to take the drums out and ... then drive down the hill out of the compound. (Tail End Charlie by Ronald John Jensen p. 110)

(146) *Sally hammered the metal into shape into bars.

(147) *Sally rolled the ball into the box into the street.

(148) Copper plate is now run off in a press rather than beaten flat into shape. http://sportsportraitartist.blogspot.ca/ (Retreived Nov 18, 2013)

The last group of tests to be discussed are those which classify the path and property resultatives differently from each other: fixed preposition, and prepositional content. 
Together, these tests demonstrate that property and path resultatives show different behaviour in at least some ways. We can look at both the FIXED PREPOSITION and PREPOSitional CONTENT tests at the same time using examples (149)-(152). For the property resultatives (149) - (150), the preposition is fixed (or mostly fixed in the case of to vs. into), while the preposition in the path resultatives is able to vary. According to the fixed preposition test, property result phrases are more likely to be arguments and path result phrases are more likely to be adjuncts.

(149) Kim broke the vase into/to/*over/*across/*down pieces.

(150) The water froze into/*to/*over/*across $/ *^{*}$ down a block. (the starred examples are no longer property resultatives)

(151) Sally kicked the ball down/across/over the path.

(152) The ball rolled across/over/into the goal.

For the prepositional content test, the variance in the prepositions heading the path result phrases shows us that the meaning of those prepositions is utilized, making the path result phrases more adjunct-like. Conversely, the path result phrases do not utilize the literal meaning of the prepositions without changing the interpretation of the sentence into a path meaning. Thus, according to the prepositional content test, property result phrases are more likely to be considered argument phrases.

It should be noted, though, that the mixed behaviour of the different result phrase categories for this group of tests can be explained by the properties of both the tests themselves and path phrases in general. The fixed preposition and prepositional content tests are both designed to test for the status of prepositions in phrasal verbs, 
and not for general prepositions, so they expect the preposition to be both fixed and semantically bleached. Since path phrases denote the direction of travel using their preposition, there is both semantic content and variability in the PP no matter what kind of sentence the path is being used in. Additionally, both of these tests state that a phrase is more likely to be an argument/adjunct, not that the phrase in question should definitely be considered either an argument or an adjunct (Needham and Toivonen, 2011). Thus, more than other tests, failing either the fixed preposition or the prepositional content tests does not mean that the phrase in question is not an argument.

In conclusion, for the semantic classes of resultative, the major division is between property and path resultatives, with the agentive/non-agentive split not demonstrating many differences between categories. So far the difference is only apparent in the preposition-specific tests, but the property/path distinction is reflected in the experimental data which is presented in Chapter 4, which shows that native speakers judge the grammaticality of VP preposed resultatives differently depending on if they are property or path resultatives. Even though the differences between property and path resultatives stem from the properties of path phrases in general, the distinction is still important for defining templates for the resultative, especially when combined with the differences noted in Chapter 2. Table 3.1 shows a summary of all of the test results for each semantic type.

\subsubsection{Argument structure distinctions}

Path resultatives will be excluded from testing for other divisions in the next two subsections (argument structure and lexical category divisions). This is because in- 


\begin{tabular}{lcccc}
\hline Test & $\begin{array}{c}\text { Agentive } \\
\text { Property }\end{array}$ & $\begin{array}{c}\text { Non-agentive } \\
\text { Property }\end{array}$ & $\begin{array}{c}\text { Agentive } \\
\text { Path }\end{array}$ & $\begin{array}{c}\text { Non-agentive } \\
\text { Path }\end{array}$ \\
\hline \hline Core participants & inconsistent & AR & inconsistent & inconsistent \\
Syntactic obligatoriness & AJ & AJ & AJ & AJ \\
VP preposing & AR & AR & AR & AR \\
VP anaphora & AR & AR & AR & AR \\
Pseudocleft & $\mathrm{AR}$ & $\mathrm{AR}$ & $\mathrm{AR}$ & $\mathrm{AR}$ \\
Verb specificity & $\mathrm{AR}$ & $\mathrm{AR}$ & $\mathrm{AR}$ & $\mathrm{AR}$ \\
Uniqueness / Iterativity & $\mathrm{AR}$ & $\mathrm{AR}$ & $\mathrm{AR}$ & $\mathrm{AR}$ \\
Fixed preposition & $\mathrm{AR}$ & $\mathrm{AR}$ & $\mathrm{AJ}$ & AJ \\
Prepositional content & $\mathrm{AR}$ & $\mathrm{AR}$ & AJ & AJ \\
\hline
\end{tabular}

Table 3.1: Argument/adjunct test results by semantic type

cluding them in a group with property resultatives when testing for other divisions could lead to inconsistency on the prepositional content and fixed preposition tests, as we have already established a difference in those categories. Thus, for the sake of consistent testing, path resultatives will not be tested for the rest of the chapter.

The argument structure divisions of the resultative give meaningful distinctions for the structure of the resultative: transitive resultatives have both a subject and object, unaccusative resultatives have only a subject, and unergative resultatives have a subject as well as an object which is not normally associated with the verb and is often reflexive. The following discussion will show that these three categories do not demonstrate differences between each other where argumenthood is considered and all of them behave as property resultatives did in the previous section: adjunct-like for the syntactic obligatoriness test; variable for the core participants test (with some verbs entailing a result, and some not); and, argument-like for the remaining tests.

The SYNTACTIC OBLigatoriness test shows that the unergative result phrase may be an argument, while the other classes of result phrase are adjuncts. If the result phrase is omitted for the transitive resultative, the sentence remains grammatical 
(153), and the same is true of the unaccusative resultative (154). However, if the result phrase is omitted in the unergative resultative, the sentence becomes ungrammatical, whether the fake reflexive (155) or fake object (156) form is under consideration.

(153) Sally hammered the metal (flat).

(154) The river froze (solid).

(155) Sally danced herself *(breathless).

(156) Sally ran her shoes *(threadbare).

However, the resulting ungrammaticality of (155) and (156) may not be due to the argument status of the result phrase, but rather the status of the postverbal noun phrase (NP). As discussed in both Carrier and Randall (1992) and Kratzer (2005), the postverbal NP in unergative resultatives is not an argument of the verb, but rather is an argument of the result phrase. The sentences could be ungrammatical due to an unlicensed NP, and not the lack of result phrase, or, more simply, they could be ungrammatical because there are too many elements present, and not too few. Thus, although the initial investigation made it seem as if the unergative result phrase was an argument, the syntactic obligatoriness test does show that the result phrase is an adjunct in all syntactic forms of the resultative.

The next test to discuss is the CORE PARTICIPANTS test, which shows that unaccusative result phrases are entailed by the verb, but there is inconsistency for transitive and unergative resultatives. For this test, we are looking to see if the result phrase is entailed by the verb. To find out, we will look at example pairs to determine if there is always an understood or expressed result when the main event takes place. 
Similar to the discussion in section 3.3.1, examples can both be given of verbs which entail or do not entail a change, and thus entail a resulting state. For the transitive resultative, break in (158) entails a change, while hammer in (157) does not.
a. Kim hammered the metal flat.
b. Kim hammered the metal for hours, but it remained a useless lump.
a. Sam broke the vase into pieces.
b. *Sam broke the vase, but it remained whole.

For the unergative resultatives, the same pattern can be found: laugh in (159) does not entail a change, while run in (160) does.
a. Kim laughed herself silly.
b. Kim laughed, but was still sad.
a. Kelly ran herself ragged.
b. \#Kelly ran for hours, but her body never deteriorated.

However, for the unaccusative resultative, all of the verbs require a change of some sort. Both rust in (161) and freeze in (162) require that something changes state in order for the sentence to be interpretable.
a. The old car rusted to bits.
b. \#The car rusted, but it remained entirely shiny and new.
a. The river froze solid.
b. \#The river froze, but remained a slushy mess.

The remaining tests all show that the result phrase is an argument in all syntactic 
forms of the resultative (when only property resultatives are considered). This includes the VP preposing, VP anaphora, pseudocleft, verb specificity, uniqueness, fixed preposition, prepositional content tests. For the VP PREPOSING test, we can see that when the VP is preposed without the result phrase, the sentence is ungrammatical. This includes the transitive (163), unaccusative (164) and unergative (165)-(166).

a. Sam hammered the metal flat. (transitive)

b. *Sam wanted to hammer the metal flat, and hammer the metal she did flat.

a. The river froze solid. (unaccusative)

b. *The river needed to freeze solid and freeze it did solid.

a. Sarah ran her shoes to tatters. (fake object)

b. *Sarah wanted to run her shoes to tatters, and run her shoes she did to tatters.

a. Kevin danced himself into a tizzy. (fake reflexive)

b. *Kevin wanted to dance himself into a tizzy, and dance himself he did into a tizzy.

For the VP ANAPHORA (or do so) test, all of the syntactic categories pattern together again: a result phrase cannot occur after VP anaphoric do so. Thus, each of the $(c)$ sentences are ungrammatical, including the transitive resultative (167), the unaccusative resultative (168) and the unergative (169)-(170). 
a. Sally hammered the metal flat. (transitive)

b. Sarah hammered the metal into a disc.

c. * Sally hammered the metal flat and Sarah did so into a disc.

(168) a. The river froze solid. (unaccusative)

b. The water froze into a block.

c. * The river froze solid and the water did so into a block.

a. Kevin ran his shoes to tatters. (fake object)

b. Kelly ran her shoes to uselessness.

c. *Kevin ran his shoes to tatters and Kelly did so to uselessness.

a. Sally danced herself tired. (fake reflexive)

b. Sarah danced herself breathless.

c. *Sally danced herself tired and Sarah did so breathless.

For the PSEUDOCLEFT test, the same pattern emerges: all syntactic categories for the resultative show that the result phrase is an argument of the verb. For each of the categories under discussion, the result phrase cannot be placed after do in a VP focused pseudocleft, including transitive (171), unaccusative (172) and unergative (173).

(171) a. Kim hammered the metal flat. (transitive)

b. *What Kim did flat was hammer the metal.

(172) a. The river froze solid. (unaccusative)

b. *What the river did solid was freeze. 

a. Kim danced herself breathless. (fake reflexive)
b. *What Kim did breathless was dance herself.

For the VERB SPECIFICITY test, as discussed in section 3.3.1, all resultatives, no matter the classification system, pattern like arguments. This is a basic feature of resultatives: that they occur with some verbs and not others. As a simple example, we can look at (174), in which the result phrase can appear with hammer (174-a), but not lick (174-b).

a. Kelly hammered the metal flat.

b. *Kelly licked the metal flat.

Thus, definitionally, the result phrase is an argument of the verb according to the verb specificity test, as it is specifically restricted to "verbs of contact or change of state" (Simpson, 1983b, p. 150), or at least verbs which enforce, or at a minimum permit, a change in state or location (Levin, 1993).

For the UNIQUENESS test, there cannot be more than one result phrase (unless the second phrase is actually a further specification of the first). This is the case for all syntactic types of resultative: transitive (175), unaccusative (176) and unergative (177)-(178)
a. Sally hammered the metal flat. (transitive)
b. Sally hammered the metal into a disc.
c. *Sally hammered the metal flat into a disc. 

a. The water froze solid. (unaccusative)
b. The water froze into a block.
c. *The water froze solid into a block.

a. Sally ran her shoes to tatters. (fake object)

b. Sally ran her shoes threadbare.

c. *Sally ran her shoes threadbare to tatters.
a. Sally danced herself breathless. (fake reflexive)
b. Sally danced herself dizzy.
c. *Sally danced herself breathless dizzy.

Finally, for the FIXED PREPOSITION and PREPOSITIONAL CONTENT tests, when only property resultatives are considered, all syntactic forms of the resultative pattern as arguments. This is because the only prepositions available to express states are to and into. This means that the preposition is either severely restricted or entirely fixed simply because of the type of phrase that it occurs in. Additionally, the preposition will be semantically bleached, as the stative use of those two prepositions does not denote the physical location interpretation of the preposition, but rather the transformational one, which is a secondary meaning.

Thus, each of the tests which test for arguments which are initially associated with the verb's argument structure show that the transitive and unergative resultatives are either more adjunct-like or inconsistent in their behaviour, while unaccusative resultatives are either more argument-like or inconsistent in their behaviour. When it comes to the tests which can be used to classify both original and added or derived arguments (Needham and Toivonen, 2011; Toivonen, 2012, 2013b), the resultative 


\begin{tabular}{lccc}
\hline Test & Transitive & Unaccusative & Unergative \\
\hline \hline Syntactic obligatoriness & AJ & AJ & AJ \\
Core participants & inconsistent & AR & inconsistent \\
VP preposing & AR & AR & AR \\
VP anaphora (do so) & AR & AR & AR \\
Pseudocleft & AR & AR & AR \\
Verb specificity & AR & AR & AR \\
Uniqueness/Iterativity & AR & AR & AR \\
Fixed preposition & AR & AR & AR \\
Prepositional content & AR & AR & AR \\
\hline
\end{tabular}

Table 3.2: Argument/adjunct test results by argument structure type

patterns like an argument in all syntactic forms. Table 3.2 shows a summary of the test results for each argument structure type of resultative. From this, we can conclude that the resultative is an added argument, as it is not in the initial argument structure, but it behaves like an argument in respect to structural and meaning relationships within a sentence. These results are consistent with my previous claims that the resultative should be considered an added argument with in-between status (Christie and Toivonen, 2013; Christie, 2013b a).

\subsubsection{Lexical category distinctions}

When the lexical category distinctions of the resultative are considered using the argument/adjunct tests, the pattern that emerges yields no distinctions between the categories. When a single category of resultatives is considered (transitive property in the following discussion) the result phrase can be headed by either a noun, an adjective or a preposition, and the results for the tests remain the same: syntactic obligatoriness shows that the result phrase is an adjunct, core participants can't decide in either direction, and the remaining tests show that the result phrase is 
an argument of the verb. This continues to show that the result phrase should be considered an added or derived argument. The only tests in which the lexical category of the result phrase head does matter are the ones which investigate the properties of the preposition, as they cannot be applied to the result phrases which are headed nouns and adjectives.

These results lead me to assert that for English resultatives, the lexical category of the result phrase head does not matter for categorizing the properties of the structure. However, this may not be the case for all languages, as choice of lexical head has been shown to affect the grammaticality of resultatives in other languages, including Italian (Napoli, 1992) and Icelandic (Whelpton, 2010), among other languages. Kratzer (2005) also proposes that the lexical category of the head of the result phrase is meaningful in both German and English, however, this proposal does not work with my treatment. This is because I accept path resultatives as being part of what Goldberg and Jackendoff (2004) call the family of English resultatives, and I aim to treat all members of that family. Since Kratzer's analysis does not include path resultatives and mine does, I cannot claim that the lexical category matters for English.

Below I will discuss each of the same tests addressed in the previous sections and will show that the lexical category of the result phrase head does not provide a meaningful division between categories. To begin with, we can see that all three types of result phrases are SYNTACTICALLY OPTIONAL, marking them as more adjunct-like. This is true of nominal result phrase heads (179), adjectival result phrase heads (180), and prepositional result phrase heads (181).

(179) Kevin painted the room (a bright shade of pink).

(180) Sally hammered the metal (flat). 
(181) Steve broke the vase (into 6 pieces).

For the CORE PARTICIPANTS test, we are looking to see if the result phrase is entailed by the verb. To find out, we will look at example pairs to determine if there is always an understood or expressed result when the main event takes place. As with the other categorizations, verbs can be found in all three categories which can either entail or not entail a change. This is because the resultative is specifically restricted to "verbs of contact or change of state" (Simpson, 1983b, p. 150), or at least verbs which enforce, or at a minimum permit, a change in state or location (Levin, 1993), meaning both types of verbs can occur. In the nominal result phrase category, (182) entails a change of some sort, while (183) permits the object to remain unchanged by the action.

a. Kevin painted the room a bright shade of pink.

b. *Kevin painted the room, but it stayed a dirty grey.

(183) a. She pushed the rock a little closer to the centre of the room.

b. She pushed the rock, but it didn't move.

For the adjectival and prepositional result phrase heads, we can look at examples from the previous sections to show that we can find verbs which must entail a change as well as verbs which permit the object to remain unchanged by the action. For example, the adjectival result phrase in (184) occurs with a verb which must entail a change, while the adjectival result phrase in (185) occurs with a verb which can potentially leave the object unchanged during the action. 
a. Lancelot licked the plate clean. ${ }^{4}$

b. ?Lancelot licked the plate, but it remained dirty.

a. Sally hammered the metal flat.

b. Sally hammered the metal, but it remained a useless lump.

For the prepositional result phrases, we see that (186) entails a change, while (187) does not, yielding inconsistent results again.

a. Steve broke the vase into 6 pieces.

b. \#Steve broke the vase, but it remained whole.

a. Bill pushed the rock up the hill.

b. Bill pushed the rock, but it wouldn't budge.

Thus, the resultative does not pattern consistently in any lexical division. All three lexical categorizations of the resultative are able to combine both with verbs which do entail a change of state or location and verbs which can allow the object to remain unchanged by the action.

The remaining argumenthood tests all show that the result phrase consistently behaves like an argument in all lexical categorizations. That is, no matter what the lexical head of the result phrase, the results are the same for the tests. This includes the VP preposing test, the VP anaphora test, the pseudocleft test, the verb specificity test, and uniqueness tests. There is also a pair of tests (the fixed preposition and prepositional content tests) which cannot be applied to all categories of the resultative in this categorization frame. For the VP PREPOSING TEST, we can see that all three

\footnotetext{
${ }^{4}$ (184-a) is from Rappaport Hovav and Levin (2001), (1a).
} 
result phrase lexical heads behave in the same manner: the result phrase cannot be left behind when the VP is preposed. This is true of nominal result phrases (188), adjectival result phrases (189) and prepositional result phrases (190).

a. Kevin painted the room a bright shade of pink.

b. *Kevin wanted to paint the room a bright shade of pink and paint the room he did a bright shade of pink.

a. Sam hammered the metal flat.

b. *Sam wanted to hammer the metal flat, and hammer the metal she did flat.

(190) a. Kim broke the vase into 6 pieces.

b. *Kim wanted to break the vase into 6 pieces, and break the vase she did into 6 pieces.

For the VP ANAPHORA test, we again see that the lexical head of the result phrase does not matter: none of the forms can be added to a VP anaphoric do so clause. First, nominal result phrases:
a. Kelly painted the room a bright shade of pink.
b. Kevin painted the room a putrid green.
c. *Kelly painted the room a bright shade of pink and Kevin did so a putrid shade of green.

Since you can combine the adjectival and prepositional categories via conjunction (192), we can test both categories for the VP anaphora test at the same time (193). In these two examples, we can see that both resultatives are available together and 
separately, but when the VP anaphora is used, the sentence is ungrammatical, making the result phrase more argument-like.

(192) Sally hammered the metal flat, and Sarah did so too.
a. Sally hammered the metal flat.
b. Sarah hammered the metal into a disc.
c. * Sally hammered the metal flat and Sarah did so into a disc.

Thus, all three lexical head categories of resultative behave like an argument when the VP anaphora test is considered. The result phrase in any form cannot follow a VP anaphoric do so.

Moving on to the PSEUDOCLEFT test, we can see that all three lexical heads cannot be added to a VP-focused pseudocleft. This is true of all three types: nominal result phrases (194), adjectival result phrases (195) and prepositional result phrases (196).

(195) *What Kevin did flat was hammer the metal.

(196) *What Sally did into 6 pieces was break the vase.

For the VERB SPECIFICTY test, like in the previous sections, we can conclude that the resultative is an argument based on its description without resorting to test sentences. This is because the resultative is specifically restricted to "verbs of contact or change of state" (Simpson, 1983b, p. 150), or at least verbs which enforce, or at a minimum permit, a change in state or location (Levin, 1993). However, for the lexical categories distinctions of the resultative, I will also present the following sentences, which show that the result phrase can occur with some verbs and not others. Again, this is true 
of all three lexical categorizations: nominal result phrases (200), adjectival result phrases (198) and prepositional result phrases (201).

a. Kevin painted the wall a bright shade of pink.

b. *Kevin hit the wall a bright shade of pink.

(198) a. Sarah hammered the metal flat.

b. *Sarah saw the metal flat.
a. Steve broke the vase into 6 pieces.
b. *Steve hit the vase into 6 pieces.

For the UNIQUENESS test, the resultative again patterns as an argument no matter what the lexical category of the result phrase head. For the nominal result phrase (200), we can see that although two result phrases can be motivated independently (as in the $a$ and $b$ sentences) they cannot be combined (as in the $c$ sentence).
a. Sally dyed her skirt a light red.
b. Sally dyed her skirt a dark pink.
c. *Sally dyed her skirt red pink.

For the prepositional resultative (201), we again see that two separate result phrases are acceptable on their own, but not when combined (201-c).
a. Sally broke the vase into six pieces.
b. Sally broke the vase into small pieces.
c. *Sally broke the vase into six pieces into small pieces.

Additionally, even though two different lexical category heads can be used in the 
resultative (202), you cannot combine result phrases across categories.
a. Sally hammered the metal flat.
b. Sally hammered the metal into a disc.
c. *Sally hammered the metal flat into a disc.

For the FIXED PREPOSITION and PREPOSITIONAL CONTENT tests, there are two things to discuss. First, these two tests cannot be used to evaluate the argumenthood of result phrases across lexical categories, as they can only apply to one of the three categories. One cannot assess the content or variability of a preposition heading a noun phrase, as that would make the phrase in question a prepositional phrase. Thus, these two tests cannot be used to evaluate the lexical categories distinctions of the resultative.

However, for the sake of consistency, I will include them here as they pertain to the prepositional result phrases. As discussed in the previous sections, if only the transitive property result phrases are taken into consideration, then the result phrase has a fixed or minimally semi-fixed preposition, as statives can only be realized as either to or into. Additionally, the content of the preposition in statives is not the full interpretation of the preposition (physical transferral), but rather a secondary meaning of transformation.

The complete results of the argumenthood tests on the lexical categories distinctions of the resultative can be seen in Table 3.3. As stated in the introduction to this section, the results show us that there are no distinctions between categories for the lexical category of the result phrase head. This means that in terms of argumenthood, the lexical category of the result phrase head does not matter. 


\begin{tabular}{lccc}
\hline Test & Adjective & Preposition & Noun \\
\hline \hline Syntactic obligatoriness & AJ & AJ & AJ \\
Core participants & inconsistent & inconsistent & inconsistent \\
VP preposing & $\mathrm{AR}$ & $\mathrm{AR}$ & $\mathrm{AR}$ \\
VP anaphora (do so) & $\mathrm{AR}$ & $\mathrm{AR}$ & $\mathrm{AR}$ \\
Pseudocleft & $\mathrm{AR}$ & $\mathrm{AR}$ & $\mathrm{AR}$ \\
Verb specificity & $\mathrm{AR}$ & $\mathrm{AR}$ & $\mathrm{AR}$ \\
Uniqueness/Iterativity & $\mathrm{AR}$ & $\mathrm{AR}$ & $\mathrm{AR}$ \\
Fixed preposition & $\mathrm{n} / \mathrm{a}$ & $\mathrm{AR}$ & $\mathrm{n} / \mathrm{a}$ \\
Prepositional content & $\mathrm{n} / \mathrm{a}$ & $\mathrm{AR}$ & $\mathrm{n} / \mathrm{a}$ \\
\hline
\end{tabular}

Table 3.3: Argument/adjunct test results by lexical category of result phrase

\subsection{Conclusion}

In conclusion, the argument status of the result phrase can be measured using a variety of tests. This chapter has both laid out the tests and run them on all three major methods of dividing up the resultative: semantic, argument-structure and lexical categories.

The semantic divisions of the resultative showed that there is a difference between property and path resultatives, but that those differences stem from the differences between statives and paths in a more general manner. The argument structure divisions of the resultative yield a meaningful distinction between unaccusative result phrases and other result phrases (a fact which may be attributable to their differing structure or their stipulation to be a specific set of verbs (Simpson, 1983b)). The lexical categories distinction did not yield any meaningful distinctions between categories of the resultative based on the argumenthood of the result phrase.

Chapter 5 will address the distinctions found in this chapter in order to best handle them in a consistent manner when the resultative is modelled in the formal grammar of LFG using both the a-structure and the template hierarchy. 


\section{Chapter 4}

\section{Experimental results}

\subsection{Introduction}

This chapter will present the experimental findings of my thesis. This portion consists of three surveys which overlapped in design and administration, but will be analyzed separately, and discussed both individually and as a group.

The purpose of the experimental portion of my thesis is to test, and hopefully confirm, the introspective grammaticality judgements that form the basis for the data presented in previous chapters by surveying speakers of English on a larger scale. To do this, I will evaluate one of the tests discussed in Chapter 3 to see if my judgements line up with the experimental opinions of sentences.

This task was completed using three separate experimental designs administered through two surveys, one containing only the transitive resultative, and one containing both the unaccusative and unergative resultatives. These three categorizations were selected based on argument structure so that sentences could be designed to have the same properties in each group. Additionally, sentences of both property and path 
resultatives were evaluated to investigate the difference between the two constructions found in Chapter 3.

The test selected was the VP preposing test (see section 3.2.3 for a full description). For this test, the transitive and unaccusative resultatives were used to determine if the phrase she/it did could appear after the verb (so the verb is preposed before the subject), but before the argument phrase (203), result phrase (204) or adjunct phrase (205) (full item sets will be given for each experiment in their Methods sections, with the complete stimuli being given in the appendices).

(203) Kelly wanted to hammer the metal flat on Tuesday and hammer she did the metal flat on Tuesday.

(204) Kelly wanted to hammer the metal flat on Tuesday and hammer the metal she did flat on Tuesday.

(205) Kelly wanted to hammer the metal flat on Tuesday and hammer the metal flat she did on Tuesday.

The literature predicts that the pre-adjunct phrase condition should be more acceptable than the pre-argument phrase condition. My hypothesis is that the preresult phrase condition will pattern between the pre-argument phrase and pre-adjunct phrase conditions in terms of acceptability, marking a statistically significant difference between the three categories (arguments, adjuncts and added/derived arguments), and adding to the body of evidence for the added/derived argument category.

In addition to the VP preposing test for the transitive and unaccusative resultatives, the unergative resultative was compared to the way-construction, which is 
similar in interpretation to the fake reflexive resultative construction. ${ }^{1}$ Based on my intuition and relative prevalence of the two constructions discussed in the literature, the hypothesis for the third experiment was that the way-construction should be more acceptable in general than the fake reflexive resultative construction.

For all three experiments, a single ethics approval was obtained from the Carleton University Ethics Board. Participants were recruited either via a link sent by email and Facebook, or via posters placed around the university campus, and were not compensated for their time. In order to participate, respondents needed to be at least 18 years of age, and be a native speaker of Canadian English.

\subsection{Experiment 1: Transitive resultatives}

\subsubsection{Methods}

\section{Sample}

For the first experiment, a total of 50 people completed the survey divided among ten lists of stimuli on a Latin Square so that no participant saw the same sentence under two different conditions. As stated in the introduction to this chapter, participants were a minimum of 18 years old and native speakers of Canadian English.

\section{Materials and Design}

As discussed in the introduction, the target phrase she did was manipulated between locations in a VP preposed sentence. Additionally, two control sentences were used

\footnotetext{
${ }^{1}$ See Jackendoff (1990); Levin (1993) and Christie (2011) (among others) for discussion of the similarities between the two constructions.
} 
to check that participants accepted resultative sentences more generally, as well as sentences which are bi-clausal including the she did emphasis. When the additional manipulation of the type of result phrase (property or path) is added, the full data collection included ten conditions per stimulus item, summarized in the table in Table 4.1. A full list of experimental stimuli can be found in Appendix A.

To collect the data, a repeated measures design was used. Each participant provided five responses per condition, and the mean for each condition was taken for analysis. To ensure that there were no effects from repeated stimulus items, ten Latin Square lists were devised, so that participant one saw stimulus items 1-1 (item 1-condition 1), 2-2, 3-3, 4-4, 5-5, 6-6, 7-7, 8-8, 9-9, 10-10, 11-11, etc.; participant two saw items 1-2, 2-3, 3-4, 4-5, 5-6, 6-7, 7-8, 8-9, 9-10, 10-1, 11-2, etc.; participant three saw 1-3, 2-4, 3-5, 4-6, 5-7, 6-8, 7-9, 8-10, 9-1, 10-2, 11-3 etc.; and so forth, so that each participant only saw a given stimulus item one time and in a single condition. For more information on Latin Squares, and why they are useful for linguistic stimuli, see Cowart (1997).

\section{Procedures}

Potential participants were provided a link to the informed consent form, which, once they agreed to the experiment and clicked next, brought them to the University of Goettingen OnExp server (http://onexp.textstrukturen.uni-goettingen.de/). OnExp is a survey management program provided by the University of Goettingen Courant Research Centre Text Structures Group to administer surveys in a Latin Square automatically using a single link. This program assigned each participant to a group arbitrarily upon click through, sending participants to the group which 


\begin{tabular}{|c|c|c|}
\hline \multicolumn{2}{|r|}{ Condition } & Sample item \\
\hline 1 & $\begin{array}{l}\text { Property } \\
\text { result control }\end{array}$ & $\begin{array}{l}\text { The landscaper broke the twigs into tiny matchsticks on Mon- } \\
\text { day. }\end{array}$ \\
\hline 2 & $\begin{array}{l}\text { Property } \\
\text { VP control }\end{array}$ & $\begin{array}{l}\text { The landscaper was ordered to break the twigs into tiny } \\
\text { matchsticks on Monday, and she did break the twigs into tiny } \\
\text { matchsticks on Monday. }\end{array}$ \\
\hline 3 & $\begin{array}{l}\text { Property } \\
\text { Pre-argument }\end{array}$ & $\begin{array}{l}\text { The landscaper was ordered to break the twigs into tiny } \\
\text { matchsticks on Monday, and break she did the twigs into tiny } \\
\text { matchsticks on Monday. }\end{array}$ \\
\hline 4 & $\begin{array}{l}\text { Property } \\
\text { Pre-result }\end{array}$ & $\begin{array}{l}\text { The landscaper was ordered to break the twigs into tiny } \\
\text { matchsticks on Monday, and break the twigs she did into tiny } \\
\text { matchsticks on Monday. }\end{array}$ \\
\hline 5 & $\begin{array}{l}\text { Property } \\
\text { Pre-adjunct }\end{array}$ & $\begin{array}{l}\text { The landscaper was ordered to break the twigs into tiny } \\
\text { matchsticks on Monday, and break the twigs into tiny match- } \\
\text { sticks she did on Monday. }\end{array}$ \\
\hline 6 & $\begin{array}{l}\text { Path } \\
\text { result control }\end{array}$ & The landscaper broke the twigs into the campfire on Monday. \\
\hline 7 & $\begin{array}{l}\text { Path } \\
\text { VP control }\end{array}$ & $\begin{array}{l}\text { The landscaper was ordered to break the twigs into the camp- } \\
\text { fire on Monday, and she did break the twigs into the campfire } \\
\text { on Monday. }\end{array}$ \\
\hline 8 & $\begin{array}{l}\text { Path } \\
\text { Pre-argument }\end{array}$ & $\begin{array}{l}\text { The landscaper was ordered to break the twigs into the camp- } \\
\text { fire on Monday, and break she did the twigs into the campfire } \\
\text { on Monday. }\end{array}$ \\
\hline 9 & $\begin{array}{l}\text { Path } \\
\text { Pre-result }\end{array}$ & $\begin{array}{l}\text { The landscaper was ordered to break the twigs into the camp- } \\
\text { fire on Monday, and break the twigs she did into the campfire } \\
\text { on Monday. }\end{array}$ \\
\hline 10 & $\begin{array}{l}\text { Path } \\
\text { Pre-adjunct }\end{array}$ & $\begin{array}{l}\text { The landscaper was ordered to break the twigs into the camp- } \\
\text { fire on Monday, and break the twigs into the campfire she did } \\
\text { on Monday. }\end{array}$ \\
\hline
\end{tabular}

Table 4.1: A single stimulus item showing all ten conditions for experiment 1, including control conditions.

contained the fewest number of participants. Once the participant agreed to take part in the survey, they were assigned to a group automatically and presented with a set of ten sentences and asked to rate them on a scale of 1 (not at all acceptable) to 7 (very acceptable), after which they clicked next, and were presented with another 10 


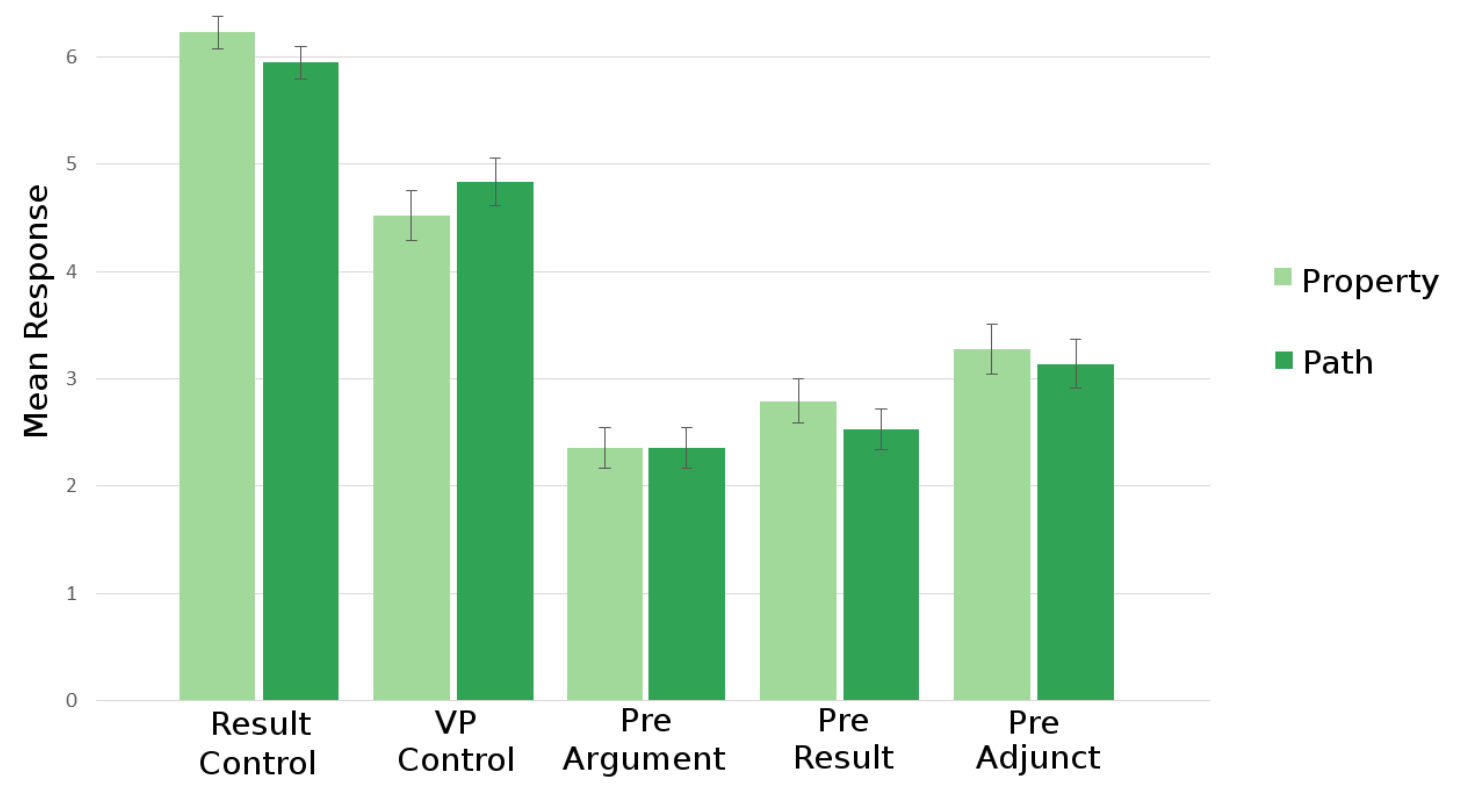

Figure 4.1: Mean participant responses by condition for experiment 1: transitive resultatives (Error bars represent 1 standard deviation)

sentences to rate. In total, they rated 15 pages of 10 sentences each, and then were thanked for their time. Any participant who did not complete all ten pages of the study had their data deleted, as that was the method of withdrawal according to my ethics approval.

\subsubsection{Results}

A graph showing the mean response for all 10 conditions can be found in Figure 4.1.

To ensure that participants accepted the resultative in general, and to check for any differences between property and path results in general, paired samples $t$-tests were performed on both the result control and VP control conditions. Analysis of the result control conditions showed that resultative sentences of both varieties were 
highly acceptable $(M=6.09, S E=.14)$, and that property resultatives $(M=6.23$, $S E=.15)$ were more acceptable than path resultatives $(M=5.94, S E=.15), t=$ 2.51, $r=.34$. Analysis of the VP control conditions showed that bi-clausal sentences including a she did emphasis of both varieties were acceptable $(M=4.68, S E=.22)$, and that property resultatives $(M=4.52, S E=.23)$ were less acceptable than path resultatives $(M=4.84, S E=.22), t=-2.5, r=.34$.

For the purpose of experimental analysis, the control conditions were removed (as they were not designed to be experimentally equivalent to the manipulated conditions), making the analysis a 2 (Type of result phrase: property and path) by 3 (Location of target phrase: pre-argument, pre-result phrase, and pre-adjunct) design. A repeated measures ANOVA showed that there was a significant effect of the location of the target phrase on the acceptability of the sentences, $F(2,98)=25.46$, MSE $=18.61, \eta^{2}=.34$. Additionally, there was a significant effect of result phrase type on the acceptability of the sentences, $F(1,49)=6.96$, MSE $=.20, \eta^{2}=.12$. There was no significant interaction between result phrase type and the location of the target phrase for the experimental conditions; see the graph in Figure $4.2^{2}$ All effects are reported as significant at $p<.05$ unless otherwise noted.

Bonferroni adjusted pairwise comparisons of condition type yielded significant differences between each possible location of the pronoun-auxiliary pair (she did), showing that stranding the core argument (the metal) was less acceptable than stranding either the result phrase $($ flat $)(p<.05)$ or the adjunct phrase (on Tuesday) $(p<.01)$, and stranding the result phrase (flat) was less acceptable than stranding the adjunct

\footnotetext{
${ }^{2}$ Visually, the graph seems to indicate an interaction, and the pre-result condition did show a significant difference between property $(M=2.79, S E=.21)$ and path $(M=2.53, S E=.19), t=$ $2.85, r=.09$, while neither the pre-argument nor pre-adjunct conditions did. However, the ANOVA, which is more reliable, showed that there was no significant interaction.
} 


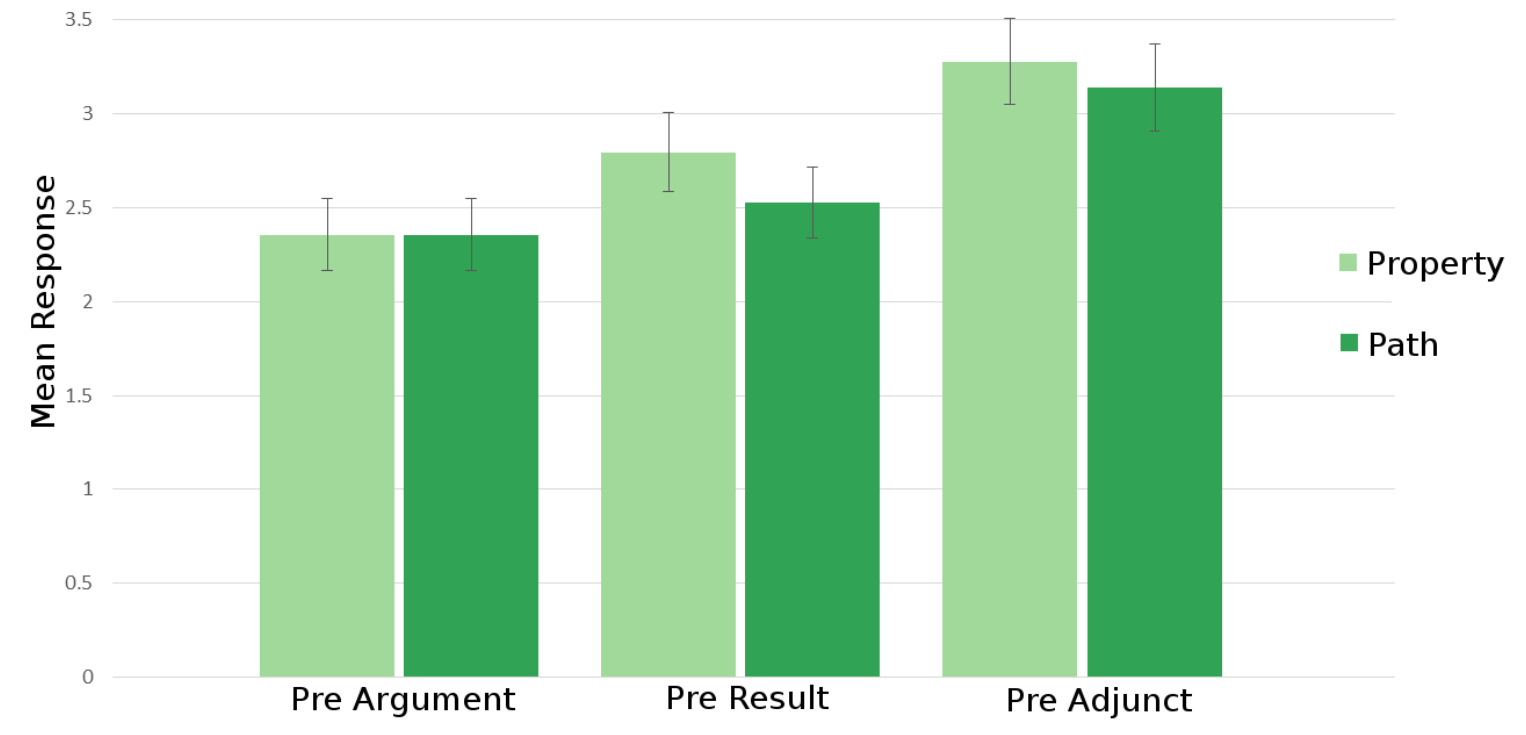

Figure 4.2: Mean participant responses by location of target phrase for Experiment 1: Transitive Resultatives (Error bars represent 1 standard deviation)

phrase (on Tuesday) $(p<.01)$.

\subsubsection{Discussion of experiment 1}

The results of this experiment show that participants accepted the resultative as a whole, but were less permissive of longer sentences. The relative acceptability of VP preposed sentences showed a three way distinction between preposed sentences with stranded arguments, result phrases and adjuncts. Additionally, there was a significant difference between property and path resultative sentences in a VP-preposed configuration with stranded result phrases, with property resultatives being the more acceptable. 


\subsection{Experiment 2: Unaccusative resultatives}

\subsubsection{Methods}

\section{Sample}

For the second experiment, a total of 17 people $^{3}$ completed the survey divided among four lists of stimuli on a Latin Square so that no participant saw the same sentence under two different conditions. As stated in the introduction to this chapter, participants were a minimum of 18 years old and native speakers of Canadian English.

\section{Materials and design}

As discussed in the introduction, the target phrase it did was manipulated between locations in a VP preposed sentence. Additionally, two control sentences were used to check that participants accepted resultative sentences more generally, as well as sentences which are bi-clausal including the it did emphasis. When the additional manipulation of the type of result phrase (property or path) is added, the full data collection included eight conditions per stimulus item, summarized in the table in Table 4.2. A full list of experimental stimuli can be found in appendix B.

To collect the data, a repeated measures design was used. Each participant provided five responses per condition, and the mean for each condition was taken for analysis. To ensure that there were no effects from repeated stimulus items, four Latin Square lists were devised, so that each participant only saw a given stimulus item one time and in a single condition. Four lists were used as information was not shared between the property and path conditions, and thus, there was no overlap

\footnotetext{
${ }^{3}$ The same 17 people completed both experiment 2 and experiment 3.
} 


\begin{tabular}{|c|c|c|}
\hline \multicolumn{2}{|r|}{ Condition } & Sample Item \\
\hline 15 & $\begin{array}{l}\text { Property } \\
\text { result control }\end{array}$ & The building collapsed into a heap on Tuesday. \\
\hline 16 & $\begin{array}{l}\text { Property } \\
\text { VP control }\end{array}$ & $\begin{array}{l}\text { The building needed to collapse into a heap on Tuesday and } \\
\text { it did collapse into a heap on Tuesday. }\end{array}$ \\
\hline 17 & $\begin{array}{l}\text { Property } \\
\text { Pre-result }\end{array}$ & $\begin{array}{l}\text { The building needed to collapse into a heap on Tuesday and } \\
\text { collapse it did into a heap on Tuesday. }\end{array}$ \\
\hline 18 & $\begin{array}{l}\text { Property } \\
\text { Pre-adjunct }\end{array}$ & $\begin{array}{l}\text { The building needed to collapse into a heap on Tuesday and } \\
\text { collapse into a heap it did on Tuesday. }\end{array}$ \\
\hline 19 & $\begin{array}{l}\text { Path } \\
\text { result control }\end{array}$ & The oil seeped out of the furnace on Tuesday. \\
\hline 20 & $\begin{array}{l}\text { Path } \\
\text { VP control }\end{array}$ & $\begin{array}{l}\text { The oil needed to seep out of the furnace on Tuesday and it } \\
\text { did seep out of the furnace on Tuesday. }\end{array}$ \\
\hline 21 & $\begin{array}{l}\text { Path } \\
\text { Pre-result }\end{array}$ & $\begin{array}{l}\text { The oil needed to seep out of the furnace on Tuesday and seep } \\
\text { it did out of the furnace on Tuesday. }\end{array}$ \\
\hline 22 & $\begin{array}{l}\text { Path } \\
\text { Pre-adjunct }\end{array}$ & $\begin{array}{l}\text { The oil needed to seep out of the furnace on Tuesday and seep } \\
\text { out of the furnace it did on Tuesday. }\end{array}$ \\
\hline
\end{tabular}

Table 4.2: A single stimulus item showing all eight conditions for experiment 2, including control conditions.

between those two conditions.

\section{Procedures}

Potential participants were provided a link to the informed consent form, which, once they agreed to the experiment and clicked next, brought them to the University of Goettingen OnExp server (http://onexp.textstrukturen.uni-goettingen.de/). Once the participant agreed to take part in the survey, they were assigned to a group automatically and presented with a set of 12 sentences and asked to rate them on a scale of 1 (not at all acceptable) to 7 (very acceptable), after which they clicked next, and were presented with another 12 sentences to rate. In total, they rated nine pages of 12 sentences each, and then were thanked for their time. Any participant who did 


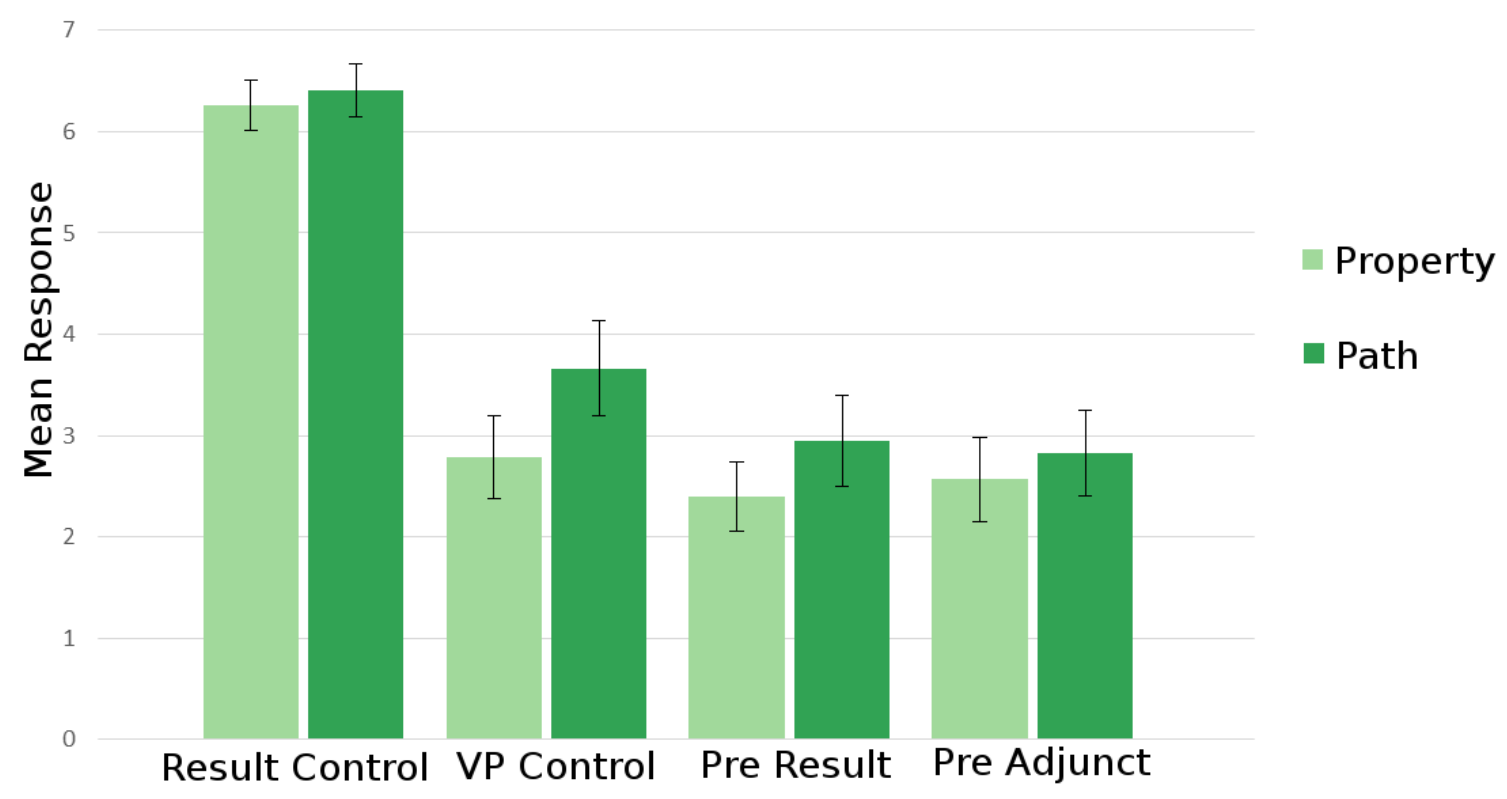

Figure 4.3: Mean participant responses by condition for Experiment 2: Unaccusative Resultatives (Error bars represent 1 standard deviation)

not complete all ten pages of the study had their data deleted.

\subsubsection{Results}

A graph showing the mean response per condition can be found in Figure 4.3.

To ensure that participants accepted the resultative in general, and to check for any differences between property and path results in general, paired samples $t$-tests were performed on both the result control and VP control conditions. Analysis of the result control conditions showed that resultative sentences of both varieties were highly acceptable $(M=6.33, S E=.24)$, and that property resultatives $(M=6.26, S E$ $=.25)$ and path resultatives $(M=6.41, S E=.26)$ were not significantly different from each other. Analysis of the VP control conditions showed that bi-clausal sentences including a she did emphasis of both varieties were less acceptable than the resultative 
base condition but more acceptable than the experimental conditions $(M=4.68, S E$ $=.22)$, and that property resultatives $(M=2.79, S E=.41)$ were less acceptable than path resultatives $(M=3.66, S E=.47), t=-3.35, p<.05, r=.64$.

For the purpose of experimental analysis, the control conditions were removed (as they were not designed to be experimentally equivalent to the manipulated conditions), making the analysis a 2 (Type of result phrase: property and path) by 2 (Location of target phrase: pre-result phrase, and pre-adjunct) design. A repeated measures ANOVA showed that there was a significant effect of result phrase type on the acceptability of the sentences, $F(1,16)=13.48$, MSE $=.21, \eta^{2}=.46$. Additionally, there was neither a significant effect of target phrase location nor a significant interaction between result phrase type and the location of the target phrase for the experimental conditions, as shown in the line graph in Figure 4.4. All effects are reported as significant at $p<.05$.

\subsubsection{Discussion of experiment 2}

For unaccusative resultatives, participants rated sentences with stranded result phrases a in VP preposed configuration higher if they were path resultatives than if there were property resultatives. However, unaccusative resultatives did not show a significant difference between stranded result phrases and stranded adjunct phrases, and without argument phrases to compare with, unaccusative resultatives did not support the three-way distinction discussed here. 


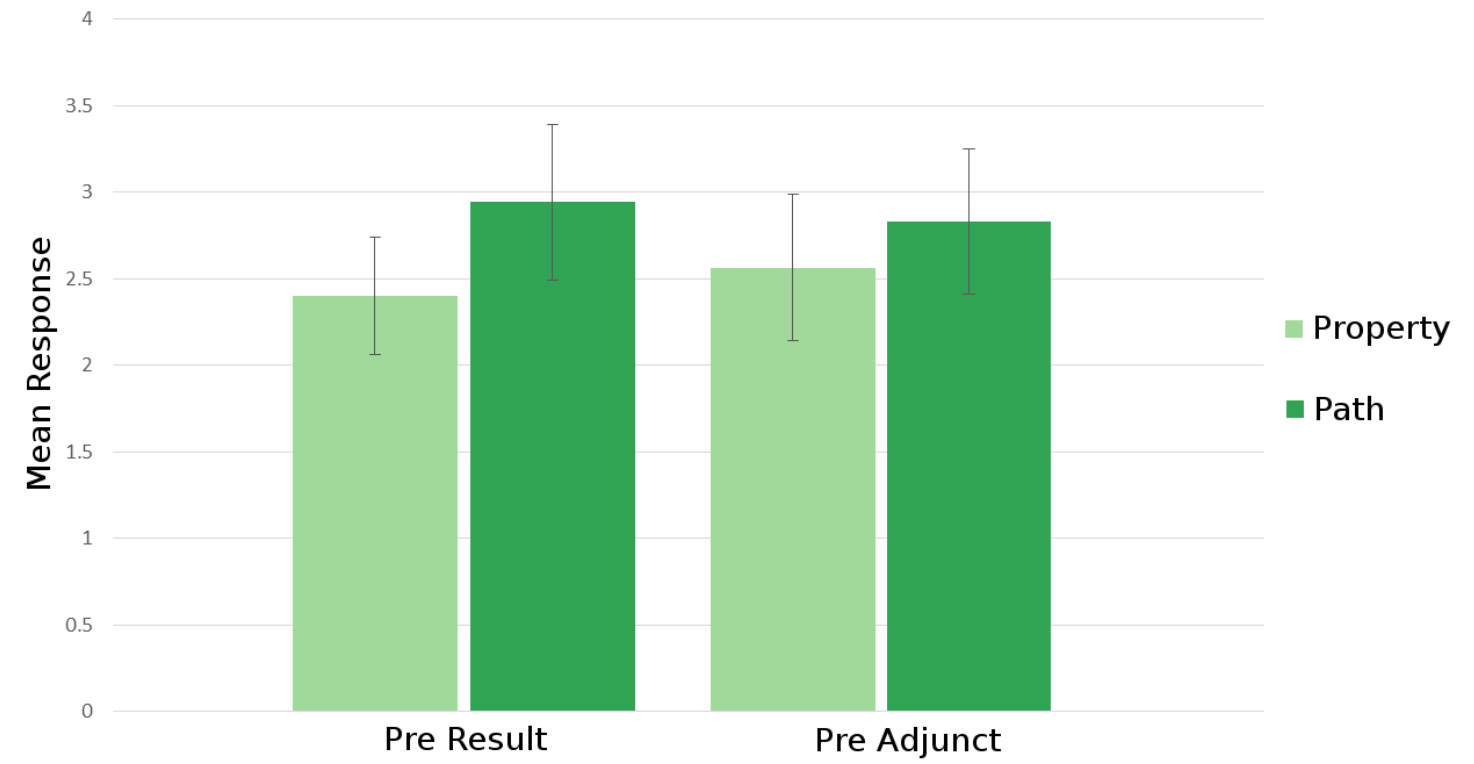

Figure 4.4: Mean participant responses by location of target phrase for Experiment 2: Unaccusative Resultatives (Error bars represent 1 standard deviation)

\subsection{Experiment 3: Unergative resultatives}

\subsubsection{Methods}

\section{Sample}

For the third experiment, a total of 17 peopl $^{4}$ completed the survey divided among two lists of stimuli on a Latin Square so that no participant saw the same sentence under two different conditions. As stated in the introduction to this chapter, participants were a minimum of 18 years old and native speakers of Canadian English.

\footnotetext{
${ }^{4}$ The same 17 people completed both experiment 2 and experiment 3 .
} 


\begin{tabular}{|c|l|l|}
\hline \multicolumn{2}{|l|}{ Condition } & Sample Item \\
\hline \hline 11 & $\begin{array}{l}\text { Property } \\
\text { Way- } \\
\text { construction }\end{array}$ & She sang her way into the hearts of the people on Tuesday. \\
\hline 12 & $\begin{array}{l}\text { Property } \\
\text { Fake reflexive }\end{array}$ & She sang herself into the hearts of the people on Tuesday. \\
\hline 13 & $\begin{array}{l}\text { Path } \\
\text { Way- } \\
\text { construction }\end{array}$ & Kim skated her way to work on Tuesday. \\
\hline 14 & $\begin{array}{l}\text { Path } \\
\text { Fake reflexive }\end{array}$ & Kim skated herself to work on Tuesday. \\
\hline
\end{tabular}

Table 4.3: A single stimulus item showing all four conditions for experiment 3

\section{Materials and design}

As discussed in the introduction, the stimuli were manipulated along two lines: type of construction (the fake reflexive resultative construction and the way-construction) and type of result phrase (property and path) yeilding four conditions per stimulus item, summarized in the table in Table 4.3. A full list of experimental stimuli can be found in appendix $\mathrm{C}$.

To collect the data, a repeated measures design was used. Each participant provided three responses per condition, and the mean for each condition was taken for analysis. To ensure that there were no effects from repeated stimulus items, two Latin Square lists were devised. Two lists were used as information was not shared between the property and path conditions, and thus, there was no overlap between those two conditions. 


\section{Procedures}

Potential participants were provided a link to the informed consent form, which, once they agreed to the experiment and clicked next, brought them to the University of Goettingen OnExp server (http://onexp.textstrukturen.uni-goettingen.de/). Once the participant agreed to take part in the survey, they were assigned to a group automatically and presented with a set of 12 sentences and asked to rate them on a scale of 1 (not at all acceptable) to 7 (very acceptable), after which they clicked next, and were presented with another 12 sentences to rate. In total, they rated nine pages of 12 sentences each, and then were thanked for their time. Any participant who did not complete all ten pages of the study had their data deleted.

\subsubsection{Results}

A graph showing the mean response per condition can be found in Figure 4.5.

For the analysis of the data, a 2 (Type of result phrase: property and path) by 2 (Type of construction: way-construction, and fake reflexive resultative construction) design was used. A repeated measures ANOVA showed that there was a significant effect of result phrase type on the acceptability of the sentences, $F(1,16)=10.12$, MSE $=.67, \eta^{2}=.39$. Additionally, there was a significant effect of type of construction $F(1,16)=11, \operatorname{MSE}=1.15, \eta^{2}=.41$, as well as a significant interaction $F(1,16)=$ 15.08, $\mathrm{MSE}=.42, \eta^{2}=.49$. All effects are reported as significant at $p<.01$.

Because of the interaction, simple comparisons were run to compare the type of result phrase for each type of construction. For the way-construction, there is no difference between property $(M=5.80, S E=.29)$ and path results $(M=5.80, S E=.29)$. Additionally, there was no significant difference between property way-construction 


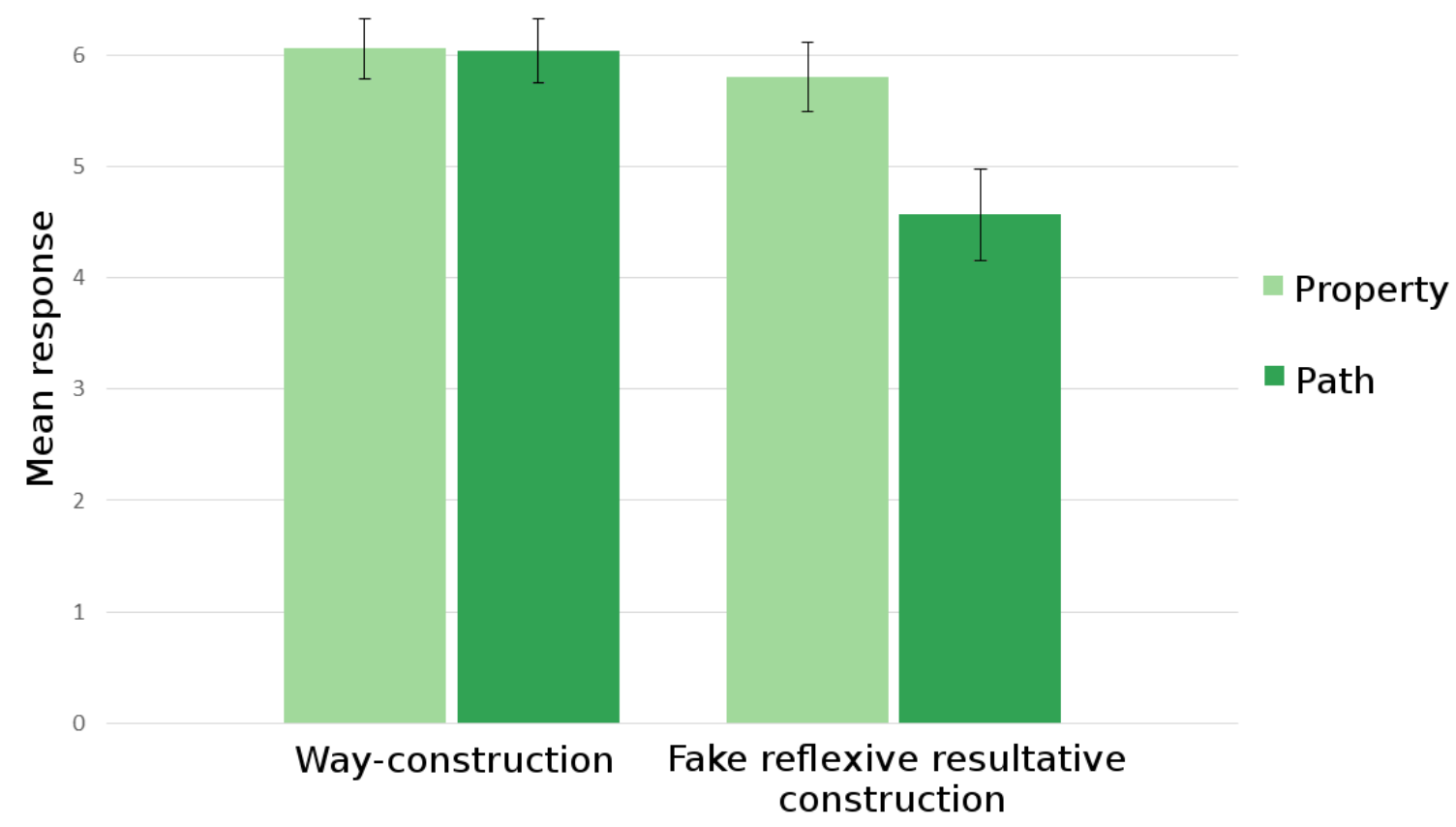

Figure 4.5: Mean participant responses by condition for Experiment 3: Unergative Resultatives

sentences $(M=5.80, S E=.29)$ and property fake reflexive resultative sentences $(M$ $=5.80, S E=.29)$. However, for the fake reflexive resultative construction, there is a significant difference between property results $(M=5.80, S E=.29)$ and path results $(M=4.56, S E=.41), t(16)=3.84, p<.01, r=.69$. Additionally, there was a significant difference between path fake reflexive resultatives $(M=4.570 S E=.41)$ and path way-construction sentences $(M=6.04, S E=.31), t(16)=4.29, p<.01, r$ $=.45$. However, it should be noted that these results have not been adjusted for multiple comparisons, and, thus should be taken as a guideline of the overall pattern. 


\subsubsection{Discussion of experiment 3}

Fake reflexive resultative sentences were rated as less acceptable overall than the wayconstruction, and property results as more acceptable than path results. However, a significant interaction was also present, meaning that the difference between property and path results was much smaller in the way-construction than in the fake reflexive resultative construction, indeed there was no significant difference property and path way-construction sentences.

\subsection{General discussion}

The results of this set of experiments all show that there is a significant difference between property and path resultatives, although the direction of that difference can change according to which type of resultative we look at, and how that resultative sentence is phrased. Additionally, experiment one demonstrated a three-way distinction between arguments, adjuncts and result phrases, while experiment two was unable to show such a distinction. More generally, these experiments served to show that the observations based on traditional introspection generally hold.

To begin with, the difference between property and path resultatives is in line with the general assumption that these two constructions may be completely separate from each other, or, as Goldberg and Jackendoff (2004) put it, separate branches on a family tree. Interestingly, the property resultatives were rated higher than path resultatives in both the transitive and unergative resultatives, and lower than the path resultatives in the unaccusative resultative. This information could provide evidence for a connection between transitive and unergative besides agentivity, but further 
study would be necessary to confirm this. Additionally, it shows an extra difference between resultatives with and without a post-verbal object. What those differences can be attributed to (telicity of the main verb or a lack of patient argument), is outside the scope of this thesis.

Next, experiment one shows that there is a statistical difference between the acceptability of VP-preposed sentences which strand either the argument, the result phrase or the adjunct phrase. This supports my conclusions in Chapter 3, and is in line with the body of evidence that states that there should be a three-way distinction rather than a dichotomy of argument versus adjunct. This three-way distinction for transitive result phrases is in line with work on instruments from Boland (2005a b) and Boland and Blodgett (2006), on directional PPs from Van Luven (2014), and on benefactives from Toivonen $(2012,2013 \mathrm{~b})$ further adding to the body of evidence for the category of added arguments.

Experiment three also showed a difference between property and path results, and showed that that difference does not extend to the similar way-construction. The way-construction is often used as a paraphrase for the fake reflexive, but I have shown that although this similarity is very common for the property resultative, path results are more acceptable in the way-construction than in the fake reflexive resultative construction. The difference between these two constructions has been refelcted formally by my use of a separate template for the fake reflexive which, like all of my templates, is an extension of the work of Asudeh et al. (2013) which included the way-construction in its treatment. For further discussion of that construction, please see their work.

More generally, it would be interesting to analyze which sources of variation were 
more influential upon the data. When analyzing the data, each participant gave 3-5 data points per condition (depending on which survey they were filling out) which were then averaged to provide a single point per participant per condition. These participant means were then analyzed for the overall patterns of the experiments. The individual means and standard deviations per participant for each data point can be found in Appendix D. However, the question of whether participants in general rate result phrases as in-between the ratings for arguments and adjuncts, or some participants treat them like arguments while others treat them as adjuncts I leave for future work.

Future experiments could be improved by collecting data for surveys one and two on a single survey, thus allowing for a repeated measures design to compare between resultatives with and without a post-verbal object. The size of the experiment could be mitigated by removing the result control and VP control conditions as these were not relevant to the analysis here. Instead, the control conditions could be used as filler items so that the manipulation could be tested without having more conditions in the main experiment than necessary. 


\section{Chapter 5}

\section{Analysis}

\section{$5.1 \quad$ Introduction}

This chapter will introduce and provide support for my formal model of the resultative. Section 5.2 will describe Lexical Mapping Theory (LMT) and show how it forms the basis of my analysis of resultatives in LFG. Section 5.3 will discuss the information needed to propose resultative templates, including the needed c- and f-structures (5.3.1), the target semantics for the resultative (5.3.2), and the proposed templates themselves (5.3.3). Finally, proofs will be given for three types of resultatives in Section 5.4: transitive property (5.4.1), unaccusative path (5.4.2), and unergative fake reflexive property (5.4.3).

\subsection{Proposed resultative construction}

Following Bresnan and Zaenen (1990), I propose that capturing the resultative in all of its forms requires reference to argument-structure in LFG: the result phrase is 
only predicated of a specific type of argument as formalised within the architecture. This treatment is in line with the Direct Object Restriction (Simpson (1983b); Levin and Rappaport Hovav (1995); see discussion in Chapter 2) and other generalizations regarding how the resultative combines with the main verbal object, as discussed in Chapter 2. My treatment differs from that of Bresnan and Zaenen (1990) in two ways: first, I will be formalizing the analysis with LFG-Glue and templates, presenting a more fully developed treatment; second, my formalism will differ in how it treats the exceptional instances of the resultative and what constitutes an exceptional instance. I first provide an overview of the formalism for linking or mapping to argument structure that will be used: Lexical Mapping Theory.

Lexical Mapping Theory (LMT) provides a theory of argument-function mapping for LFG (Bresnan and Kanerva, 1989; Bresnan and Moshi, 1990; Bresnan and Zaenen, 1990; Bresnan, 2001; Kibort, 2004, 2006, 2008, 2012; Findlay, 2014; Asudeh et al., 2014). In this theory, arguments of the verb can be divided into four categories using two features: $[ \pm r]$ (restricted) and $[ \pm o]$ (objective), shown in (206).

\begin{tabular}{c|cc} 
& {$[+o]$} & {$[-o]$} \\
\hline$[+r]$ & OBJ $_{\theta}$ & OBL $_{\theta}$ \\
{$[-r]$} & OBJ & SUBJ
\end{tabular}

These features refer to the semantic restrictedness and object-like properties of the argument in question: OBJ and $\mathrm{OBJ}_{\theta}$ are object-like $([+o])$ and $\mathrm{OBJ}_{\theta}$ and $\mathrm{OBL}_{\theta}$ are semantically restricted $([+r])$. The subscripted $\theta$ marks the semantically restricted arguments, as they must be restricted by the thematic role they play in the sentence.

In order to account for the English resultative we will need two things which are already in the literature: the resultative rule from Bresnan and Zaenen (1990) and a 
resultative generalization from Toivonen $(1999,2006)$.

Bresnan and Zaenen (1990) introduce a resultative rule for the a-structure which requires that the subject of the resultative be a $[-r]$ argument from the matrix clause. This predicts that the resultative will (1) never be predicated of a second object or an oblique $\left(\mathrm{OBJ}_{\theta}\right.$ or $\left.\mathrm{OBL}_{\theta}\right)$, and (2) will be predicated of either a SUBJ or an OBJ.

The second prediction from Bresnan and Zaenen (1990), however, needs to be qualified slightly as the resultative is never predicated of "the subject of a transitive or an unergative verb, except indirectly, by means of a fake reflexive" (Simpson, 1983b, p. 153). There are examples of resultatives which are predicated of transitive subjects, including those discussed in section 2.1.1. Thus, in order to account for the data at hand, we must add a further constraint. Toivonen $(1999,2003)$ notes that Swedish particles can only occupy the particle position in a sentence if they have the resultative meaning. If a specific realization can be tied to an interpretation, then perhaps we can conclude that a specific semantic role can be tied to the resultative meaning in English. Drawing from Toivonen's $(2003,2006)$ work on particles and resultatives in English and Swedish, I propose that the resultative can only be predicated of the Lowest Core Grammatical Function, which I will call the LCGF GENERALIZATION. When this generalization is combined with the $[-r]$ rule, we can propose the equation in (207) as a method for identifying the resultative subject.

\section{LCGF GENERALIZATION}

The subject of the resultative XCOMP will be the LCGF of the main predicate which is marked as $[-r]$.

(207) means that the best available argument for the resultative to be predicated of is the object, but, if no object is available, then a subject will do. This generalization 
can explain how the resultative is able to be predicated of the subject of an unaccusative verb like freeze without reference to an "underlying" object, thus avoiding the shortcomings of the DOR and related generalizations, as discussed in chapter 2 . This is because the unaccusative subject is the LCGF because it is the only core grammatical function available, and it fits the $[-r]$ restriction because subjects are $[-r,-o]$.

For the transitive resultative, the treatment is straightforward, as the object is the subject of the result phrase in (208):

Kim hammered the metal flat.

For the unaccusative (209), as mentioned above, the subject of the sentence is the lowest available $[-r]$ argument as it is the only available $[-r]$ argument:

The river froze solid.

This is additionally true for non-subcategorized objects (210) and fake reflexive objects (211) of unergative verbs. As pointed out in Bresnan and Zaenen (1990), nonsubcategorized objects are by default $[-r]$, as the verb is unable to semantically restrict such an object.

(210) Kim ran her shoes threadbare.

(211) Kim danced herself silly.

This model also accounts for the subject-directed result phrases discussed in Section 2.1.1, with select examples repeated here as (212)-(213).

(212) The wise men followed the star out of Bethlehem. 
(213) Kim swam laps to exhaustion.

In these examples the $[-r]$ LCGF would be the object, but it is the subject of the sentence which is shared with the resultative. While the theoretical justification for my analysis does not account for these examples, the formal analysis given below can be extended to include them. It will be a project for further study to determine how the subject is shared using this theoretical framework.

\subsection{Resultative templates}

The template architecture was first introduced to LFG as a method for generalizing repeated information in the construction of computational models of the grammar (Dalrymple et al., 2004). Templates were meant to collect the repeated information so that a given lexical entry could call to a template for further specification rather than having multiple lexical entries repeat the same things over and over again. As an example, we can look at (214)-(216). ${ }^{1}$

$$
\begin{aligned}
& \text { PRESENT }:= \\
& (\uparrow \text { TENSE })=\text { PRESENT } \\
& 3 \mathrm{SG}:= \\
& (\uparrow \text { SUBJ PERSON })=3 \\
& (\uparrow \text { SUBJ NUM })=\mathrm{SG}
\end{aligned}
$$

\footnotetext{
${ }^{1}(214)-(216)$ are based on (2)-(20) in Dalrymple et al. (2004)
} 


$$
\begin{aligned}
\text { yawns } \mathrm{V} \quad & (\uparrow \mathrm{PRED})=\text { 'yawn' } \\
& @ \text { PRESENT } \\
& @ 3 \mathrm{SG}
\end{aligned}
$$

These examples show the basic parts of a grammar which uses templates. (214) is a template for the present tense which specifies that the parent f-structure's tense will be the value PRESENT. (215) states that the person and number values of the parent f-structure's subject will be 3 (third person) and SG (singular), respectively. (216) shows how the first two templates are called into action, specifying a predicate value for the verb, and calling to the PRESENT and 3SG templates to complete the needed information.

Templates were put to semantic work by Asudeh et al. $(2008,2013)$, who used the power given by the generalizations to create meaningful differences between templates which could contain information about the structure or meaning of a sentence without breaking the barrier between syntax and the lexicon. Templates could then be used to store information which can be called on to build complex structures and meanings without having to put general information inside the lexical entries of words (Asudeh et al., 2008; Asudeh, 2012; Asudeh et al., 2013; Asudeh and Toivonen, 2014; Asudeh et al., 2014).

\subsubsection{Resultative c- and f-Structures}

This section will show and describe the c(onstituent)- and f(unctional)-structures for each of the different types of resultative I will be discussing. To begin with, we can look at the c-structure for the transitive property resultative sentence Kim hammered the metal flat (217). 


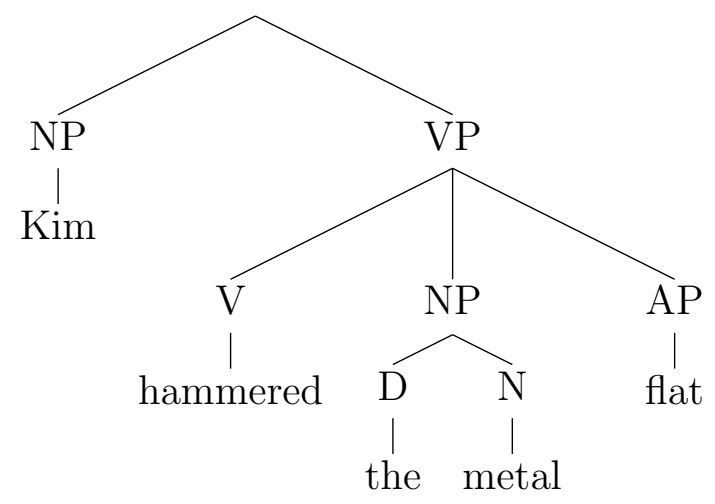

As discussed in section 2.2, the constituency facts of the resultative point to a flat VP structure. So, for this structure the result phrase is sister to both the $\mathrm{V}$ and the NP that it takes as its subject. This explains how the phrase must be displaced as a whole, as shown by the tests in Chapter 2. To this we can add the f-structure (218). ${ }^{2}$

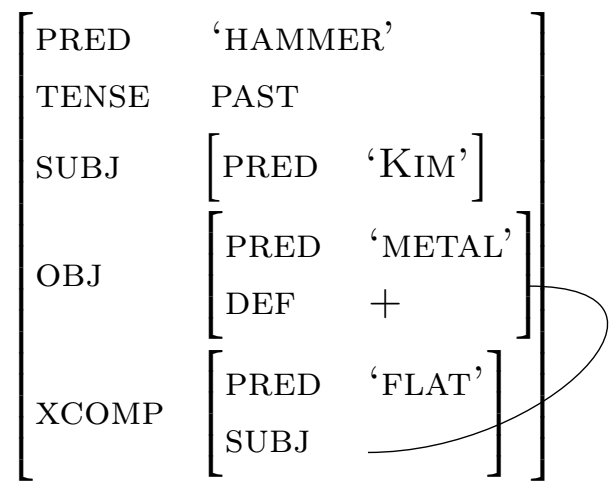

In this f-structure, we can see that the main predicate hammer takes a subject, object and subject-less complement (ХCOMP), and that the XCOMP predicate flat takes a subject. Additionally, we know that the sentence will be in past tense, as indicated by the attribute TENSE and its value PAST. We also know that the subject of the main predicate is a predicate which refers to Kim, and that the object of the main predicate is a definite noun phrase which refers to the metal. Finally, we also know

\footnotetext{
${ }^{2}$ Following Asudeh (2012, pp. 112-114) and Asudeh et al. (2013), the f-structures given here will have no subcategorization frames attached to them. It is assumed that the resource-sensitive Glue logic will determine which elements can be interpreted in the structure.
} 
that the information about the subject of the XCOMP is shared with the object of the main predicate, as indicated by the line which links the main predicate object and XCOMP subject.

Next we can look at the c-structure for the unaccusative property resultative sentence The river froze solid (219).

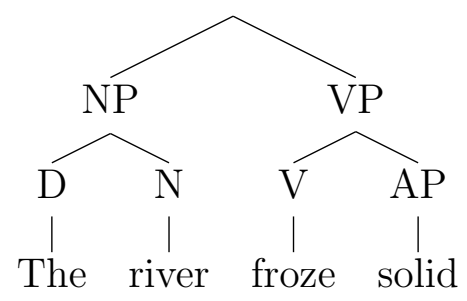

This structure again places the result phase as a sister to $\mathrm{V}$, following the constituency facts explored in Chapter 2. We can also look at the f-structure for this sentence (220).

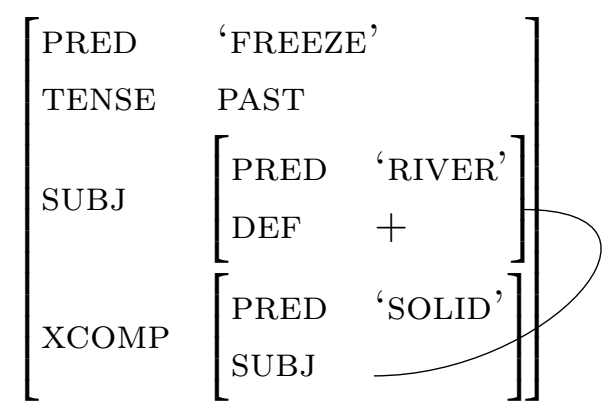

In this f-structure, we can see that the main predicate freeze takes a subject and a subject-less complement (XCOMP), and that the XCOMP predicate solid takes a subject. We also know that the subject of the main predicate is a predicate which refers to a definite noun phrase which refers to a specific river. Finally, we also know that the information about the subject of the XCOMP is shared with the subject of the main predicate, as indicated by the line which links the main predicate subject and XCOMP subject. 
Next we can look at the c-structure for the fake reflexive property resultative sentence Suzy danced herself silly (221).

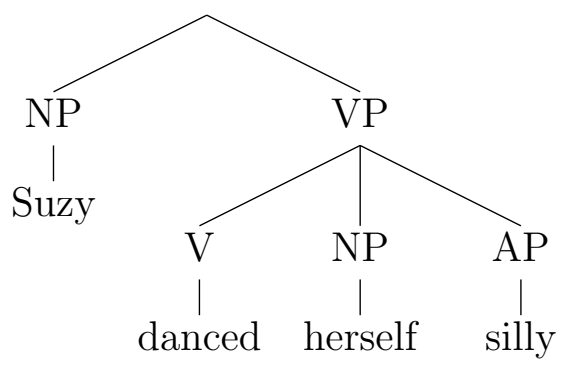

Like the c-structure for the transitive property resultative (217), the c-structure for the unergative property resultative (221) places the post-verbal NP and result phrase in a single constituent with the verb. Thus, on a c-structural level, the transitive and unergative resultatives are identical. We can also look at the f-structure for this sentence (222).

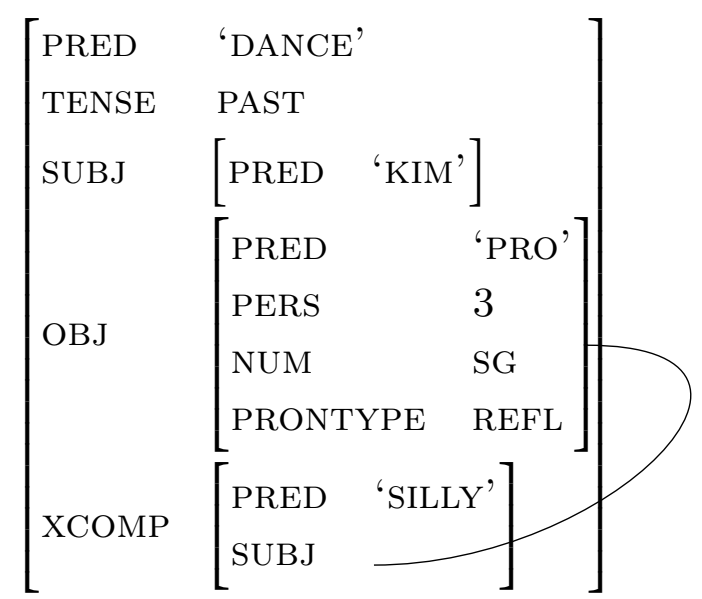

In this f-structure, we can see that the main predicate dance takes a subject, a subjectless complement (XCOMP) and an object. Additionally, the XCOMP predicate flat takes a subject. We also know that the subject of the main predicate is a predicate which refers to Kim, and that the object of the main predicate is is a reflexive pronoun, as indicated by the PRED value of pro and the pronoun type being reflexive. Finally, we 
know that the information about the subject of the XCOMP is shared with the fake reflexive object of the main predicate, as indicated by the line which links the main predicate object and XCOMP subject.

Now that the property resultatives are complete, we can look at the path resultatives, beginning with the transitive path resultative sentence Kim mixed the ingredients into the bowl (223).

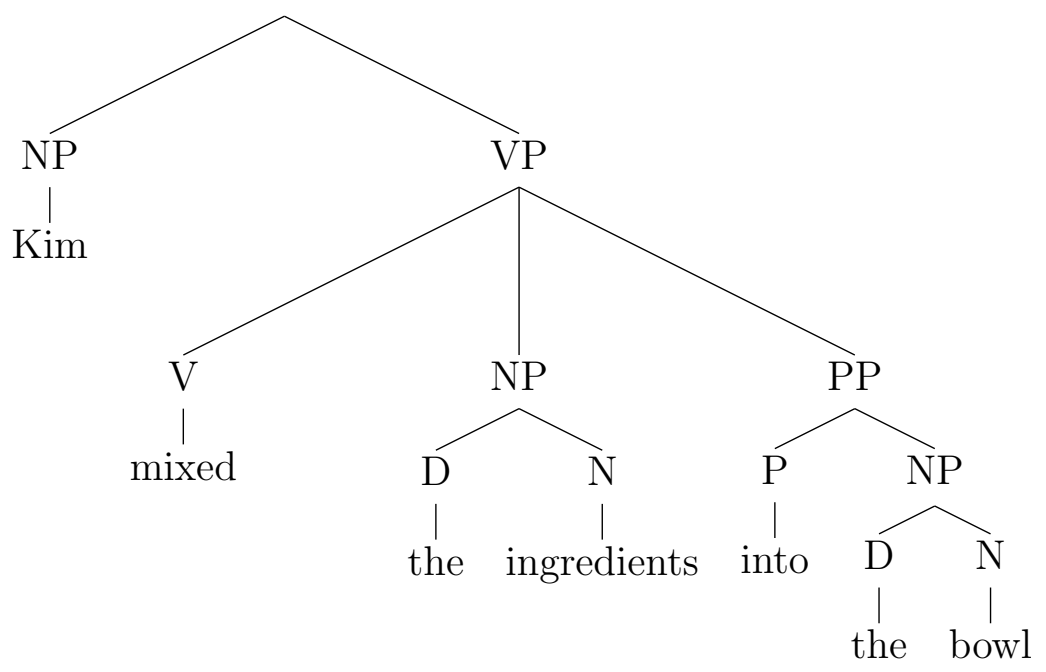

Here we can note that the c-structures for the property and path resultatives are identical, as the tests in chapter 3 showed that the two types of resultatives behaved the same, except for the general differences between states and locations. However, the f-structures for the path resultatives are different from the property versions, as the prepositional phrase which makes up the XCOMP requires both a subject and an object. For the transitive path resultative we can look at (224): 


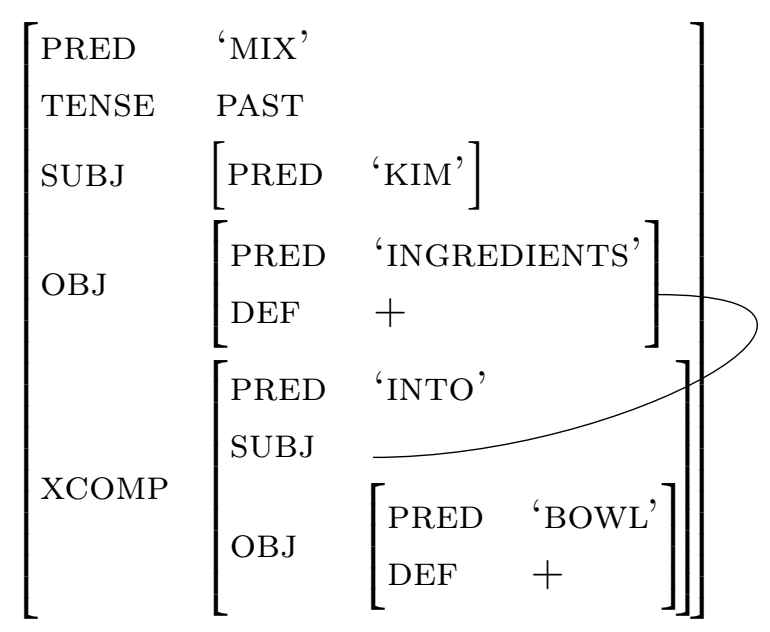

Similar to the transitive property resultative f-structure (218), the transitive path resultative f-structure (224) is past tense; contains a main predicate with a subject, object and subject-less complement (XCOMP); has a subject with the value referring to Kim; and shares the value of the main predicate object with the XOMP subject. However, unlike the property resultative, the path resultative XCOMP contains both a subject and an object. Finally, the value for the XCOMP object is a definite noun phrase which refers to bowl.

Next we can look at the c-structure for the unaccusative path resultative sentence The syrup flowed down the tubes (225).

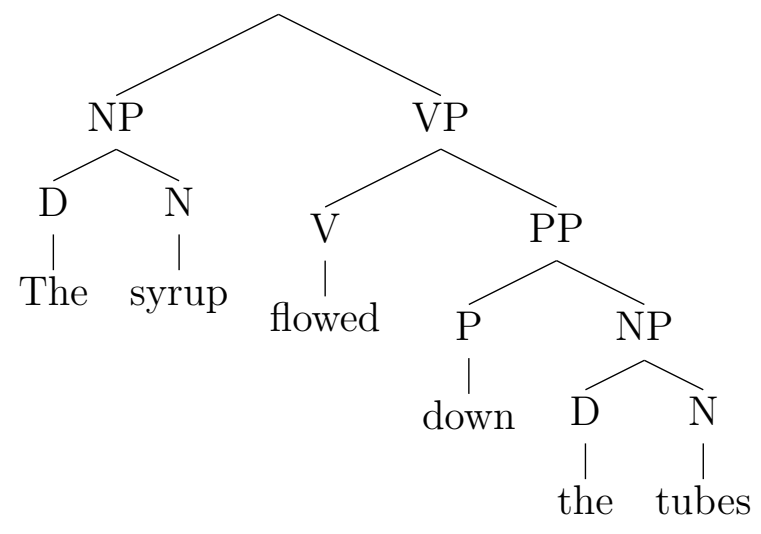


As with the transitive, the c-structure for the path version of the resultative is the same as the property one previously discussed, except that the result XP is headed by a preposition rather than an adjective. Additionally, we can look at the f-structure for this sentence (226).

$$
\left[\begin{array}{ll}
\text { PRED } & \text { 'FLOW' } \\
\text { TENSE } & \text { PAST } \\
\text { SUBJ } & {\left[\begin{array}{ll}
\text { PRED } & \text { 'SYRUP' } \\
\text { DEF } & +
\end{array}\right]} \\
\text { XCOMP } & {\left[\begin{array}{ll}
\text { PRED } & \text { 'DOWN' } \\
\text { SUBJ } & \\
\text { OBJ } & {\left[\begin{array}{ll}
\text { PRED } & \text { 'TUBE' } \\
\text { NUM } & \text { PL } \\
\text { DEF } & +
\end{array}\right]}
\end{array}\right]}
\end{array}\right.
$$

Similar to the unaccusative property resultative f-structure (220), the unaccusative path resultative f-structure (226) is past tense; contains a main predicate with a subject, and subject-less complement (XCOMP); and shares the value of the main predicate subject with the XOMP subject. However, unlike the property resultative, the path resultative XCOMP contains both a subject and an object. Finally, the value for the XCOMP object is a definite noun phrase which refers to the tubes.

Finally, we can look at the c- and f-structures for the fake reflexive path resultative sentence Suzy skated herself to work, beginning with the c-structure (227). 


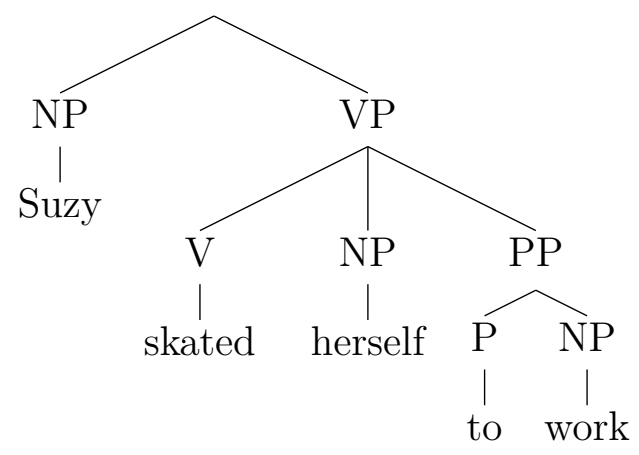

As with the other resultative types, the c-structure is identical to its property sibling (which is also identical to the transitive versions of the resultative). The deviation occurs in the f-structure (228).

$$
\left[\begin{array}{ll}
\text { PRED } & \text { 'SKATE' } \\
\text { TENSE } & \text { PAST } \\
\text { SUBJ } & {\left[\begin{array}{ll}
\text { PRED } & \text { 'SUZY' }
\end{array}\right]} \\
\text { OBJ } & {\left[\begin{array}{ll}
\text { PRED } & \text { 'PRO' } \\
\text { PERS } & 3 \\
\text { NUM } & \text { SG } \\
\text { PRONTYPE } & \text { REFL }
\end{array}\right]} \\
\text { XCOMP } & {\left[\begin{array}{ll}
\text { PRED } & \text { 'TO' } \\
\text { SUBJ } & \\
\text { OBJ } & \text { [PRED 'WORK' }
\end{array}\right]}
\end{array}\right]
$$

Similar to the unergative property resultative f-structure (222), the unergative path resultative f-structure (228) is past tense; contains a main predicate with a subject, subject-less complement (XCOMP), and object; contains a fake reflexive pronoun for its object; and shares the value of the main predicate object with the xomP subject. However, unlike the property resultative, the path resultative XCOMP contains both a subject and an object. Additionally, the values for the specific information have changed to reflect the difference between dance and skate. Finally, the value for the 
XCOMP object is a definite noun phrase which refers to work.

Together, these c- and f-structures show us the forms that my c-structural rules and template calls must interact with in order to derive the intended meanings of the resultative sentences.

\subsubsection{Target semantics for the resultative}

Next we can look at the target semantics for each of the example resultative sentences that we are describing. These target semantics will deviate from the simple semantics introduced in chapter 2 , as they are meant to be the fully fleshed out semantics of the resultative, rather than a simple introduction to the information which makes up the resultative construction. We can look at all six types of resultative to discover more general patterns, and then we can look at the individual types of resultative to describe them in detail. To begin with we have the transitive property resultative (229), unaccusative property resultative (230), fake reflexive property resultative (231), transitive path resultative (232), unaccusative path resultative(233), and fake reflexive path resultative $(234){ }^{3}$

a. Kim hammered the metal flat.

b. $\exists e^{\prime} \exists e . h a m m e r\left(e^{\prime}\right) \wedge \operatorname{agent}\left(e^{\prime}\right)=\operatorname{kim} \wedge \operatorname{patient}\left(e^{\prime}\right)=\operatorname{metal}_{\iota} \wedge \exists s[\operatorname{flat}(s)$ $\wedge \operatorname{patient}(s)=$ metal $_{\iota} \wedge$ become $(e) \wedge$ undergoer $(e)=\operatorname{metal}_{\iota} \wedge$ $\operatorname{terminus}(e)=s] \wedge \operatorname{cause}(e)=e^{\prime}$

a. The river froze solid.

b. $\exists e^{\prime} \exists e . \operatorname{freeze}\left(e^{\prime}\right) \wedge \operatorname{patient}\left(e^{\prime}\right)=\operatorname{river}_{\iota} \wedge \exists s\left[\operatorname{solid}(s) \wedge \operatorname{patient}(s)=\operatorname{river}_{\iota}\right.$

\footnotetext{
${ }^{3}$ It should be noted that metal $_{\iota}$ is a notational shorthand for the instantiated definite noun phrase $\iota x[\operatorname{metal}(x)]$. This shorthand will be used for all subsequent definite noun phrases.
} 
$\left.\wedge \operatorname{become}(e) \wedge \operatorname{undergoer}(e)=\operatorname{river}_{\iota} \wedge \operatorname{terminus}(e)=s\right] \wedge \operatorname{cause}(e)=e^{\prime}$

(231) a. Kim danced herself silly.

b. $\exists e^{\prime} \exists e . \operatorname{dance}\left(e^{\prime}\right) \wedge \operatorname{agent}\left(e^{\prime}\right)=\operatorname{kim} \wedge \exists s[\operatorname{silly}(s) \wedge \operatorname{patient}(s)=k i m \wedge$ $\operatorname{become}(e) \wedge$ undergoer $(e)=\operatorname{kim} \wedge \operatorname{terminus}(e)=s] \wedge \operatorname{cause}(e)=e^{\prime}$

(232) a. Kim mixed the ingredients into the bowl.

b. $\exists e^{\prime} \exists e^{\prime \prime} \cdot \operatorname{mix}\left(e^{\prime}\right) \wedge \operatorname{agent}\left(e^{\prime}\right)=\operatorname{kim} \wedge \operatorname{patient}\left(e^{\prime}\right)=$ ingredients $_{\iota} \wedge$ $\exists e\left[\operatorname{into}(e) \wedge\right.$ patient $(e)=$ ingredients $_{\iota} \wedge$ go $\left(e^{\prime \prime}\right) \wedge \operatorname{undergoer}\left(e^{\prime \prime}\right)=$ ingredients $\left._{\iota} \wedge \operatorname{path}(e)=\operatorname{path}\left(e^{\prime \prime}\right)\right] \wedge \operatorname{cause}\left(e^{\prime \prime}\right)=e^{\prime}$

(233) a. The syrup flowed down the tubes.

b. $\exists e^{\prime} \exists e^{\prime \prime}$.flow $\left(e^{\prime}\right) \wedge$ patient $\left(e^{\prime}\right)=\operatorname{syrup}_{\iota} \wedge \exists e[\operatorname{down}(e)$

$\wedge \operatorname{patient}(e)=\operatorname{syrup}_{\iota} \wedge g o\left(e^{\prime \prime}\right) \wedge \operatorname{undergoer}\left(e^{\prime \prime}\right)=\operatorname{syrup}_{\iota} \wedge$ $\left.\operatorname{path}(e)=\operatorname{path}\left(e^{\prime \prime}\right)\right] \wedge \operatorname{cause}\left(e^{\prime \prime}\right)=e^{\prime}$

(234) a. Suzy skated herself to work.

b. $\exists e^{\prime} \exists e^{\prime \prime} . \operatorname{skate}\left(e^{\prime}\right) \wedge \operatorname{agent}\left(e^{\prime}\right)=\operatorname{suzy} \wedge \exists e[\operatorname{to}(e) \wedge \operatorname{patient}(e)=\operatorname{suzy}$ $\left.\wedge g o\left(e^{\prime \prime}\right) \wedge \operatorname{undergoer}\left(e^{\prime \prime}\right)=\operatorname{suzy} \wedge \operatorname{path}(e)=\operatorname{path}\left(e^{\prime \prime}\right)\right] \wedge \operatorname{cause}\left(e^{\prime \prime}\right)=e^{\prime}$

The difference between the simple semantics of Chapter 2 and this semantics can be seen in the addition of an extra event variable, and its related material. It is within this added event variable that the difference between property and path resultatives is encoded: property resultatives are events of becoming and path resultatives are events of going. All of the resultative types also have an undergoer semantic role for the event which is filled by the patient of the resulting state or location, with property resultatives having the result state as the terminus for the event and path resultatives 
specifying that the going event takes place along the same path as the result event. Path resultatives also have an existential event for their prepositional phrase which states the direction of the action. Finally, all resultative types state that the cause of the going or becoming event is the main predicate event.

This could potentially be seen as an issue for this treatment, as the result state or location is not directly caused by the main event, as per the discussion of direct causation in Kratzer (2005). However, there are no intervening states between the main event variable and the causing of the become/go event, and the resulting state or location. Thus, the main event does cause the result state or location directly, as the only intervention is the act of transition between the initial and final state or location, which is arguably required for the final state or location to be achievable.

On a case by case basis, the transitive resultatives ((229) for property and (232) for path) still contain agent and patient roles for the main predicate, the unaccusative resultatives ((230) for property and (233) for path) still contain a patient but no agent for the main predicate, and the fake reflexive resultatives $((231)$ for property and (234) for path) still contain an agent but no patient for the main predicate.

\subsubsection{Proposed templates}

In order to achieve the target semantics from the c- and f-structures I have given, I propose the template hierarchy in Figure 5.1.

The hierarchy consists of 11 templates each contributing either f-structure or semantic information, with the c-structure information coming from the regular mapping operations available in LFG. The templates are: @SECONDARYPREDICATION, which can be called by either @PredicAtionKind or @PREDicATiOnTARGet. 


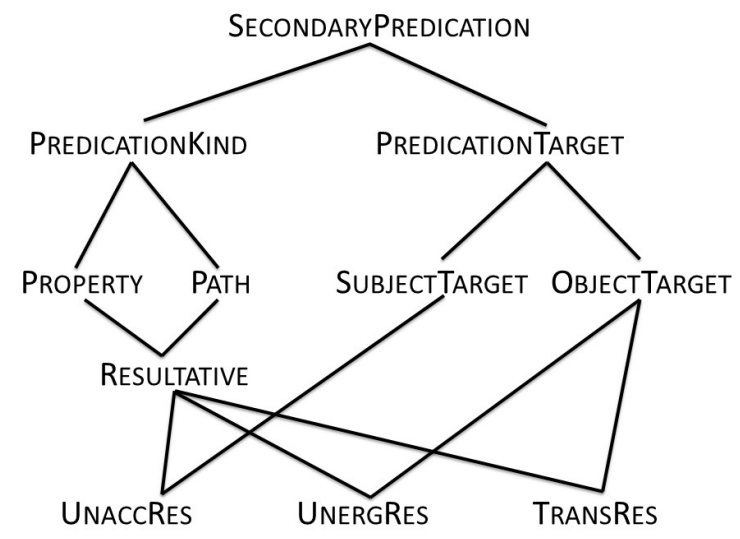

Figure 5.1: LFG templates for the resultative

@PREDicationKind, in turn, can be called by either @Property or @PATH, while @PredicationTarget can be called by @SubjectTarget or @ObJectTarget. @Resultative can call to either @Property or @Path. Finally, the bottom leaves of the hierarchy represent each of the different realizations of the resultative: @UnACCRes for the unaccusative which calls for the @Resultative and a @SubjectTarget; @UnergRes for the unergative which also calls the @Resultative, but calls to @OBJEctTARget where the unaccusative called to the subject version; and, @TRAnsRes for the transitive, which calls @Resultative and @ObjectTarget. @UnergRes also calls a template for the fake reflexive, not shown here, but discussed below.

Looking at the templates individually, I will begin with the top of the tree and work my way down. First @SecondaryPredication (235): 


$$
\begin{aligned}
& \text { SecondaryPredication(Trigger) := } \\
& \% \mathrm{SP}=(\uparrow \mathrm{XCOMP})
\end{aligned}
$$

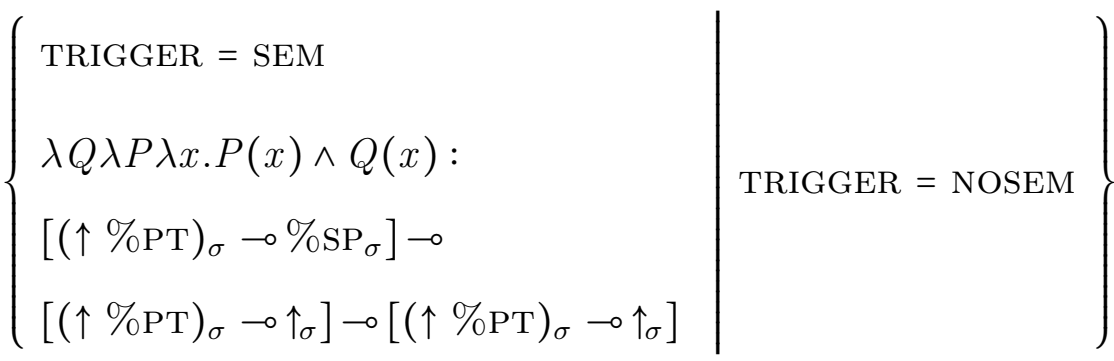

This template does a lot of heavy lifting for the construction. First, and most importantly, it adds the XCOMP to the parent f-structure for the secondary predicate to be inserted into the interpretation of the sentence using the temporary/local variable \%PT. Additionally, it can either add semantic information if the value of TRIGGER is SEM, or add nothing if the value is NOSEM.

The semantic information added by the SEM trigger states that there are two predicates (P and $\mathrm{Q})$ which affect the same argument $(x)$. The Glue side of the meaning constructor (after the colon) states that it will take in a term which takes in the semantic interpretation of \% PT (the predication target, whatever it may be specified as) and returns the semantic interpretation of the secondary predicate as a whole. This means that the meaning constructor takes in a secondary predicate which is looking for the semantic interpretation of its predication target to yield a secondary predicate f-structure, and gives back a two-part equation which is in need of the predication target. This process deals with the shared argument by consuming the extra instance of its use while combining the uses within the lambda calculus.

The next template is PredicationKind (236): 


$$
\begin{aligned}
& \text { PredicationKind }:= \\
& \text { @SecondaryPredicaton(SEm) }
\end{aligned}
$$

This template is one of two which are designed simply to collect similar things together, and thus it does not do much except call the secondary predication template into action with the target set to SEM, thus putting the semantics of the argument sharing into action. For the aspect of the template which collects information, this template acts as a landing point for the two types of resultative predication: property and path.

Next is the second collector template, @PredicationTarget (237):

$$
\begin{aligned}
& \text { PredicationTarget }:= \\
& \text { @SECONDARyPREDication(NOSEM) } \\
& \% \mathrm{PT}=(\% \text { SP SUBJ })
\end{aligned}
$$

This template again calls SECONDARYPREDICATION into action, but this time avoids triggering the semantic information by setting the trigger to NOSEM. Additionally, @PredicationTarget sets the local variable \% PT to be the subject of the f-structure for the local variable \%sp. This means that the predication target is actually the subject of the secondary predicate.

Next we can look at the @SubjectTarget template (238).

$$
\begin{aligned}
& \text { SubjectTarget }:= \\
& \text { @PredicAtionTARget } \\
& \% \mathrm{PT}=(\uparrow \text { SUBJ })
\end{aligned}
$$

This template sets the value of the local variable \%PT to be the subject of the matrix f-structure and allows for subject-directed result phrases. 
Next we can look at the @OBJectTarget template (239).

$$
\begin{aligned}
& \text { ObJectTARget }:= \\
& \text { @PREDiCATIONTARGET } \\
& \% \mathrm{PT}=(\uparrow \text { OBJ })
\end{aligned}
$$

Like the @SubjectTARget template, the @OBjectTARGet template sets the value of the local variable \% $\mathrm{PT}$, but this time, it sets it to the object of the main predicate's f-structure. This allows for resultatives in which the object of the main verb is the subject of the result phrase.

Now we can move on to three templates which contribute meaning information to the construction, beginning with @PROPERTY (240).

$$
\begin{aligned}
& \text { Property }:= \\
& \text { @PREdicationKind } \\
& \lambda P \lambda x \lambda e \exists s . P(x)(s) \wedge \text { become }(e) \wedge \text { undergoer }(e)=x \wedge \text { terminus }(e)=s: \\
& {\left[\% \mathrm{PT}_{\sigma} \multimap\left(\% \mathrm{SP}_{\sigma} \text { EVENT }\right) \multimap \% \mathrm{SP}_{\sigma}\right] \multimap\left[\% \mathrm{PT}_{\sigma} \multimap\left(\% \mathrm{SP}_{\sigma} \text { EVENT }\right) \multimap \% \mathrm{SP}_{\sigma}\right]}
\end{aligned}
$$

This template begins by calling the @PREDICATIONKIND template into action (which in turn calls the semantic version of the @SECONDARYPREDICATION template). It then adds additional meaning, through a Glue meaning constructor which tells the grammar how to incorporate the additional meaning. The lambda expression tells us that there is a predicate, an argument, an event and an existentially bound state, and that the event is an event of becoming which terminates in the state, and the argument undergoes the becoming event. The meaning constructor tells us that this template takes in one Glue term and returns the exact same thing, thus making this a modifying template. The thing that the meaning constructor is looking for is a term 
which takes in both the semantic interpretation of the \% PT variable and the event which corresponds to the \% SP variable to spit out the semantic interpretation of the $\%$ sP variable. This means that it takes in the predication target and the event of the secondary predicate and returns the meaning of the secondary predicate as a whole. That the meaning constructor takes in and returns the same equation means that the lambda term serves to modify the predicate argument.

The next template with semantic content is the counterpart to @PROPERTY, @PATH (241).

$$
\begin{aligned}
& \text { PATH }:= \\
& \text { @PredicAtionKInd } \\
& \lambda P \lambda x \lambda e^{\prime} \exists e . P(y)(x)(e) \wedge g o\left(e^{\prime}\right) \wedge \text { undergoer }\left(e^{\prime}\right)=x \wedge \text { path }\left(e^{\prime}\right)=\operatorname{path}(e): \\
& {\left[\left(\% \mathrm{SP} \mathrm{SUBJ}_{\sigma} \multimap\left(\% \mathrm{SP}_{\sigma} \text { EVENT }\right) \multimap \% \mathrm{SP}_{\sigma}\right] \multimap\right.} \\
& {\left[(\% \mathrm{SP} \mathrm{SUBJ})_{\sigma} \multimap\left(\% \mathrm{SP}_{\sigma} \text { EVENT }\right) \multimap \% \mathrm{SP}_{\sigma}\right]}
\end{aligned}
$$

Like the Property template, the path template begins with a call to the @PredichtionKind template (which calls for the semantic version of @SecondaryPredication) and then adds a meaning constructor. The Glue term in the meaning constructor is identical to that of the @PROPERTY, but the $\lambda$-term provides a different meaning to be incorporated. The $\lambda$-term introduces a new event and states that the event will be an event of going, with an undergoer argument which is shared with an argument applied to a second predicate. The other predicate in the $\lambda$-term (P) must have a path which will be the same path as that of the going event.

The final template with semantic content is @Resultative (242): 


$$
\begin{aligned}
& \text { Resultative }:= \\
& \{\text { @Property } \mid @ \text { Path }\} \\
& \lambda P \lambda e^{\prime} \exists e . P(e)\left(e^{\prime}\right) \wedge \operatorname{cause}(e)=e^{\prime}: \\
& {\left[\left(\% \mathrm{SP}_{\sigma} \operatorname{EVENT}\right) \multimap\left(\uparrow_{\sigma} \operatorname{EVENT}\right) \multimap \uparrow_{\sigma}\right] \multimap\left[\left(\uparrow_{\sigma} \text { EVENT }\right) \multimap \uparrow_{\sigma}\right]}
\end{aligned}
$$

This template begins with a disjunction, allowing for a call to either the @PROPERTY or @PAтH template (but not both). It then adds the information that is crucial to the resultative: that the main event causes the secondary event. On the meaning constructor side of the template, it takes in a term which is looking for the meaning of the secondary predicate's event and the meaning of the main event to produce the meaning of the sentence, and returns a term which is looking for the meaning of the main event to produce the meaning of the sentence as a whole.

The last three templates to be discussed are the ones which produce the specific instances of the resultative, beginning with @UNACCRES (243).

$$
\begin{aligned}
& \text { UnACCRES }:= \\
& \text { @RESUltative } \\
& \text { @SUBJECTTARGET }
\end{aligned}
$$

This template calls both the resultative template and the subject target template. This means that it can call for both property and path resultative meanings, but that the target of the resultative predication will be the subject of the main predicate. This is consistent with the unaccusative, as the subject of the main predicate is the only available argument to be shared between the two predicates.

Next we can look at the @UNERGRes template (244): 


\author{
UNERGRES := \\ @Resultative \\ @OBJectTARGet \\ @FAKEREFLEXIVE
}

This template again calls to the resultative template, but it instead calls to the @OBjectTarget template as well as a @FAkeREFlexive defined below. This template then gives us the ability to call to both property and path resultatives which share the object with the main predicate, and are restricted to having that object be a fake reflexive pronoun.

The next template to be discussed is the TransRes template (245):

$$
\begin{aligned}
& \text { TransRes }:= \\
& \text { @REsultative } \\
& \text { @OBJECTTARGET }
\end{aligned}
$$

This template is similar to the @UNERGRes template in that it calls to both @Resultative and @OBjectTARGET, but it does not call to the template requiring a fake reflexive pronoun. This means that this template can call to either the property or path versions of the resultative, and will always share its argument with the object of the main predicate.

The final template to discuss is the @FAKEREFLEXIVE template (246):

$$
\begin{aligned}
& \text { @FAKEREFLEXIVE }:= \\
& \lambda P \lambda x \lambda y \lambda e . P(x)(e) \wedge \operatorname{patient}(e)=y: \\
& {\left[(\uparrow \mathrm{SUBJ})_{\sigma} \multimap\left(\uparrow_{\sigma} \text { EVENT }\right) \multimap \uparrow_{\sigma}\right] \multimap\left[(\uparrow \mathrm{SUBJ})_{\sigma} \multimap(\uparrow \mathrm{OBJ})_{\sigma} \multimap\left(\uparrow_{\sigma} \mathrm{EVENT}\right) \multimap \uparrow_{\sigma}\right]}
\end{aligned}
$$

This template inserts an unselected patient argument into an intransitive verb's se- 
mantic interpretation and states that the inserted argument will be the patient of the action of that verb. This is accomplished by taking in a Glue meaning constructor which is in need of a subject's semantic interpretation $\left((\uparrow \mathrm{SUBJ})_{\sigma}\right)$ and the interpretation of the event for that predicate $\left(\left(\uparrow_{\sigma}\right.\right.$ EVENT $\left.)\right)$ to determine its meaning; and returning a meaning constructor which needs an additional argument for its interpretation, namely the semantic interpretation of the object of the main predicate $\left((\uparrow \mathrm{OBJ})_{\sigma}\right)$.

This template hierarchy can be expanded in two immediately apparent ways: inclusion of the depictive as a branch under @SECONDARYPREDICATION and the addition of a template to handle subject-directed transitive resultatives (247)-(248).

(247) The wise men followed the star out of Bethlehem.

Kim swam laps to exhaustion.

The secondary predication construction known as the depictive (249) could be added to this hierarchy by calling to both @PROPERTY and @SUBJECTTARGET, with additional meaning being contributed by specific construction.

\section{John came to the meeting drunk.}

Subject-directed transitive resultatives (247)-(248) could be given a separate template@TransSubjRes which calls to @Resultative and @SubjectTarget. This simple extension would account for the subject-directed examples from section 2.1.1, while still enforcing the need for the shared argument to be the main predicate subject for the unaccusative and the main predicate object for the fake reflexive. This is in line with work in HPSG by Wechsler $(1997,2000)$, but, as discussed in Section 5.2, 
would require an extension of my theoretical analysis.

Another option for the theoretical analysis of subject-directed resultatives would be to allow the @PREDiCATIONTARGET to set the target for predication to optionally choose either the subject or object of the main predicate. This would require verbs to specify which argument they would share with their secondary predicate in their lexical entry.

Of these two options, I would expect the first to be more effective for the resultative. However, it will be a project for future research to fully test each theory and determine which would be most appropriate. My current formal analysis using templates is capable of handing either extension, and would only need minor updates to accommodate the analysis which is chosen.

\subsection{Walking through the proofs}

In this section I will go through three of the proofs needed for my treatment: a transitive property resultative, an unaccusative path resultative and a fake reflexive property resultative.

\subsubsection{Transitive property resultative}

This subsection will discuss the transitive property resultative sentence in (250).

(250) Kim hammered the metal flat. 


\section{Templates called}

In order to look at the complete picture of the templates called for the transitive property resultative, we can look at the tree of called templates in (251).

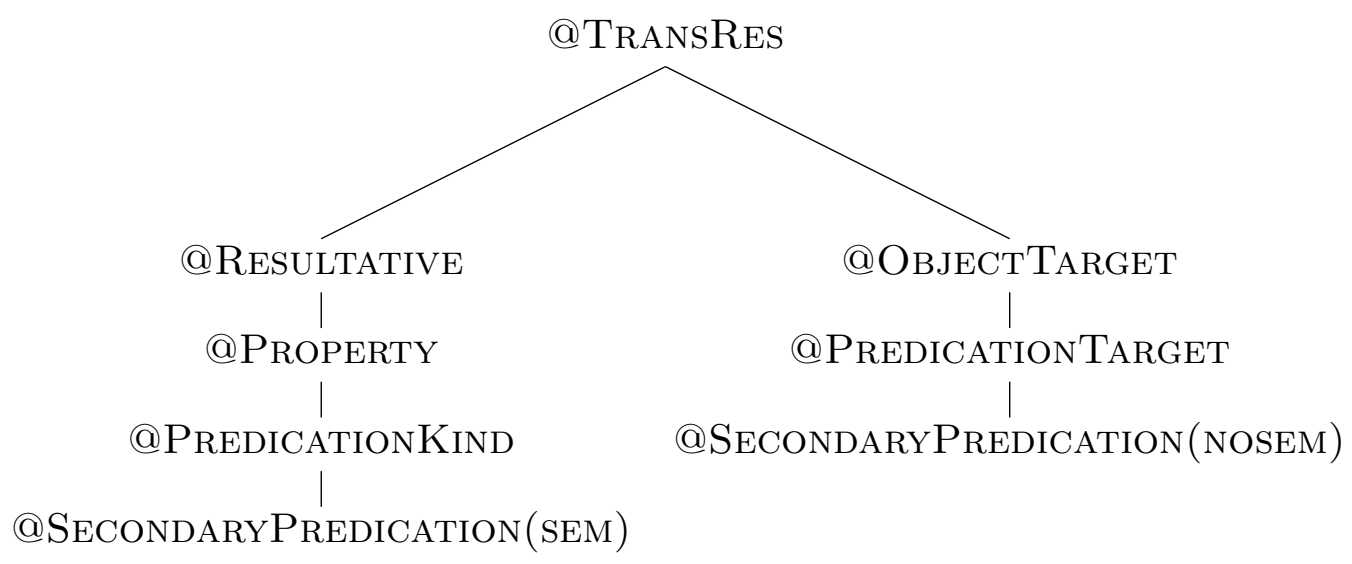

Transitive resultatives (both property and path) begin by calling the @TRAnsRes template, which in turn calls the @REsultative template. Where the two types of resultatives differ is in which template is chosen when calling the @ RESULtative template, which in this case would be the @ProperTy template. This, in turn calls the @PRedicationKind template which calls the semantic version of the @SECONDARYPREDICATION template.

The second branch of the tree shows the templates activated by the second line in the @TransRes template, starting with@ObjectTarget. That template calls@PredicationTARgET which calls the non-semantic version of @SECONDARYPREDICATION.

This results in the templates in (252)-(258) being called. 


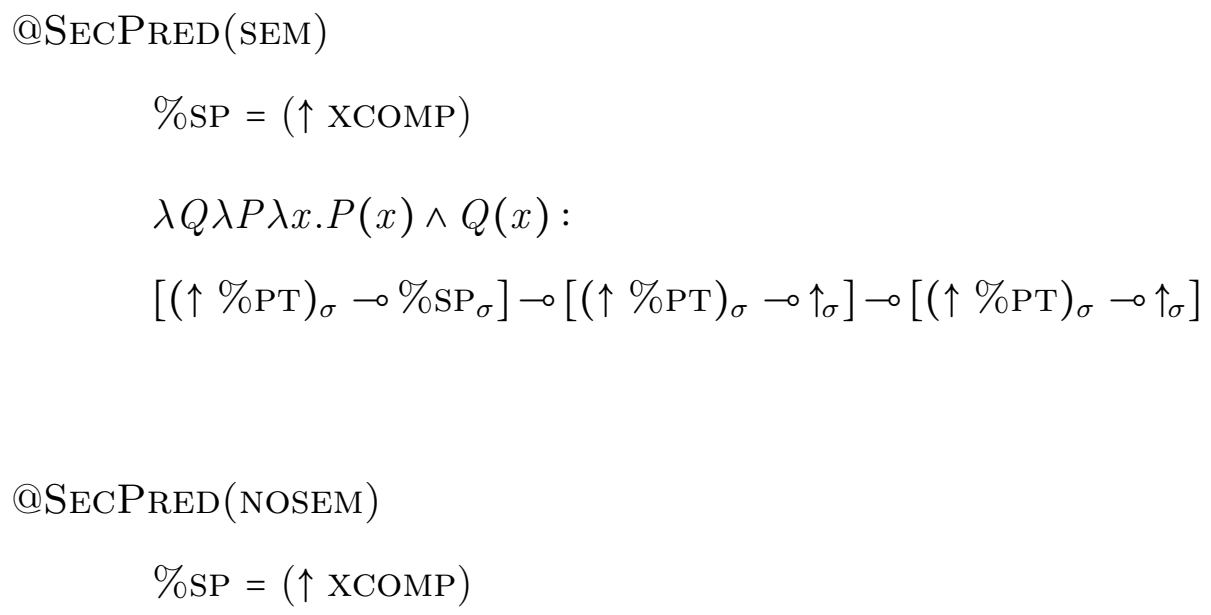

(254)@ @PREDKIND

@SECONDARYPREDiCATION(SEM)

@PREDTARGET

$$
\begin{aligned}
& @ \text { SECONDARYPREDICATION(NOSEM }) \\
& \% \mathrm{PT}=(\% \text { SP SUBJ })
\end{aligned}
$$

(256)@OBJTARget

$$
\% \mathrm{PT}=(\uparrow \mathrm{OBJ})
$$

(257) @PROPERTY

$$
\begin{aligned}
& \lambda P \lambda x \lambda e \exists s . P(x)(s) \wedge \text { become }(e) \wedge \text { undergoer }(e)=x \wedge \text { terminus }(e)=s: \\
& {\left[\% \mathrm{PT}_{\sigma} \multimap\left(\% \mathrm{SP}_{\sigma} \mathrm{EVENT}\right) \multimap \% \mathrm{SP}_{\sigma}\right] \multimap\left[\% \mathrm{PT}_{\sigma} \multimap\left(\% \mathrm{SP}_{\sigma} \mathrm{EVENT}\right) \multimap \% \mathrm{SP}_{\sigma}\right]}
\end{aligned}
$$




$$
\begin{aligned}
& @ \text { Resultative } \\
& \qquad \begin{aligned}
& \lambda P e^{\prime} \exists e . P(e)\left(e^{\prime}\right) \wedge \operatorname{cause}(e)=e^{\prime}: \\
& {\left[\left(\% \mathrm{SP}_{\sigma} \text { EVENT }\right) \multimap\left(\uparrow_{\sigma} \text { EVENT }\right) \multimap \uparrow_{\sigma}\right] \multimap\left[\left(\uparrow_{\sigma} \text { EVENT }\right) \multimap \uparrow_{\sigma}\right] }
\end{aligned}
\end{aligned}
$$

\section{Relevant lexical entries}

In order to derive the meaning of our test sentence we will need the lexical entries in (259)-(263)

$$
\begin{gathered}
\operatorname{Kim} \quad \mathrm{N}(\uparrow \text { PRED })=\text { 'Kim' } \\
\operatorname{kim}: \uparrow_{\sigma}
\end{gathered}
$$

$$
\begin{aligned}
& \text { hammered V ( } \uparrow \text { PRED })=\text { 'hammer' } \\
& \text { (@TRAnsRes) } \\
& \lambda y \lambda x \lambda e \text {.hammer }(e) \wedge \operatorname{agent}(e)=x \wedge \operatorname{patient}(e)=y: \\
& (\uparrow \mathrm{OBJ})_{\sigma} \multimap(\uparrow \mathrm{SUBJ})_{\sigma} \multimap\left(\uparrow_{\sigma} \mathrm{EVENT}\right) \multimap \uparrow_{\sigma} \\
& \text { the } \quad \mathrm{D} \quad(\uparrow \mathrm{DEF})=+ \\
& \lambda P \iota x . P(x): \\
& {\left[\left(\uparrow_{\sigma} \mathrm{VAR}\right) \multimap\left(\uparrow_{\sigma} \mathrm{RESTR}\right)\right] \multimap \uparrow_{\sigma}} \\
& \text { metal N } \quad \text { N } \uparrow \text { PRED })=\text { 'metal' } \\
& \lambda x . \operatorname{metal}(x):\left(\uparrow_{\sigma} \mathrm{VAR}\right) \multimap\left(\uparrow_{\sigma} \mathrm{RESTR}\right)
\end{aligned}
$$




$$
\begin{aligned}
\text { flat } \quad & (\uparrow \mathrm{PRED})=\text { 'flat' } \\
& \lambda x \lambda s . \text { flat }(s) \wedge \operatorname{patient}(s)=x: \\
& (\uparrow \mathrm{SUBJ})_{\sigma} \multimap\left(\uparrow_{\sigma} \text { EVENT }\right) \multimap \uparrow_{\sigma}
\end{aligned}
$$

\section{Instantiated meaning constructors for this example}

In order to derive the correct semantics for the transitive property resultative sentence (repeated here as (264)), we will need to refer to the f-structure in (265), which has been given labels for each of the sub-structures.

(264) Kim hammered the metal flat.

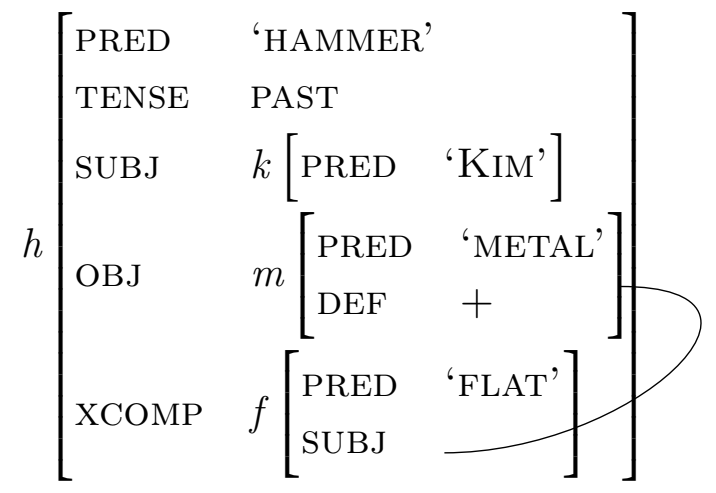

In the Glue meaning constructor portion of the following instantiated lexical entries and templates below, the letters $h, k, m$, and $f$ will stand for the semantic structure of the f-structure which is labelled with that letter. Additionally, the notation h.e and f.e will stand for the event of the semantic structure of the f-structure labelled with that letter. ${ }^{4}$

Notational shorthands have also been taken to avoid distraction from the important parts of this treatment, including the meaning constructor for the and metal

\footnotetext{
${ }^{4}$ For more on this type of notation, see Seciton 3.3.1 in Asudeh (2012).
} 
being pre-combined; $\iota x . m e t a l(x)$ being abbreviated as $m_{\iota}$; and the meaning constructor for hammered having the composition of its arguments re-ordered in the final derivation (Asudeh, 2012).

$$
\text { Kim }
$$

$k i m: k$

hammered

$$
\begin{aligned}
& \lambda x \lambda y \lambda e . h a m m e r(e) \wedge \operatorname{agent}(e)=x \wedge \operatorname{patient}(e)=y: \\
& k \multimap m \multimap h . e \multimap h
\end{aligned}
$$

(268) the metal

$$
m_{\iota}: m
$$

(269) flat

$$
\begin{aligned}
& \lambda x \lambda \text { s.flat }(s) \wedge \operatorname{patient}(s)=x: \\
& m \multimap f . e \multimap f
\end{aligned}
$$

$$
\text { @SECPRED(SEM) }
$$

$$
\begin{aligned}
& \lambda Q \lambda P \lambda x . P(x) \wedge Q(x): \\
& (m \multimap f) \multimap(m \multimap h) \multimap(m \multimap h)
\end{aligned}
$$

@PROPERTY

$$
\begin{aligned}
& \lambda P \lambda x \lambda e \exists s . P(x)(s) \wedge \text { become }(e) \wedge \text { undergoer }(e)=x \wedge \operatorname{terminus}(e)=s: \\
& (m \multimap f . e \multimap f) \multimap(m \multimap f . e \multimap f)
\end{aligned}
$$




$$
\begin{aligned}
& \text { @Resultative } \\
& \qquad \begin{array}{l}
\lambda P \lambda e^{\prime} \exists e . P(e)\left(e^{\prime}\right) \wedge \operatorname{cause}(e)=e^{\prime}: \\
(f . e \multimap h . e \multimap h) \multimap(h . e \multimap h)
\end{array}
\end{aligned}
$$

\section{Proof}

Before discussing the proof given in Figure 5.2 two rules of linear logic and one reduction/equivalence in the lambda calculus must be discussed: implication introduction, implication elimination, and beta-reduction.

Implication introduction $(273)^{5}$ allows for an assumption to be made using square brackets, which must then be discharged later in the derivation using ${ }^{\circ} \mathcal{I}, 1$. This corresponds to functional abstraction in the meaning language.

$$
\begin{aligned}
& \text { Abstraction : Implication Introduction } \\
& {[x: A]^{1}} \\
& \vdots \\
& \frac{f: B}{\lambda x . f: A \multimap B}{ }^{\circ} \mathcal{I}, 1
\end{aligned}
$$

Implication elimination $(274)^{6}$ is the removal of an antecedent of a linear logic term once it is given on another branch of the derivation. Unless otherwise noted, unmarked steps of my derivations will be implication elimination. This corresponds to functional elimination in the meaning language.

$$
\begin{aligned}
& \text { Application }: \text { Implication Elimination } \\
& \vdots \\
& \frac{a: A \quad f: A \multimap B}{f(a): B}{ }^{\circ} \mathcal{E}
\end{aligned}
$$

${ }^{5}(273)$ is from (3b) on p. 79 in Asudeh (2012).

${ }^{6}(274)$ is from (3a) on p. 78 in Asudeh (2012). 
Finally, beta-reduction $(\Rightarrow \beta)$ is the process of simplifying lambda expressions through argument application (see, e.g. Carpenter (1998)).

Moving on to the derivation at hand, Figure 5.2 shows the complete proof for the transitive property resultative. In this figure, we can see how each of the templates and lexical entries combine together to form the meaning of the entire sentence, shown at the bottom of the tree.

Beginning at the left top of the derivation, the template @PROPERTY is combined with the lexical entry for flat, yielding a modified version of the predication. Next an assumption is made that $y$ will stand for the value of $m\left([y: m]^{1}\right)$, and that is combined with the meaning constructor which resulted from the first line of the derivation. Next a second assumption is made that $e^{\prime \prime \prime}$ will stand for the event of becoming the flat state $\left(\left[e^{\prime \prime \prime}: f . e\right]^{2}\right)$, and that assumption is combined into the term. The next step discharges the first assumption $\left(-^{\circ} \mathcal{I}, 1\right)$, and reinserts the need for a subject of the flat state through $\lambda$-binding of the $y$ variable.

The next step of this derivation adds the semantic information from the @SecondaryPredication (@SecPred to save space) template, which closes the need for a subject of the predicate flat by stating that it will be shared with the main predicate in the sentence. 
The derivation continues on the right of the tree with the combination of hammered and flat, which uses up one of the resources which hammered is looking for. Then an assumption is made that $z$ will stand for $m\left([z: m]^{3}\right)$, and that is combined into the derivation. Next a fourth and final assumption is made that $e^{\prime \prime}$ will stand for the event of hammering $\left(\left[e^{\prime \prime}: h . e\right]^{4}\right)$ and then combined into the derivation. Next assumption 3 is discharged and the need for an object of hammered is reintroduced $(-\circ \mathcal{I}, 3)$.

At this point, the two larger branches of the derivation come together and the result of the secondary predicate combined with the predicate flat which is looking for a subject to share with a second predicate is combined with the predicate hammered which is in need of an object. The combination of these two equations yields a meaning constructor which is looking for a single argument to be shared between two predicates. That single argument is added in with the addition of metal.

Next the derivation discharges both assumption $4\left(\rightarrow^{\mathcal{I}, 4}\right)$ and assumption $2\left(\rightarrow^{\circ} \mathcal{I}, 2\right)$, leaving a meaning constructor which is in need of an event for both the becoming flat event and the hammering event. The becoming flat event is taken care of by the addition of the @REsultative template, which asserts the existence of one event, and says another event is the cause of it. Finally the hammering event is discharged through the generally available existential event closure $\exists_{\text {event }}$. 


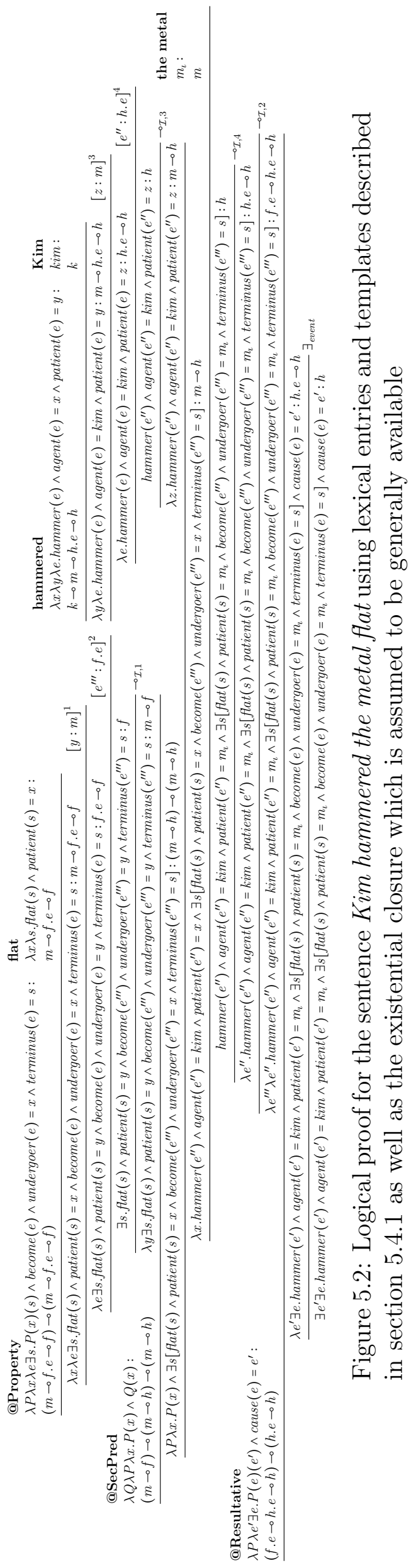




\subsubsection{Unaccusative path resultative}

This subsection will discuss the unaccusative path resultative sentence in (275).

(275) The syrup flowed down the tubes.

\section{Templates called}

The templates called while deriving the meaning of an unaccusative path sentence can been seen in (276).

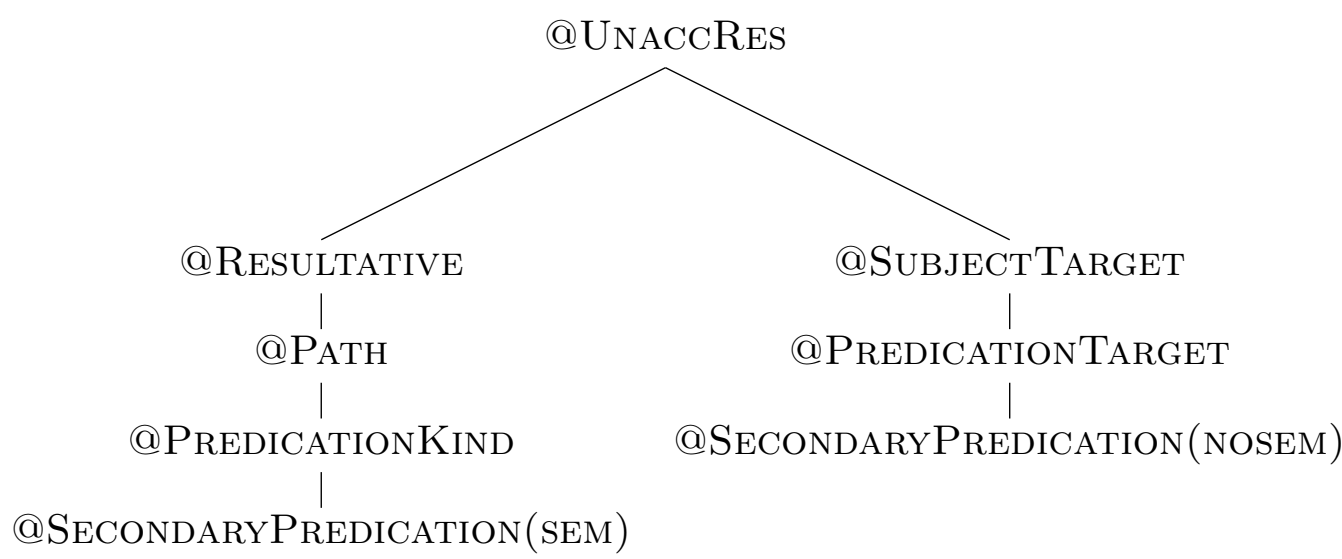

Beginning from the top of the tree, all unaccusative resultatives make a call to @UnaccRes, which then calls to both @Resultative and @SubjectTarget. Working our way down the left side of the tree, @Resultative calls to @PATh (as the test sentence is a path resultative), which calls to @PREDicATIONKIND, which finally calls to the semantic version of @SECONDARYPredication. On the right branch of the tree @SubjectTARGEt calls to @PredTARGET which calls to the nonsemnatic version of of @SECONDARYPREDICATION.

(277)-(284) show the templates which have been called into action for the unaccusative path resultative. 


$$
\begin{aligned}
& \text { UnaccRes }:= \\
& \text { @Resultative } \\
& \text { @SubJectTaRget }
\end{aligned}
$$

(278) Resultative :=

$\{@$ Property |@PAth $\}$

$\lambda P \lambda e^{\prime} \exists e . P(e)\left(e^{\prime}\right) \wedge \operatorname{cause}(e)=e^{\prime}:$

$\left[\left(\% \mathrm{SP}_{\sigma}\right.\right.$ EVENT $) \multimap\left(\uparrow_{\sigma}\right.$ EVENT $\left.) \multimap \uparrow_{\sigma}\right] \multimap\left[\left(\uparrow_{\sigma}\right.\right.$ EVENT $\left.) \multimap \uparrow_{\sigma}\right]$

(279) $\quad$ PATH $:=$

@PREDiCATIONKIND

$\lambda P \lambda x \lambda e^{\prime} \exists e . P(y)(x)(e) \wedge g o\left(e^{\prime}\right) \wedge$ undergoer $\left(e^{\prime}\right)=x \wedge \operatorname{path}\left(e^{\prime}\right)=\operatorname{path}(e):$

$\left[(\% \mathrm{SP} \text { SUBJ })_{\sigma} \multimap\left(\% \mathrm{SP}_{\sigma}\right.\right.$ EVENT $\left.) \multimap \% \mathrm{SP}_{\sigma}\right] \multimap$

$\left[\left(\% \mathrm{SP}^{\mathrm{SUBJ}}\right)_{\sigma} \multimap\left(\% \mathrm{SP}_{\sigma} \mathrm{EVENT}\right) \multimap \% \mathrm{SP}_{\sigma}\right]$

(280) PredicationKind :=

@SECONDARyPREDiCATON(SEM)

(281) SecondaryPredication(SEm) :=

$\% \mathrm{SP}=(\uparrow \mathrm{XCOMP})$

TRIGGER $=$ SEM

$\lambda Q \lambda P \lambda x . P(x) \wedge Q(x):$

$\left[(\% \mathrm{SP} \text { OBJ })_{\sigma} \multimap(\% \mathrm{SP} \text { SUBJ })_{\sigma} \multimap\left(\% \mathrm{SP}_{\sigma} \mathrm{EVENT}\right) \multimap \% \mathrm{SP}_{\sigma}\right] \multimap$

$\left[(\% \mathrm{SP} \text { OBJ })_{\sigma} \multimap(\% \mathrm{SP} \text { SUBJ })_{\sigma} \multimap\left(\% \mathrm{SP}_{\sigma} \mathrm{EVENT}\right) \multimap \% \mathrm{SP}_{\sigma}\right]$ 


$$
\begin{aligned}
& \text { SubjectTARget }:= \\
& \text { @PrEDiCATIONTARGET } \\
& \% \mathrm{PT}=(\uparrow \text { SUBJ }) \\
& \text { PrEDICATIONTARGET }:= \\
& @ \text { SECONDARYPREDICATION(NOSEM }) \\
& \% \mathrm{PT}=(\% \text { SP SUBJ })
\end{aligned}
$$

(283) PredicationTarget $:=$

$$
\begin{aligned}
& \text { SECONDARYPREDICATION(NOSEM) := } \\
& \% \mathrm{SP}=(\uparrow \mathrm{XCOMP})
\end{aligned}
$$

\section{Relevant lexical entries}

In order to derive the meaning of our test sentence we will need the lexical entries in $(285)-(289)$.

(285) the

$\mathrm{D} \quad(\uparrow \mathrm{DEF})=+$

$\lambda P \iota x . P(x):$

$\left[\left(\uparrow_{\sigma} \mathrm{VAR}\right) \multimap\left(\uparrow_{\sigma} \mathrm{RESTR}\right)\right] \multimap \uparrow_{\sigma}$

(286) syrup

$$
\begin{array}{ll}
\mathrm{N} \quad(\uparrow \mathrm{PRED})=\text { 'syrup' } \\
\quad \lambda x \cdot \operatorname{syrup}(x):\left(\uparrow_{\sigma} \mathrm{VAR}\right) \multimap\left(\uparrow_{\sigma} \mathrm{RESTR}\right)
\end{array}
$$

(287) flowed

$$
\begin{aligned}
& \mathrm{V} \quad(\uparrow \mathrm{PRED})=\text { 'flow' } \\
& (@ \mathrm{UNACCRES}) \\
& \lambda y \lambda x \lambda e . \text { flow }(e) \wedge \text { patient }(e)=x: \\
& (\uparrow \mathrm{SUBJ})_{\sigma} \multimap\left(\uparrow_{\sigma} \mathrm{EVENT}\right) \multimap \uparrow_{\sigma}
\end{aligned}
$$




$$
\begin{aligned}
& \text { down } \quad \mathrm{P} \quad(\uparrow \mathrm{PRED})=\text { 'down' } \\
& \lambda y \lambda x \lambda e . \operatorname{down}(e) \wedge \operatorname{patient}(e)=x \wedge \operatorname{location}(e)=y: \\
& (\uparrow \mathrm{SUBJ})_{\sigma} \multimap(\uparrow \mathrm{OBJ})_{\sigma} \multimap\left(\uparrow_{\sigma} \mathrm{EVENT}\right) \multimap \uparrow_{\sigma} \\
& \text { tubes } \quad \mathrm{N}(\uparrow \mathrm{PRED})=\text { 'tube' } \\
& \lambda x . \operatorname{tubes}(x):\left(\uparrow_{\sigma} \mathrm{VAR}\right) \multimap\left(\uparrow_{\sigma} \operatorname{RESTR}\right)
\end{aligned}
$$

\section{Instantiated meaning constructors for this example}

In order to derive the correct semantics for the transitive property resultative sentence (repeated here as (290)), we will need to refer to the f-structure in (291), which has been given labels for each of the sub-structures.

(290) The syrup flowed down the tubes.

$$
\left[\begin{array}{ll}
\text { PRED } & \text { 'FLOW' } \\
\text { TENSE } & \text { PAST } \\
\text { XCOMP } & d\left[\begin{array}{ll}
\text { PRED } & \text { 'SYRUP' } \\
\text { DEF } & +
\end{array}\right] \\
\text { XUBJ } & t\left[\begin{array}{ll}
\text { PRED } & \text { 'DOWN' } \\
\text { OUJ } & t\left[\begin{array}{ll}
\text { PRED } & \text { 'TUBE' } \\
\text { NUM } & \text { PL } \\
\text { DEF } & +
\end{array}\right]
\end{array}\right]
\end{array}\right.
$$

In the Glue meaning constructor portion of the following instantiated lexical entries and templates below, the letters $s, d$, and $t$ will stand for the f-structure which is labelled with that letter. Additionally, the notation d.e and f.e will stand for the event denoted by the f-structure labelled with that letter. 
Notational shorthands have also been used to avoid distraction from the important parts of this treatment, including: the meaning constructor for the and syrup being pre-combined; the meaning constructor for the and tubes being pre-combined; $\iota x . \operatorname{syrup}(x)$ being abbreviated as $s_{\iota}$; and $\iota x$.tube $(x)$ being abbreviated as $t_{\iota}$.

the syrup

$$
s_{\iota}: s
$$

(293) flowed

$$
\begin{aligned}
& \lambda x \lambda e . f l o w(e) \wedge \operatorname{patient}(e)=x: \\
& s \multimap f . e \multimap f
\end{aligned}
$$

(294) down

$$
\begin{aligned}
& \lambda y \lambda x \lambda e . \operatorname{down}(e) \wedge \operatorname{patient}(e)=x \wedge \operatorname{location}(e)=y: \\
& t \multimap s \multimap d . e \multimap d
\end{aligned}
$$

(295) the tubes

$$
t_{\iota}: t
$$

$$
\begin{aligned}
& @ \operatorname{SecPred}(\mathrm{SEM}) \\
& \qquad Q \lambda P \lambda x . P(x) \wedge Q(x): \\
& \quad(s \multimap d) \multimap(s \multimap f) \multimap(s \multimap f)
\end{aligned}
$$

@PATH

$$
\text { @PREDicAtionKind }
$$$$
\lambda P \lambda x \lambda e^{\prime} \exists e . P(y)(x)(e) \wedge g o\left(e^{\prime}\right) \wedge \text { undergoer }\left(e^{\prime}\right)=x \wedge \operatorname{path}\left(e^{\prime}\right)=\operatorname{path}(e):
$$$$
(s \multimap d . e \multimap d) \multimap(s \multimap d . e \multimap d)
$$ 


$$
\begin{aligned}
& \text { @Resultative } \\
& \qquad \begin{array}{l}
\lambda P \lambda e^{\prime} \exists e . P(e)\left(e^{\prime}\right) \wedge \operatorname{cause}(e)=e^{\prime}: \\
(d . e \multimap f . e \multimap f) \multimap(f . e \multimap f)
\end{array}
\end{aligned}
$$

\section{Proof}

Figure 5.3 shows the complete proof for the unaccusative path resultative. In this figure, we can see how each of the templates and lexical entries combine together to form the meaning of the entire sentence, shown at the bottom of the tree.

Beginning in the top left corner of the derivation, the lexical entries for down and the-tubes are combined to get a modified meaning constructor. This modified meaning constructor is then combined with the @PATH template to yield a new meaning expression in the third line down. At this point, two separate assumptions are made: $x$ will be the meaning for $s\left([x: s]^{1}\right)$; and $e$ will stand for the event denoted by d.e. This yields the meaning expression in the fifth line from the top of the left branch.

Next, the first assumption is discharged $\left(\sim^{\circ} \mathcal{I}, 1\right)$, yielding a meaning expression which is then combined with the template @SECONDARYPREDICATION to yield the $7^{\text {th }}$ meaning expression from the top. This output is combined with the shorter leftmost branch of the proof.

Beginning at the top of the leftmost branch, the lexical entry for flowed is combined with an assumption on $\mathrm{s}\left([y: s]^{3}\right)$ and an assumption on f.e $\left(\left[e^{\prime}: f . e\right]^{4}\right)$ to yield the third line down on that branch. Then the third assumption is discharged to yield the meaning expression which will be combined with the centre branch of the derivation, discussed above. 


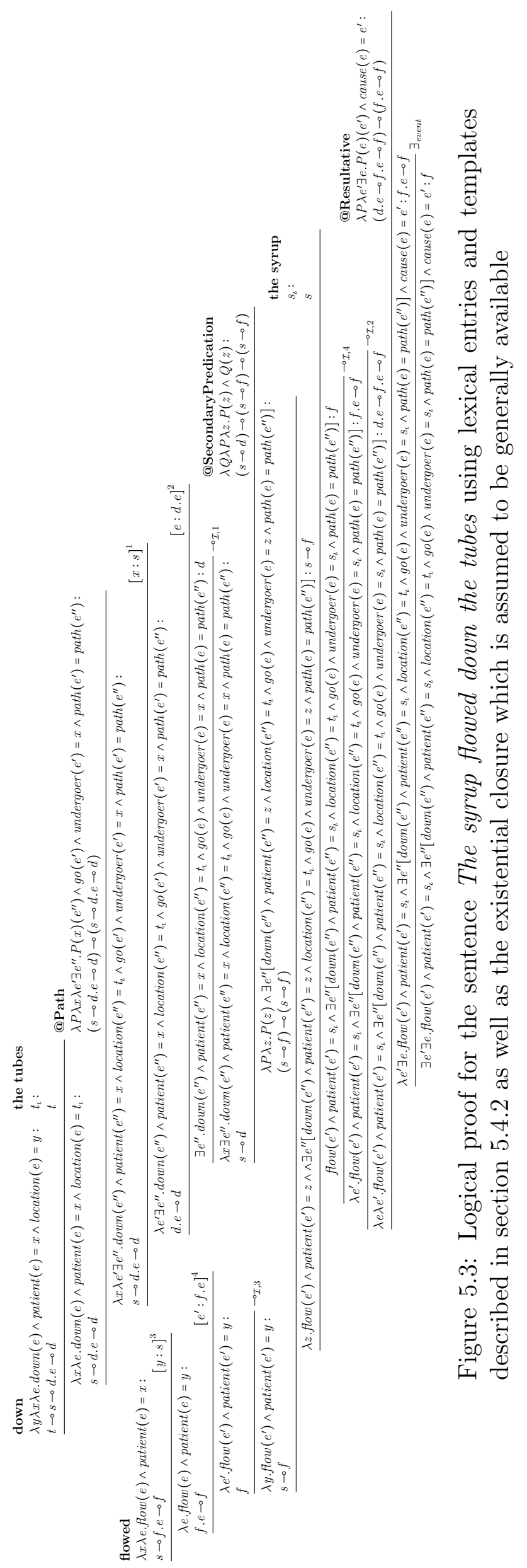


The two branches come together to yield a meaning expression which is combined with the lexical entry for the syrup. The resulting expression has assumptions four and then two discharged $\left(\rightarrow^{\circ} \mathcal{I}, 4\right.$ and $-^{\circ} \mathcal{I}, 2$, respectively) to derive the meaning expression which is third from the bottom of the tree. This is then combined with the template @Resultative, yielding the second to last line of the proof in which the result event (a location in this instance) is existentially bound.

Finally, the main event is existentially bound using the generally available existential event closure $\multimap^{\circ} \mathcal{E}$.

\subsubsection{Fake reflexive property resultative}

This subsection will discuss the fake reflexive property resultative sentence in (299).

Kim laughed herself silly.

\section{Templates called}

The templates called while deriving the meaning of an fake reflexive property sentence can been seen in (300).

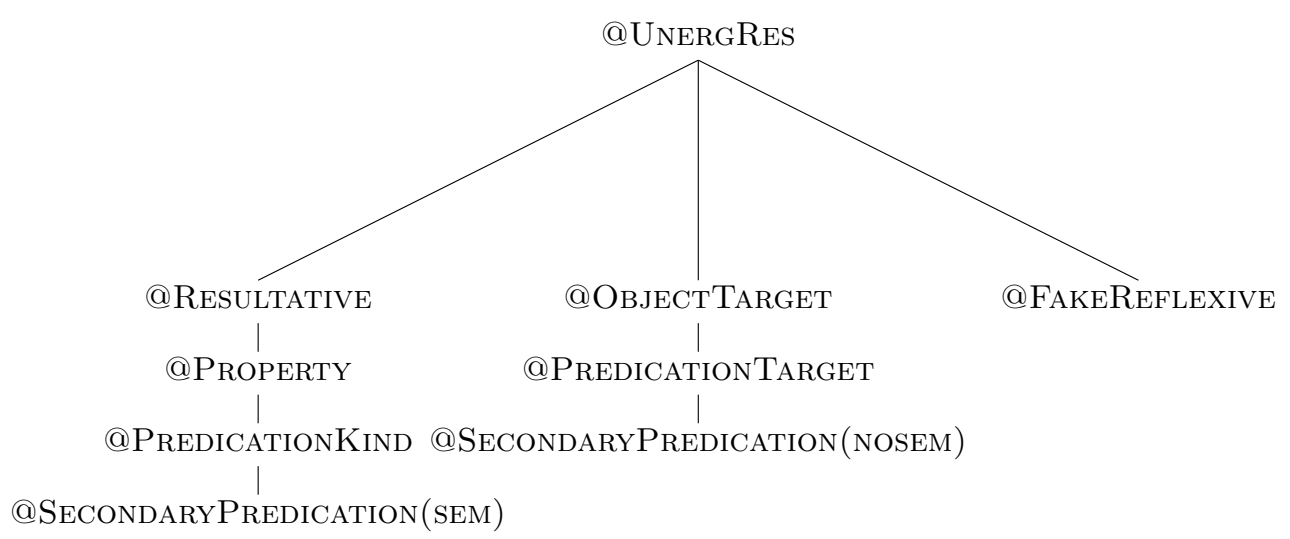


Beginning at the top of the tree, all fake reflexive resultatives resultatives make a call to @UNERGRES, which then calls to three other templates, each represented by a branch in the tree. @Resultative, on the left-most branch, calls to @Property (as the sentence we are working with is a property resultative), which calls to @PredicationKind, which calls to the semantic version of @SecondaryPredication. @ObjTarget, the middle branch of the tree, calls to @PrEDicationTARgEt, which calls to the nonsemantic version of @SecondaryPredication. Finally, @FakeReflexive, the right branch of the tree, calls no further templates.

The templates which are called in the derivation for a fake reflexive property resultative can be seen in (301)-(309).

$$
\begin{aligned}
& \text { UnERgRES }:= \\
& \text { @RESUltative } \\
& \text { @OBJECTTARGET }
\end{aligned}
$$

$$
\begin{aligned}
& \text { Resultative }:= \\
& \{@ \text { Property } \mid @ \text { Path }\} \\
& \lambda P \lambda e^{\prime} \exists e . P(e)\left(e^{\prime}\right) \wedge \operatorname{cause}(e)=e^{\prime}: \\
& {\left[\left(\% \mathrm{SP}_{\sigma} \operatorname{EVENT}\right) \multimap\left(\uparrow_{\sigma} \operatorname{EVENT}\right) \multimap \uparrow_{\sigma}\right] \multimap\left[\left(\uparrow_{\sigma} \operatorname{EVENT}\right) \multimap \uparrow_{\sigma}\right]}
\end{aligned}
$$

$$
\begin{aligned}
& \text { Property }:= \\
& \text { @PREDicationKInd } \\
& \lambda P \lambda x \lambda e \exists s . P(x)(s) \wedge \text { become }(e) \wedge \text { undergoer }(e)=x \wedge \text { terminus }(e)=s: \\
& {\left[\% \mathrm{PT}_{\sigma} \multimap\left(\% \mathrm{SP}_{\sigma} \text { EVENT }\right) \multimap \% \mathrm{SP}_{\sigma}\right] \multimap\left[\% \mathrm{PT}_{\sigma} \multimap\left(\% \mathrm{SP}_{\sigma} \text { EVENT }\right) \multimap \% \mathrm{SP}_{\sigma}\right]}
\end{aligned}
$$


(304) PREDicationKind :=

@SECONDARYPREDiCATON(SEM)

(305) SecondaryPredication(SEm) :=

\% SP $=(\uparrow \mathrm{XCOMP})$

TRIGGER $=$ SEM

$\lambda Q \lambda P \lambda x . P(x) \wedge Q(x):$

$\left[(\uparrow \% \mathrm{PT})_{\sigma} \multimap \% \mathrm{SP}_{\sigma}\right] \multimap\left[(\uparrow \% \mathrm{PT})_{\sigma} \multimap \uparrow_{\sigma}\right] \multimap\left[(\uparrow \% \mathrm{PT})_{\sigma} \multimap \uparrow_{\sigma}\right]$

(306) ObJectTARget :=

@PREDicATIONTARgET

$\% \mathrm{PT}=(\uparrow \mathrm{OBJ})$

(307) PredicationTarget :=

@SECONDARYPREDICATION(NOSEM)

$\% \mathrm{PT}=(\%$ SP SUBJ $)$

(308) SecondaryPredication(nosem) :=

$\% \mathrm{SP}=(\uparrow \mathrm{XCOMP})$

(309) FAKEREFLEXIVE :=

$\lambda P \lambda x \lambda y \lambda e . P(x)(e) \wedge$ patient $(e)=y:$

$\left[(\uparrow \text { SUBJ })_{\sigma} \multimap\left(\uparrow_{\sigma}\right.\right.$ EVENT $\left.) \multimap \uparrow_{\sigma}\right] \multimap\left[(\uparrow \text { SUBJ })_{\sigma} \multimap(\uparrow \text { OBJ })_{\sigma} \multimap\left(\uparrow_{\sigma}\right.\right.$ EVENT $\left.) \multimap \uparrow_{\sigma}\right]$ 


\section{Relevant lexical entries}

In order to derive the meaning of our test sentence, we will need the lexical entries in $(310)-(313) \cdot{ }^{7}$

$$
\begin{aligned}
& \text { Kim } \quad \mathrm{N}(\uparrow \text { PRED })={ }^{\prime K i m} ' \\
& \operatorname{kim}: \uparrow_{\sigma} \\
& \text { laughed } \quad \mathrm{V} \quad(\uparrow \text { PRED })=\text { 'laugh' } \\
& \text { (@UNERGRes) } \\
& \lambda x \lambda \operatorname{edance}(e) \wedge \operatorname{agent}(e)=x: \\
& (\uparrow \mathrm{SUBJ})_{\sigma} \multimap\left(\uparrow_{\sigma} \text { EVENT }\right) \multimap \uparrow_{\sigma} \\
& \text { herself } \quad \mathrm{D} \quad(\uparrow \text { PRED })=\text { 'pro' } \\
& \lambda y . y \times y:\left(\uparrow_{\sigma} \text { ANTECEDENT }\right) \multimap\left[\left(\uparrow_{\sigma} \text { ANTECEDENT }\right) \otimes \uparrow_{\sigma}\right] \\
& \text { silly } \quad \mathrm{N}(\uparrow \text { PRED })=\text { 'silly' } \\
& \lambda x \lambda \operatorname{s.silly}(s) \wedge \operatorname{patient}(s)=x: \\
& (\uparrow \mathrm{SUBJ})_{\sigma} \multimap\left(\uparrow_{\sigma} \text { EVENT }\right) \multimap \uparrow_{\sigma}
\end{aligned}
$$

\section{Instantiated meaning constructors for this example}

In order to derive the correct semantics for the transitive property resultative sentence (repeated here as (314)), we will need to refer to the f-structure in (315), which has been given labels for each of the sub-structures.

$$
\text { Kim laughed herself silly. }
$$

\footnotetext{
${ }^{7}$ The lexical entry for the pronoun (312) is based off the work on pronouns in Section 4.2 in Asudeh (2012).
} 


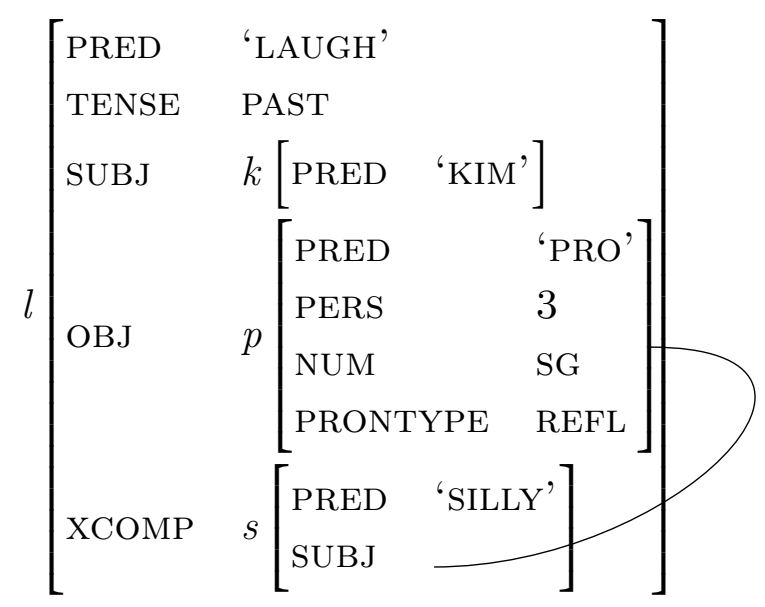

In the Glue meaning constructor portion of the following instantiated lexical entries and templates below, the letters $l, k, p$, and $s$ will stand for the f-structure which is labelled with that letter. Additionally, the notation l.e and s.e will stand for the event denoted by the f-structure labelled with that letter.

Kim

kim $: k$

(317) laughed

$$
\begin{aligned}
& \lambda x \lambda e . \operatorname{laugh}(e) \wedge \operatorname{agent}(e)=x: \\
& k \multimap l \multimap l . e \multimap l
\end{aligned}
$$

$$
\begin{array}{ll}
\text { (318) herself } & \\
& \lambda y \cdot y \times y: \\
& k \multimap(k \otimes p) \\
\text { (319) } \quad \text { silly } & \\
& \lambda x \lambda s . \operatorname{silly}(s) \wedge \operatorname{patient}(s)=x: \\
& p \multimap s . e \multimap s
\end{array}
$$




$$
\begin{aligned}
& @ \operatorname{SECPRED}(\mathrm{SEM}) \\
& \qquad \begin{array}{l}
\lambda Q \lambda P \lambda x . P(x) \wedge Q(x): \\
\quad(p \multimap s) \multimap(p \multimap l) \multimap(p \multimap l)
\end{array}
\end{aligned}
$$

@PROPERTY

$$
\begin{aligned}
& \lambda P \lambda x \lambda e \exists s . P(x)(s) \wedge \text { become }(e) \wedge \text { undergoer }(e)=x \wedge \operatorname{terminus}(e)=s: \\
& (p \multimap s . e \multimap s) \multimap(p \multimap s . e \multimap s)
\end{aligned}
$$

$$
\text { @Resultative }
$$

$$
\begin{aligned}
& \lambda P \lambda e^{\prime} \exists e . P(e)\left(e^{\prime}\right) \wedge \operatorname{cause}(e)=e^{\prime}: \\
& (\text { s.e } \multimap \text { l.e } \multimap l) \multimap(l . e \multimap l)
\end{aligned}
$$

\section{@FAKEREFLEXIVE}

$$
\begin{aligned}
& \lambda P \lambda x \lambda y \lambda e . P(x)(e) \wedge p a t i e n t(e)=y: \\
& (k \multimap l . e \multimap l) \multimap(k \multimap p \multimap l . e \multimap l)
\end{aligned}
$$

\section{Proof tree}

Before discussing the proof given in Figure 5.4 one final rule of linear logic must be discussed: conjunction elimination. Conjunction elimination (324) allows a pair of terms in a conjunction (noted by the $\otimes$ ) to be integrated into a derivation given that there are assumptions (noted by the square brackets) in play in the derivation for both of the conjoined terms. ${ }^{8}$

\footnotetext{
${ }^{8}(324)$ is from Asudeh (2012), p. 79.
} 


$$
\begin{gathered}
\text { Pairwise substitution : Conjunction Elimination } \\
\vdots \quad[x: A]^{1}[y: B]^{2} \\
\frac{a: A \otimes B \quad}{\text { let } a \text { be } x \times y \text { in } f: C} \otimes_{\mathcal{E}, 1,2}
\end{gathered}
$$

According to Asudeh (2012) the "multiplicative conjunction $A \otimes B$ corresponds to a tensor product $a \times b$, where $a$ is the proof term of $A$ and $b$ is the proof term of $B$." The term constructor, let, enforces pairwise substitution by preventing projection into the individual elements of the tensor pair with the $\beta$-reduction of the let expression shown in (325) (Asudeh, 2012, p. 80). ${ }^{9}$

$$
\text { let } a \times b \text { be } x \times y \text { in } f \quad \Rightarrow_{\beta} f[a / x, b / y]
$$

Finally, it should be noted that the let term is a slightly more structured form of functional application.

Moving on to the derivation for the fake reflexive property resultative, Figure 5.4 shows the complete proof. In this figure, we can see how each of the templates and lexical entries combine together to form the meaning of the entire sentence, shown at the bottom of the tree.

\footnotetext{
${ }^{9}(325)$ is from Asudeh $(2012,(5)$ on p. 80$)$.
} 


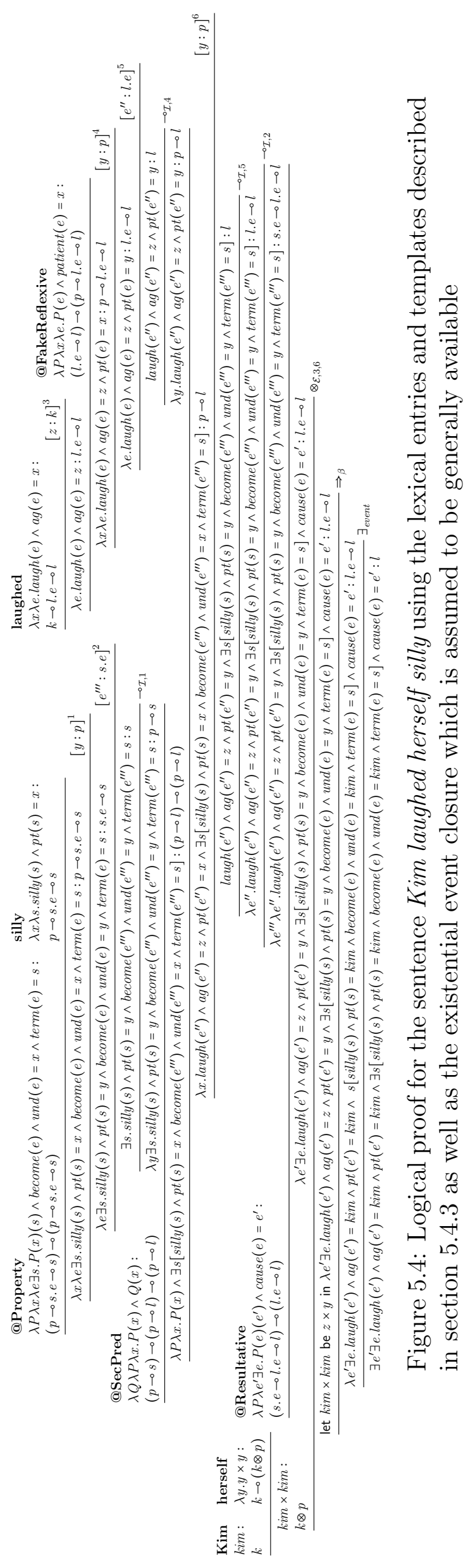


Beginning at the top of the left branch of the main derivation, the template @PROPERTY is combined with the lexical entry for silly to yield the meaning constructor in the second line. Next an assumption is given that $y$ will stand for the semantic interpretation of the subject of silly $\left([y: p]^{1}\right)$. Next an assumption is added that $e^{\prime \prime \prime}$ will stand for the semantic interpretation of the event for silly $\left(\left[e^{\prime \prime \prime}: \text { s.e }\right]^{2}\right)$, resulting in the fourth meaning constructor from the top of that branch. Then, assumption one is discharged $(-\circ \mathcal{I}, 1)$, leaving the meaning constructor which is combined with the template for @SECONDARYPREDICATION to yield the meaning constructor which is to be combined with the right branch of the derivation.

Beginning at the top of the right branch of the derivation, the lexical entry for laugh is given an assumption that $z$ will stand for the semantic interpretation of subject of laugh $\left([z: k]^{3}\right)$, yielding the meaning constructor in the second line which is then combined with the template @FAKEREFLEXIVE. The resulting meaning constructor is then given two assumptions: first that $y$ will stand for the interpretation of $p\left([y: p]^{4}\right)$, then that $e^{\prime \prime}$ will stand for the semantic interpretation of the event of laughing $\left(\left[e^{\prime \prime}: l . e\right]^{5}\right)$. Next, assumption four is discharged $-^{\circ} \mathcal{I}, 4$ yielding the meaning constructor which is then combined with the one from the left branch of the tree.

These two meaning constructors combine to form the constructor in the seventh line from the top of the derivation (on both branches), which is then given the assumption that $y$ will stand for the semantic interpretation of $p$, yielding an equation which has outstanding assumptions on $p$ and $k$, ready to undergo conjunction elimination.

On the leftmost branch of the derivation, the lexical entry for Kim is combined with the lexical entry for herself, which introduces the conjunction of Kim and the pronoun. 
Next the conjoined $k \otimes p$ is used to eliminate the assumptions 3 and 6 , integrating the meaning of both Kim and the reflexive pronoun into the overall meaning. Then assumptions 3 and 5 are discharged, leaving the meaning constructor third from the bottom of the derivation, which is looking for the event variables for both the silly and laugh events. This constructor is combined with the template @RESULTATIVE to existentially bind the silly event yielding the constructor in the second last line of the derivation. Finally, the existential event closure is used to bind the laugh event, yielding the meaning for the entire sentence.

\subsection{Conclusions}

This chapter has shown that the resultative can be accounted for using LFG templates. Each of the different types of the resultative (transitive, unaccusative and unergative of both property and path varieties) have been shown to be covered by this analysis. The difference between property and path resultatives can be found in their respective templates, with the resultative template able to call either the property or path template when constructing a meaning. These two separate templates reflect the meaning differences between property and path result phrases, while also reflecting their similarities in how they combine with the resultative.

One of the major benefits of this analysis is that the result phrase is deliberately treated as an added argument: it does not occur in the lexical entry of the verb, but is

added by the @SECONDARYPREDiCATION template. The secondary predicate itself is an XCOMP, which in LFG makes it an argument of the main predicate (rather than being the adjunct category XADJ). In this treatment arguments and adjuncts remain the same as in all other LFG treatments: arguments are associated with the lexical 
entries of the predicate; and adjuncts are marked as part of the set of adjuncts for the predicate. Added arguments are accounted for here by being added to the semantic interpretation by a template.

Additionally, the shared argument in resultative sentences is deliberately marked as such in the derivation. Unlike some previous work on the resultative, it is not an accident that the predication target is shared between the main and secondary predicate: it is specified to be shared between the two predicates in both the fstructure and semantic information of the template.

The unergative fake reflexive is accounted for by the @FAKEREFLEXIVE template, which requires that a reflexive pronoun is present in order to complete its meaning. The requirement means that when the result phrase added argument is present for an unergative, there also must also be a reflexive pronoun. More research will be needed to account for the presence of non-subcategorized objects (her shoes in (326)), but perhaps those examples are more like transitives than the fake reflexives are. However, more research will be required to determine if that is correct.

Kelly ran her shoes threadbare.

Finally, the templates introduced here are able to account for the experimental data in Chapter 4 in two crucial ways: the category of resultative is an added argument; and, there are separate templates for property and path resultatives. As discussed above, the result phrase is not associated with the main predicate, but is addded through the use of templates, and as an XCOMP, it must be an argument of the verb. The use of separate @PROPERTY and @PATH templates not only reflects a difference in the semantic interpretation of the sentence, but also the differences shown in the experimental data. 


\section{Chapter 6}

\section{Conclusions and future work}

\subsection{Conclusions}

This thesis has aimed to investigate the resultative in both a deep and broad manner using both theoretical and experimental methods. Chapter 2 explored the meaning of the resultative and the history of its treatment, including how the construction interacts with the main predicate; the argument which is shared between the main and secondary predicates; how the resultative interacts with telicity both regular and iterative; and, the syntactic structure and constituency facts of the resultative.

Chapter 3 introduced nine tests which are meant to determine a phrase's argument status in a sentence. It then used these tests to look for division within the resultative at a semantic, argument structure and lexical category level. Chapter 3 showed that there is a semantic division between property and path resultatives in terms of their argumenthood status. Additionally, it showed that under most circumstances, both property and path result phrases should be treated like an argument of the main verb, yielding more evidence for the notion of the added arguments of Kay (2005) or 
derived arguments of Needham and Toivonen (2011).

Chapter 4 focused in on one of the tests discussed in chapter 3, and tested the theoretical predictions experimentally. It showed that participants rated the acceptability of VP-preposed sentences differently depending on if an argument, adjunct or result phrase was stranded, giving more credence to the three-way distinction discussed in chapter 3 . These experimental results allowed us to confirm the typology which was devised in the previous chapters.

Finally, chapter 5 introduced and provided evidence for a treatment of resultatives using Lexical Mapping Theory, the template architecture of LFG, and Glue Semantics. It demonstrated how to derive the needed c- $\mathrm{f}$ - and semantic structures using the templates proposed, and provided complete proofs for three of the six categories of resultative discussed in this thesis.

As a whole this thesis has shown two major things: that property and path resultatives have different properties to be accounted for; and, that the resultative is an example of the category of added argument. The first major contribution allows us to see a link between the main body of researach on the resultative and some of the related elements that have been left aside for many treatments. This allows us to talk about the resultative in a new light that gives researchers the ability to still address all types of resultative, but also focus on what makes each sub-type interesting and unique without having to dismiss other sub-types as not resultatives. The second contribution adds to the body of evidence in favour of abandoning the traditional dichotomy between arguments and adjuncts in favour of a three-way distinction. This allows researchers to more broadly investigate the differences between arguments and adjuncts, without having to avoid the cases which do not fall into the same category 
on all of the possible tests for argumenthood.

The combination of theoretical modelling and experimental results allowed me to show a difference between the categories of the resultative from the perspective of both meaning/structure and human behaviour. The experimental data fed into the theoretical model by giving clear boundaries for the model to define, and showing that the resultative should be treated as an argument which is added to the structure of the verb.

\subsection{Future work}

Future directions for this study include designing a new experimental paradigm which will allow all three syntactic types of resultative to be evaluated by the same participants, so that direct comparisons can be made between transitive, unaccusative and unergative (fake reflexive) resultatives. This could be acheived through removal of the control conditions, as the control resultatives were shown to be highly acceptable. Careful consideration will also be needed to find analogous examples of the fake reflexive, as it is the most difficult to fit into a paradigm which remains the same across all resultative types. Additionally, looking at property and path resultatives separately could be avoided, as my experimental data showed that they were different from each other. Thus, an experiment could potentially be devised which looks at property resultatives of all three argument structure types, which would allow for a simpler design; and path resultatives could be invetigated separately or laid aside for another study.

From a theoretical perspective, future work could include creating and devising proofs for both subject-directed transitive resultatives and the depictive, and well 
as having a complete treatment for unergative resultatives with non-subcaetgorized objects. Additionally, further study into the semantics of change within the context of the resultative is needed. As noted by Beavers (2012), research on the semantics of change has outpaced research on the resultative, and a complete survey of how those two areas can come together in a modern treatment of the resultative would be a good addition to the literature.

Another key direction to be taken from this work would be to follow up on what exactly each of the tests for argumenthood identifies. This project took for granted that the tests in the literature would be identifying the properties of arguments/adjuncts, and thus I may have missed some data if that assumption was incorrect. A careful examination of the tests would be useful to the discussion of arguments, adjuncts and added arguments.

Finally, the most immediate direction to take this project would be to extend the treatment to other languages which utilize resultatives. For example, other Germanic languages which allow both property and path resultatives could be tested to see if the templates shown here (transitive, unaccusative and unergative/fake reflexive) still account for their data. Additionally, a good next step would be to analyze if the differences between property and path resultatives could help explain the crosslinguistic differences between languages which only accept certain kinds of result phrases, and require others to be expressed through a bi-clausal structure. 
Appendices 


\section{Appendix A}

\section{Stimuli for experiment 1:}

\section{Transitive resultatives}

For the sake of brevity, the experimental stimuli will not be listed in full. Instead, the first two items will be listed fully to demonstrate the pattern used to form the items, and then the remainder will list only the first and sixth condition (marked in bold font in the examples items). It will remain up to the interested reader to perform the necessary substitutions on the remaining items.

a. The foreman mixed the concrete to a uniform consistency on Tuesday.

b. The foreman needed to mix the concrete to a uniform consistency on Tuesday, and he did mix the concrete to a uniform consistency on Tuesday.

c. The foreman needed to mix the concrete to a uniform consistency on Tuesday, and mix he did the concrete to a uniform consistency on Tues- 
day.

d. The foreman needed to mix the concrete to a uniform consistency on Tuesday, and mix the concrete he did to a uniform consistency on Tuesday.

e. The foreman needed to mix the concrete to a uniform consistency on Tuesday, and mix the concrete to a uniform consistency he did on Tuesday.

f. The foreman mixed the concrete into a trough on Tuesday.

g. The foreman needed to mix the concrete into a trough on Tuesday, and he did mix the concrete into a trough on Tuesday.

h. The foreman needed to mix the concrete into a trough on Tuesday, and mix he did the concrete into a trough on Tuesday.

i. The foreman needed to mix the concrete into a trough on Tuesday, and mix the concrete he did into a trough on Tuesday.

j. The foreman needed to mix the concrete into a trough on Tuesday, and mix the concrete into a trough he did on Tuesday.

a. The chef mixed the ingredients into a sticky dough on Wednesday.

b. The chef endeavoured to mix the ingredients into a sticky dough on Wednesday, and she did mix the ingredients into a sticky dough on Wednesday.

c. The chef endeavoured to mix the ingredients into a sticky dough on Wednesday, and mix she did the ingredients into a sticky dough on Wednesday. 
d. The chef endeavoured to mix the ingredients into a sticky dough on Wednesday, and mix the ingredients she did into a sticky dough on Wednesday.

e. The chef endeavoured to mix the ingredients into a sticky dough on Wednesday, and mix the ingredients into a sticky dough she did on Wednesday.

f. The chef mixed the ingredients into the batter on Wednesday.

g. The chef endeavoured to mix the ingredients into the batter on Wednesday, and she did mix the ingredients into the batter on Wednesday.

h. The chef endeavoured to mix the ingredients into the batter on Wednesday, and mix she did the ingredients into the batter on Wednesday.

i. The chef endeavoured to mix the ingredients into the batter on Wednesday, and mix the ingredients she did into the batter on Wednesday.

j. The chef endeavoured to mix the ingredients into the batter on Wednesday, and mix the ingredients into the batter she did on Wednesday.

(329) a. The landscaper broke the twigs into tiny matchsticks on Monday.

b. The landscaper broke the twigs into the campfire on Monday.

(330) a. The barber brushed the hair into a spiked mohawk on Thursday.

b. The barber brushed the hair out of the sink on Thursday.

(331) a. The mother brushed the crumbs into a neat pile on Friday.

b. The mother brushed the crumbs off the table on Friday.

(332) a. The instructor coiled the ropes into a jumble after the workout.

b. The instructor coiled the ropes onto the ship after the workout. 
(333) a. The electrician coiled the wire into a large bundle on Sunday.

b. The electrician coiled the wire onto the floor on Sunday.

(334) a. The stylist curled the hair into perfect ringlets last week.

b. The stylist curled the hair onto the crown last week.

a. The owner curled the ribbon into a pretty bow yesterday.

b. The owner curled the ribbon onto the spindle yesterday.

(336) a. The ranger cut the vines into unequal hunks a month ago.

b. The ranger cut the vines off the tree a month ago.

(337) a. The woman cut the steak into jagged strips two nights ago.

b. The woman cut the steak off the bone two nights ago.

(338) a. The baker gathered the recipes into her collection a week ago.

b. The baker gathered the recipes off the desk a week ago.

(339) a. The teenager ground the chocolate into a fine powder three nights ago.

b. The teenager ground the chocolate into the carpet three nights ago.

(340) a. The barista ground the nutmeg into a light dust two hours ago.

b. The barista ground the nutmeg onto the hot chocolate two hours ago.

(341) a. The artist hammered the brass plate into a perfect circle last month.

b. The artist hammered the brass plate onto the sculpture last month.

(342) a. The smith hammered the copper into a thin plate last year.

b. The smith hammered the copper into the mould last year. 
(343) a. The child heaped the food into a sloppy mound at lunch.

b. The child heaped the food onto the platter at lunch.

(344) a. The father heaped the potatoes into a large lump at dinner.

b. The father heaped the potatoes onto the plate at dinner.

a. The worker raked the wet leaves into big clumps on Saturday.

b. The worker raked the wet leaves into a bag on Saturday.

(346) a. The volunteer raked the stones into a big circle three days ago.

b. The volunteer raked the stones off the grass three days ago.

(347) a. The fireman sawed the branches into sections six weeks ago.

b. The fireman sawed the branches into the wagon six weeks ago.

(348) a. The workman sawed the frozen tuna into single portions last Tuesday.

b. The workman sawed the frozen tuna into the ship's hold last Tuesday.

(349) a. The student shook the sprinkles into a neat pattern this morning.

b. The student shook the sprinkles onto the cake this morning.

(350) a. The farmer shook the barley into tidy rows this spring.

b. The farmer shook the barley into the mill this spring.

(351) a. The cook shredded the cheese into a neat layer two days ago.

b. The cook shredded the cheese onto the casserole two days ago.

(352) a. The athlete shredded the coconut into tiny flakes yesterday evening.

b. The athlete shredded the coconut onto the dessert yesterday evening. 
(353) a. The actor grated the ginger into a grainy pulp yesterday afternoon.

b. The actor grated the ginger into the pot yesterday afternoon.

(354) a. The actress grated the carrots into a fine mush last night.

b. The actress grated the carrots into the mixture last night.

(355) a. The teacher sliced the mushrooms into big chunks four days ago.

b. The teacher sliced the mushrooms onto the salad four days ago.

(356) a. The caterer sliced the chicken into thin strips before the party.

b. The caterer sliced the chicken onto the tray before the party.

(357) a. The player spread the batter into a thin layer before the dinner.

b. The player spread the batter into the pan before the dinner.

(358) a. The clown mashed the bananas into a mushy paste on the weekend.

b. The clown mashed the bananas onto the counter on the weekend.

(359) a. The people squished the grapes into a pulpy mush this afternoon.

b. The people squished the grapes into the wine this afternoon.

(360) a. The girl squished the raspberries into sticky jelly before the meal.

b. The girl squished the raspberries through the strainer before the meal.

(361) a. The porter stacked the boxes into a large pyramid after the party.

b. The porter stacked the boxes onto the truck after the party.

(362) a. The architect stacked the rocks into a beautiful sculpture a year ago.

b. The architect stacked the rocks onto the lawn a year ago. 
(363) a. The sales clerk swept the dirt into a small mound three weeks ago.

b. The sales clerk swept the dirt under the carpet three weeks ago.

(364) a. The assistant swept the glass into a small pile after the storm.

b. The assistant swept the glass off the floor after the storm.

(365) a. The editor tore the pages into pieces three hours ago.

b. The editor tore the pages out of the book three hours ago.

(366) a. The collector tore the poster into equal lengths two weeks ago.

b. The collector tore the poster off the wall two weeks ago.

(367) a. The leader glued the beads into an octagon six minutes ago.

b. The leader glued the beads onto the sweater six minutes ago.

(368) a. The boy glued the paper into a canoe shape four weeks ago.

b. The boy glued the paper onto the backdrop four weeks ago.

(369) a. The employee crushed the rocks into coarse gravel two months ago.

b. The employee crushed the rocks into the concrete mixer two months ago.

(370) a. The manager crushed the garlic into a thick paste an hour and a half ago.

b. The manager crushed the garlic into the sauce an hour and a half ago.

(371) a. The author ripped the article to tattered shreds a couple hours ago.

b. The author ripped the article out of the magazine a couple hours ago.

(372) a. The drummer ripped the jeans into frayed rags last Wednesday. 
b. The drummer ripped the jeans off the mannequin last Wednesday.

(373) a. The waiter ladled the soup into equal portions before the lunch.

b. The waiter ladled the soup into the bowls before the lunch.

(374) a. The poet scooped the ice cream into a giant sundae after dinner.

b. The poet scooped the ice cream onto the pie after dinner.

(375) a. The guard bundled the blankets into neat packages before shipping them.

b. The guard bundled the blankets into the closet before shipping them.

(376) a. The contractor shovelled the snow into a big heap last Monday.

b. The contractor shovelled the snow off the driveway last Monday. 


\section{Appendix B}

\section{Stimuli for experiment 2:}

\section{Unaccusative resultatives}

For the sake of brevity, the experimental stimuli will not be listed in full. Instead, the first two items will be listed fully to demonstrate the pattern used to form the items, and then the remainder will list only the first condition (marked in bold font in the examples items). It will remain up to the interested reader to perform the necessary substitutions on the remaining items.

a. The ball bounced off the stage on Tuesday.

b. The ball had to bounce off the stage on Tuesday, and it did bounce off the stage on Tuesday.

c. The ball had to bounce off the stage on Tuesday, and bounce it did off the stage on Tuesday.

d. The ball had to bounce off the stage on Tuesday, and bounce off the stage it did on Tuesday. 
(378) a. The balloon floated into the distance on Thursday.

b. The balloon was about to float into the distance on Thursday, and it did float into the distance on Thursday.

c. The balloon was about to float into the distance on Thursday, and float it did into the distance on Thursday.

d. The balloon was about to float into the distance on Thursday, and float into the distance it did on Thursday.

(379) a. The ship sank to the bottom of the sea on Wednesday.

(380) a. The raft floated down the river on Monday.

(381) a. The mat slid down the stairs on Friday.

(382) a. The glass slid off the counter on Saturday.

(383) a. The plate slipped off the table on Sunday.

(384) a. The bowl slipped out of her hands last week.

(385) a. The snake glided down the path yesterday.

(386) a. The boat glided out to sea a month ago.

(387) a. The eagle flew away from the building last year.

(388) a. The bird flew out of the window a week ago.

(389) a. The water flowed over the rocks last month.

(390) a. The syrup flowed down the tubes in April. 
(391) a. The oil seeped out of the furnace an hour ago.

(392) a. The rain seeped into the room six hours ago.

(393) a. The water trickled into the pond in March.

(394) a. The sweat trickled down her face after working out.

(395) a. The slime oozed out of the pipes two days ago.

(396) a. The mud oozed under the door three days ago.

(397) a. The vase broke into little shards six weeks ago.

(398) a. The dam broke into hefty blocks last Tuesday.

(399) a. The ice melted into a big puddle two weeks ago.

(400) a. The cheese melted into gooey blobs this morning.

(401) a. The water froze into beautiful icicles in January.

(402) a. The driveway froze into a skating rink yesterday evening.

(403) a. The logs burnt to ashy cinders yesterday afternoon.

(404) a. The roast burnt into a blackened lump last night.

(405) a. The barrel blew into microscopic pieces after the experiment.

(406) a. The flowers wilted into a wrinkly mess after the party.

(407) a. The spinach wilted to a dark green before the dinner.

(408) a. The building collapsed into a giant heap six months ago. 
(409) a. The tower collapsed into a charred ruin after the fire.

(410) a. The tire burst into shreds of rubber yesterday morning.

(411) a. The car rusted into big red lumps a year ago.

(412) a. The chain rusted into an immobile loop over the winter.

(413) a. The vase shattered into sharp pieces three weeks ago.

(414) a. The windows shattered into tiny razor blades during the storm.

(415) a. The banana peel dried into a hardened husk in a month.

(416) a. The herbs dried into a flaky mess two months ago. 


\section{Appendix C}

\section{Stimuli for experiment 3:}

\section{Unergative resultatives}

(417) a. The sailor crawled his way onto the ship.

b. The sailor crawled himself onto the ship.

(418) a. The musician cycled her way to the concert.

b. The musician cycled herself to the concert.

(419) a. The daredevil paddled her way over the falls.

b. The daredevil paddled herself over the falls.

(420) a. The girl paddled her way across the river.

b. The girl paddled herself across the river.

(421) a. The writer skated her way to work.

b. The writer skated herself to work.

(422) a. The hockey player skated her way down the rink. 
b. The hockey player skated herself down the rink.

(423) a. The officer skied her way through the scary woods.

b. The officer skied herself through the scary woods.

(424) a. The tutor skied his way down the hill.

b. The tutor skied himself down the hill.

(425) a. The child swam his way away from the rocks.

b. The child swam himself away from the rocks.

(426) a. The boy swam his way to the boat.

b. The boy swam himself to the boat.

(427) a. The assistant cycled his way out of the room.

b. The assistant cycled himself out of the room.

(428) a. The manager walked her way out of the kitchen.

b. The manager walked herself out of the kitchen.

(429) a. The drummer drank his way out of a job.

b. The drummer drank himself out of a job.

(430) a. The teenager hiccoughed his way into the record books.

b. The teenager hiccoughed himself into the record books.

(431) a. The employee jogged his way into shape.

b. The employee jogged himself into shape.

(432) a. The sales clerk laughed his way into hysterics. 
b. The sales clerk laughed himself into hysterics.

(433) a. The photographer lied his way onto the committee.

b. The photographer lied himself onto the committee.

(434) a. The athlete ran his way into scoring position.

b. The athlete ran himself into scoring position.

(435) a. The contestant sang her way to notoriety.

b. The contestant sang herself to notoriety.

(436) a. The student studied her way into the advanced class.

b. The student studied herself into the advanced class.

(437) a. The toddler worked her way into a tantrum.

b. The toddler worked herself into a tantrum.

(438) a. The lawyer worked her way to exhaustion.

b. The lawyer worked herself to exhaustion.

(439) a. The editor worried her way into a depression.

b. The editor worried herself into a depression.

(440) a. The agent worried her way into an anxious fit.

b. The agent worried herself into an anxious fit. 
Appendix D

Participant Means and Standard Deviations 


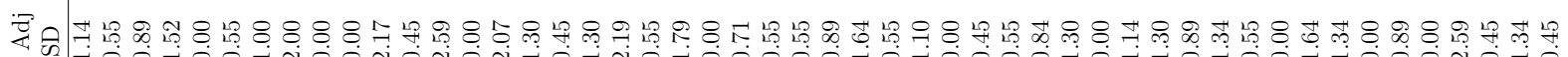

象

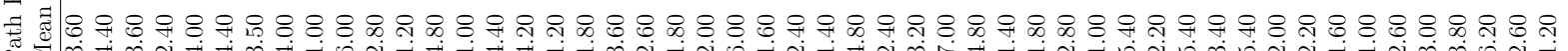
ص

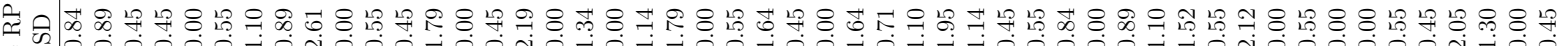

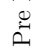

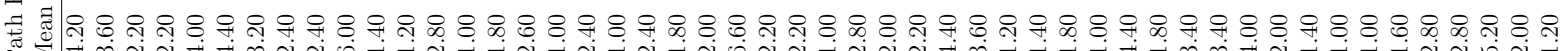

正

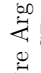

D.

垔

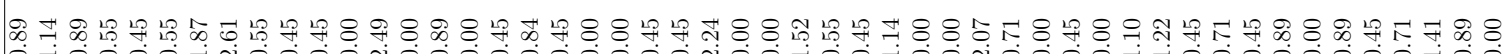

竞

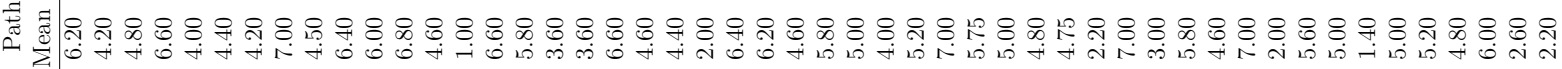

৩

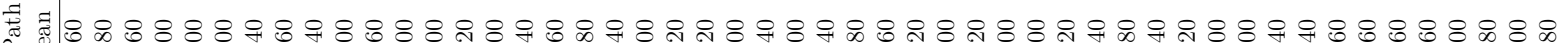

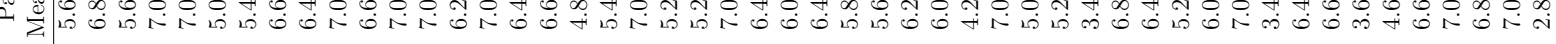

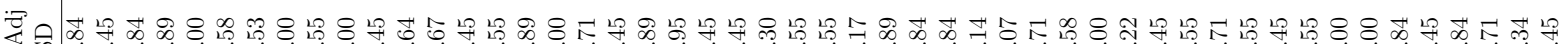
至

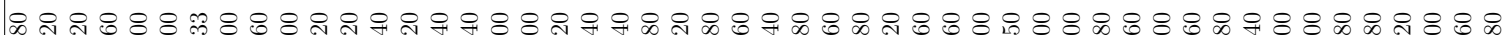

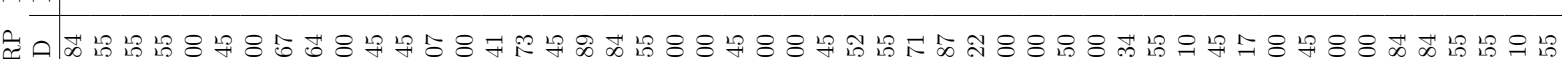

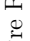

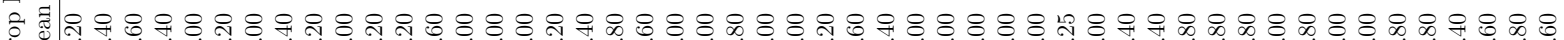

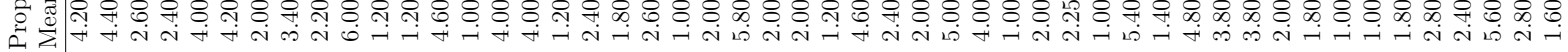

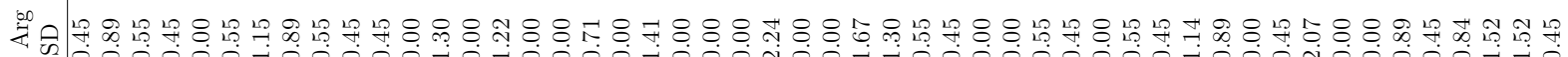

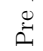

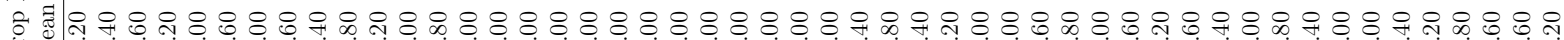

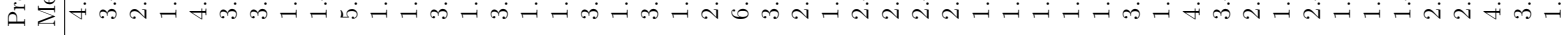

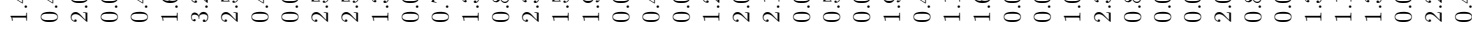

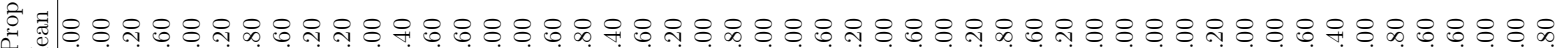

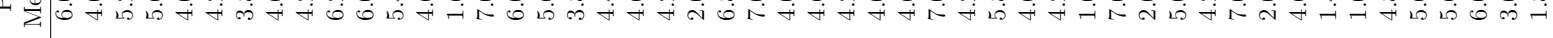

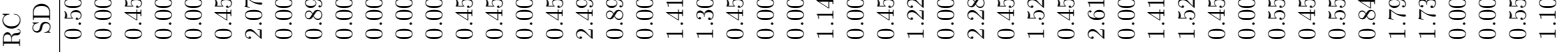

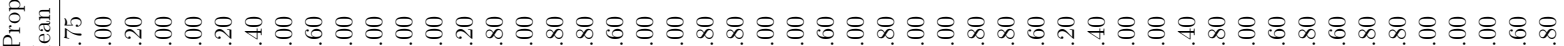

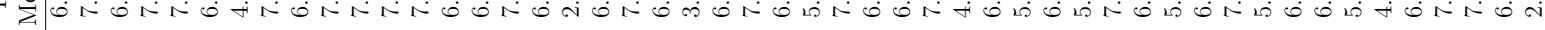




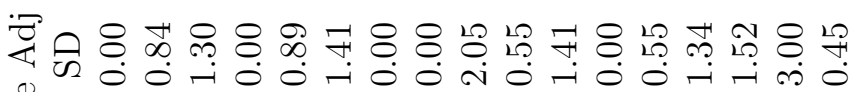
幽

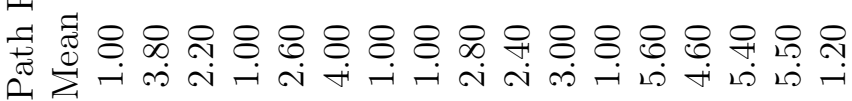

药 (

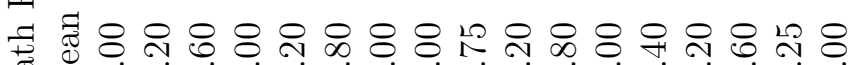

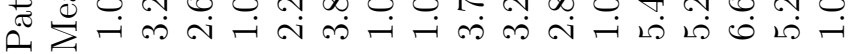

म

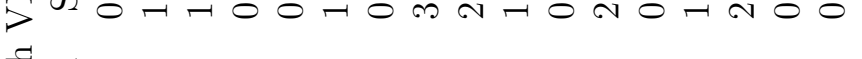

퓰

蓜

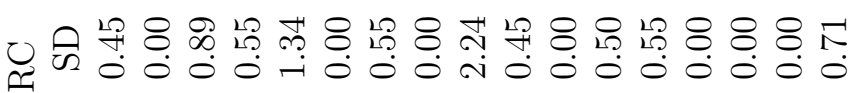

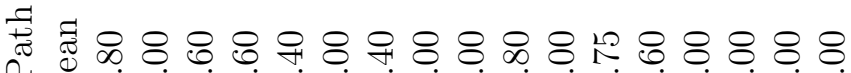

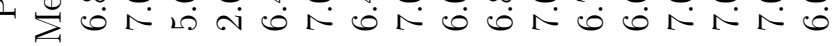

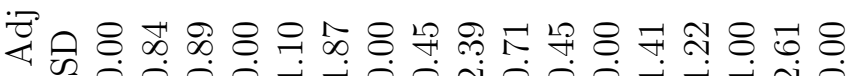
(1)

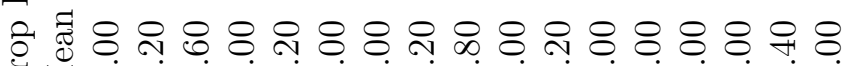

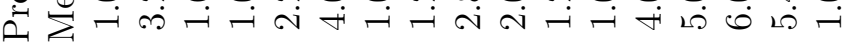

舀 竞

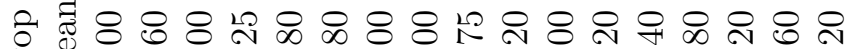

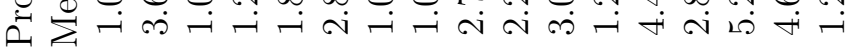

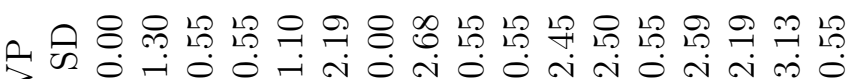

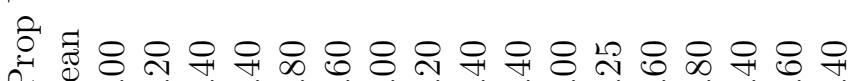

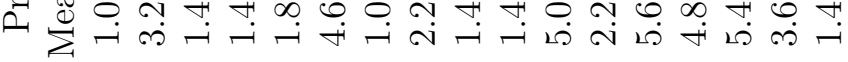
U

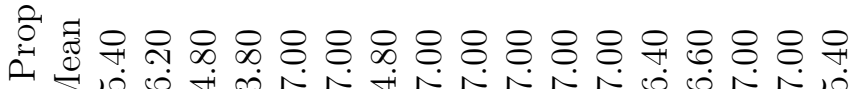

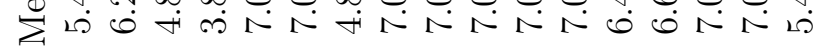

\#

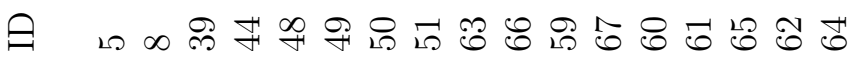




\begin{tabular}{l|cc|cc|cc|ccc} 
ID \# & \multicolumn{2}{|c}{ Prop Way } & \multicolumn{2}{c}{ Prop Fake Refl } & \multicolumn{3}{c}{ Path Way } & \multicolumn{2}{c}{ Path Fake Refl } \\
& Mean & SD & Mean & SD & Mean & SD & Mean & SD \\
5 & 6.67 & 0.58 & 4.33 & 3.06 & 7.00 & 0.0 & 04.33 & 2.31 \\
8 & 6.00 & 1.00 & 7.00 & 0.00 & 7.00 & 0.0 & 06.33 & 1.15 \\
39 & 4.33 & 1.53 & 6.00 & 0.00 & 4.00 & 1.7 & 33.33 & 1.53 \\
44 & 3.33 & 0.58 & 3.33 & 1.53 & 2.67 & 0.5 & 83.33 & 1.53 \\
48 & 4.67 & 2.08 & 5.67 & 2.31 & 5.00 & 3.4 & 65.00 & 3.46 \\
49 & 7.00 & 0.00 & 7.00 & 0.00 & 7.00 & 0.0 & 06.67 & 0.58 \\
50 & 5.00 & 1.73 & 5.00 & 1.73 & 5.33 & 1.1 & 52.67 & 1.53 \\
51 & 6.67 & 0.58 & 5.00 & 3.46 & 5.67 & 2.3 & 12.00 & 1.73 \\
63 & 7.00 & 0.00 & 5.67 & 2.31 & 5.33 & 2.8 & 93.00 & 2.65 \\
66 & 7.00 & 0.00 & 7.00 & 0.00 & 7.00 & 0.0 & 07.00 & 0.00 \\
59 & 7.00 & 0.00 & 7.00 & 0.00 & 7.00 & 0.0 & 06.67 & 0.58 \\
67 & 7.00 & 0.00 & 6.33 & 0.58 & 7.00 & 0.0 & 06.67 & 0.58 \\
60 & 6.00 & 0.00 & 4.33 & 2.52 & 6.00 & 0.0 & 04.33 & 1.53 \\
61 & 6.67 & 0.58 & 7.00 & 0.00 & 7.00 & 0.0 & 06.00 & 1.73 \\
65 & 6.33 & 1.15 & 6.67 & 0.58 & 7.00 & 0.0 & 04.33 & 2.52 \\
62 & 7.00 & 0.00 & 7.00 & 0.00 & 7.00 & 0.0 & 03.00 & 3.46 \\
64 & 5.33 & 1.15 & 4.33 & 2.52 & 5.67 & 0.5 & 83.00 & 1.00
\end{tabular}

Table D.3: Participant means and standard deviations per condition for experiment 3 


\section{Bibliography}

Asudeh, Ash. 2012. The Logic of Pronominal Resumption. Oxford University Press.

Asudeh, Ash, Dalrymple, Mary and Toivonen, Ida. 2008. Constructions with Lexical Integrity: Templates as the lexicon-syntax interface. In Miriam Butt and Tracy Holloway-King (eds.), Proceedings of the LFG08 Conference, pages 68-88, CSLI Publications.

Asudeh, Ash, Dalrymple, Mary and Toivonen, Ida. 2013. Constructions with Lexical Integrity. Journal of Language Modelling 1, 1-54.

Asudeh, Ash and Giorgolo, Gianluca. 2012. Flexible Composition for Optional and Derived Arguments. In Miriam Butt and Tracy Holloway King (eds.), Proceedings of the LFG12 Conference.

Asudeh, Ash, Giorgolo, Gianluca and Toivonen, Ida. 2014. Meaning and valency. In Miriam Butt and Tracey Holloway King (eds.), Online Proceedings of the LFG14 Conference, pages 68-88.

Asudeh, Ash and Toivonen, Ida. 2014. With Lexical Integrity. Theoretical Linguistics 40(1-2), 175-186. 
Baker, Carl L. 1978. Introduction to Generative Transformational Syntax. Englewood Cliffs, New Jersey: Prentice-Hall.

Baker, Mark. 1988. Incorporation: a Theory of Grammatical Function Changing. Chicago, Illinois: University of Chicago Press.

Baker, Mark. 1996. On the Structural Position of Themes and Goals. In J. Rooryck and L. Zaring (eds.), Phrase Structure and the Lexicon, pages 7-34, Kluwer, Dordrecht.

Baltin, Mark. 2006. The Nonunity of VP-Preposing. Language 82(4), 734-766.

Barbu, Roxana-Maria. 2015. Verbs and Participants: Nonlinguists' Intuitions. Masters Thesis, Carleton University.

Beavers, John. 2002. Aspect and the distribution of prepositional resultative phrases in English. Unpublished ms, Stanford University, Stanford, CA .

Beavers, John. 2008. Scalar complexity and the structure of events. Event structures in linguistic form and interpretation pages 245-265.

Beavers, John. 2012. Resultative Constructions. In Robert I. Binnick (ed.), Oxford Handbook of Tense and Aspect, pages 908-933, Oxford University Press.

Boas, Hans C. 2003. A Constructional Approach to Resultatives. CSLI Publications.

Boland, Julie E. 2005a. Cognitive mechanisms and syntactic theory. Twentyfirst century psycholinguistics: Four cornerstones pages 23-42.

Boland, Julie E. 2005b. Visual Arguments. Cognition 95(3), 237-274. 
Boland, Julie E. and Blodgett, Allison. 2006. Argument status and PP-attachment. Journal of Psycholinguistic Research 35(5), 385-403.

Borer, Hagit. 2005. Structuring Sense, Volume II: The normal course of events. Oxford University Press.

Bowers, J. 1997. A binary analysis of resultatives. Texas Linguistics Forum 38, 4358.

Bresnan, Joan. 1982. Control and complementation. Linguistic Inquiry 13(3), 343434, also in Joan Bresnan, ed. 1982. The Mental Representation of Grammatical Relations, Chapter 5, pp. 282-390. Cambridge, MA: The MIT Press.

Bresnan, Joan. 2001. Lexical-Functional Syntax. Oxford: Blackwell Publishers.

Bresnan, Joan and Kanerva, Jonni. 1989. Locative inversion in Chichewa: a case study of factorization in grammar. Linguistic Inquiry 20(1), 1-50, reprinted in Tim Stowell and Eric Wehrli (eds.), Syntax and Semantics No. 26: Syntax and the Lexicon, pp. 53-101. New York: Academic Press.

Bresnan, Joan and Moshi, Lioba. 1990. Object asymmetries in comparative Bantu syntax. Linguistic Inquiry 21(2), 147-185, reprinted in Sam A. Mchombo (ed.) Theoretical Aspects of Bantu Grammar 1, 47-91. Stanford: CSLI Publications.

Bresnan, Joan and Zaenen, Annie. 1990. Deep Unaccusativity in LFG. In Patrick Farrell, Katarzyna Dziwirek and Errapel Mejias-Bikandi (eds.), Grammatical Relations: A Cross-Theoretical Perspective, pages 45-58, CSLI Publications.

Broccais, Cristiano. 2003. The English Change Network. Mouton De Gruyter. 
Burzio, L. 1986. Italian Syntax: A Government-Binding Approach. Studies in Natural Language and Linguistic Theory, D. Reidel Publishing Company.

Carnie, Andrew. 2002. Syntax: A Generative Introduction. Blackwell Publishers Inc.

Carnie, Andrew. 2007. Syntax: A Generative Introduction. Introducing Linguistics, Blackwell Publishing, second edition.

Carpenter, Bob. 1998. Type-Logical Semantics. MIT Press.

Carrier, Jill and Randall, Janet H. 1992. The Argument Structure and Syntactic Structure of Resultatives. Linguistic Inquiry 23(2), 173-234.

Christie, Elizabeth. 2010. Using Templates to Account for English Resultatives. In Miriam Butt and Tracy Holloway-King (eds.), Online Proceedings of the LFG' 10 Conference, pages 155-164, CSLI Publications.

Christie, Elizabeth. 2011. Investigating the differences between the English wayconstruction and the fake reflexive resultative construction. In Lisa Armstrong (ed.), Proceedings of the 2011 annual conference of the Canadian Linguistic Association., pages 1-14.

Christie, Elizabeth. 2013a. Categories of the English Resultative. Poster given at the 2013 Institute of Cognitive Science Spring Conference.

Christie, Elizabeth. 2013b. Testing the argument status of the unaccusative resultative. In Sixth Toronto-Ottawa-Montreal Semantics Workshop.

Christie, Elizabeth and Toivonen, Ida. 2013. The argument status of result phrases. 
Paper given at the 25th Annual Scandanavian Conference of Linguistics. Reykjavik, Iceland.

Cowart, Wayne. 1997. Experimental syntax: Applying objective methods to sentence judgments. Sage publications.

Culicover, Peter. 1997. Principles and parameters: an introduction to syntactic theory. Oxford Textbooks in Linguistics Series, Oxford University Press, Incorporated.

Dalrymple, Mary. 2001. Lexical-Functional Grammar (Syntax and Semantics, Volume 34) (Syntax and Semantics). Academic Press.

Dalrymple, Mary, Kaplan, Ronald M and Holloway King, Tracy. 2004. Linguistc Generalizations Over Descriptions. In On-line Proceedings of the LFG2004 Conference, pages 199-208, CSLI Publications.

Depraetere, Ilse. 1995. On the necessity of distinguishing between (un)boundedness and (a)telicity. Linguistics and Philosophy 18(1), 1-19.

Dowty, David. 1979. Word meaning and Montague grammar. Synthese language library, D. Reidel Pub. Co.

Dowty, David. 1982. Grammatical Relations and Montague Grammar. In Pauline Jacobson and Geoffrey K. Pullum (eds.), The Nature of Syntactic Representation, pages 79-130, D. Reidel Publishing Company.

Dowty, David. 2003. The Dual Analysis of Adjuncts and Complements in Categorial Grammar. In E. Lang, C. Maienborn and C. Fabricius-Hansen (eds.), Modifying Adjuncts, Interface Explorations, Mouton De Gruyter. 
Embick, D. 2004. On the structure of resultative participles in English. Linguistic Inquiry 35(3), 355-392.

Emonds, Joseph. 1970. Root and structure-preserving transformations. Ph. D.thesis, MIT.

Fillmore, Charles. 1968. The Case for Case. In Emmon Bach and Richard Harms (eds.), Universals in Linguistic Theory, pages 1-90, New York, New York: Holt, Rinehart and Winston.

Findlay, Jamie. 2014. Mapping Theory without Argument Structure.

Folli, Raffaella and Harley, Heidi. 2006. On the licensing of causatives of directed motion: Waltzing Matilda all over. Studia Linguistica 60(2), 121-155.

Goldberg, Adele E. 1992. In Support of a Semantic Account of Resultatives. Technical Report, CSLI.

Goldberg, Adele E. 1995. Constructions. The University of Chicago Press.

Goldberg, Adele E. and Jackendoff, Ray. 2004. The English Resultative as a Family of Constructions. Language 80, 532-568.

Grône, Maryse. 2014. Les résultatives de l'anglais. Ph. D.thesis, Université Paris Diderot Paris 7.

Haegeman, Liliane. 1994. Introduction to Government and Binding Theory Second Edition. Blackwell Publishers Inc.

Hall, Barbara. 1965. Subject and object in modern English. Ph. D.thesis, MIT. 
Halliday, M. A. K. 1967. Notes on Transitivity and Theme in English: Part 1. Journal of Linguistics 3(1), 37-81.

Hedberg, Nancy and DeArmond, Richard C. 2009. On complements and adjuncts. Snippets 19, 11-12.

Hoekstra, Teun. 1988. Small Clause Results. Lingua 74, 101-139.

"into". 2013. Oxford English Dictionary Online. Oxford University Press, http://www.oed.com/viewdictionaryentry/Entry/98530.

Irimia, Monica-Alexandrina. 2005. Types of secondary predication. Toronto Working Papers in Linguistics 25, 20-29.

Iwata, Seizi. 2006. Argument resultatives and adjunct resultatives in a lexical constructional account: the case of resultatives with adjectival result phrases. Language Sciences 28, 449-496.

Jackendoff, Ray. 1990. Semantic Structures. MIT Press.

Jackendoff, Ray. 2002. Foundations of Language: Brain, Meaning, Grammar, Evolution. Oxford University Press.

Kaplan, Ronald M and Bresnan, Joan. 1982. Lexical Functional Grammar: A Formal System for Grammatical Representation. In Joan Bresnan (ed.), The Mental Representation of Grammatical Relations, pages 173-281, The Massachusetts Institute of Technology.

Kay, Paul. 2005. Argument Structure Constructions and the Argument-Adjunct Dis- 
tinction. In Mirjam Fried and Hans Boas (eds.), Grammatical Constructions: Back to the Roots, pages 71-98, Benjamins.

Kearns, Kate. 2000. Semantics. Palgrave Modern Linguistics, Palgrave Macmillan.

Kearns, Kate. 2006. Semantics. Palgrave Macmillan, second edition.

Kennedy, Chris and McNally, Louise. 2005. Scalar Structure, Degree Modification and the Semantics of Gradable Predicates. Language 81(2), 345-381.

Kibort, Anna. 2004. Passive and passive-like constructions in English and Polish. Ph. D.thesis, University of Cambridge.

Kibort, Anna. 2006. Extending the applicability of Lexical Mapping Theory. In Miriam Butt and Tracey Holloway King (eds.), Proceedings of the LFG07 Conference, CSLI Publications.

Kibort, Anna. 2008. Impersonals in Polish: an LFG perspective. Transactions of the Philological Society 106(2), 246-289.

Kibort, Anna. 2012. Participles, adjectives, and the role of argument structure. In Miriam Butt and Tracey Holloway King (eds.), Proceedings of LFG12, pages 323340, CSLI Publications.

Koenig, Jean-Pierre, Mauner, Gail and Bienvenue, Breton. 2003. Arguments for adjuncts. Cognition 89, 67-103.

Kratzer, Angelika. 2005. Building Resultatives. In Claudia Maienborn and Angelika W. Leisten (eds.), Event Arguments: Foundations and Applications, pages 177-212, Niemeyer. 
Krifka, Manfred. 1989. Nominal reference, temporal constitution and quantification in event semantics. Semantics and contextual expression 75115.

Krifka, Manfred. 1992. Thematic Relations as Links between Nominal Reference and Temporal Consitiution. In Ivan A. Sag and Anna Szabolsci (eds.), Lexical Matters, pages 29-53, CSLI.

Kroeger, Paul. 2004. Analyzing Syntax: A Lexical-Functional Approach. Cambridge: Cambridge University Press.

Lakoff, George and Ross, John R. 1966. Criterion for Verb Phrase Constituency. Technical Report NSF-17, Aiken Computation Laboratory, Harvard University.

Larson, Richard. 1990. Double objects revisited: reply to Jackendoff. Linguistic Inquiry 21(4), 589-632.

Levin, B. and Rappaport Hovav, M. 1995. Unaccusativity: At the Syntax-Lexical Semantics Interface. Linguistic Inquiry Monographs, MIT Press.

Levin, Beth. 1993. English Verb Classes and Alternations. University of Chicago Press.

Levin, Beth and Rappaport Hovav, Malka. 2005. Argument Realization. Research Surveys in Linguistics, Cambridge University Press.

MacGregor, Elizabeth. 2009. Using Templates to Account for English Resultatives. Masters Thesis, University of Essex.

Mateu, Jaume. 2011. Conflation and incorporation processes in resultative construc- 
tions. In Dins V. Demonte and L. McNally (eds.), Telicity, Change, and State: A Cross-Categorial View of Event Structure., pages 252-278, Oxford University Press.

Napoli, Donna. 1992. Resultative Predicates in Italian. Journal of Ling 28, 53-90.

Needham, Stephanie and Toivonen, Ida. 2011. Derived Arguments. In Miriam Butt and Tracy Holloway King (eds.), Proceedings of the LFG11 Conference, pages 401421, CSLI Publications.

Perlmutter, David and Postal, Paul. 1984. The 1-Advancement Exclusiveness Law. In David Perlmutter and Carol Rosen (eds.), Studies in Relational Grammar volume 2, University of Chicago Press.

Perlmutter, David. M. 1977. Impersonal Passives and the Unaccusative Hypothesis. In Proceedings of the 4th Annual Meeting of the Berkley Linguistics Society, pages $157-190$.

Pollard, Carl Jesse and Sag, Ivan A. 1987. Information-based syntax and semantics. Sanford, CA: Center for the Study of Language and Information.

Radford, Andrew. 1981. Transformational Syntax: A Students Guide to Chomskys Extended Standard Theory. Cambridge, England.: . Cambridge University Press.

Radford, Andrew. 1988. Transformational grammar: A first course, volume 1. Cambridge University Press.

Radford, Andrew. 2004. Minimalist syntax: Exploring the structure of English. Cambridge University Press.

Randall, Janet. 2010. Linking: The Geometry of Argument Structure. Springer. 
Rappaport Hovav, Malka and Levin, Beth. 2001. An Event Structure Account of English Resultatives. Language 77(4), 766-797.

Simpson, Jane. 1983a. Aspects of Warlpiri Morphology and Syntax. Ph. D.thesis, MIT, Department of Linguistics and Philosophy.

Simpson, Jane. 1983b. Resultatives. In Lori S. Levin, Malka Rappaport and Annie Zaenen (eds.), Papers in Lexical-Functional Grammar, pages 143-157, Bloomington: Indiana University Linguistics Club.

Smith, Carlotta. 1991. The Parameter of Aspect. Dordrecht: Kluwer Academic Publishers.

Tallerman, Maggie. 2005. The Celtic Languages. In Guglielmo Cinque and Richard S. Kayne (eds.), The Oxford Handbook of Comparative Syntax, pages 839-879, Oxford: Oxford University Press.

Tenny, Carol. 1992. The Aspectual Interface Hypothesis. In Ivan A. Sag and Anna Szabolsci (eds.), Lexical Matters, pages 1-27, CSLI.

Tenny, Carol. 1994. Aspectual roles and the syntax-semantics interface. Kluwer Academic Publishers Dordrecht.

Thepkanjana, Kingkarn and Uehara, Satoshi. 2009. Resultative constructions with "implied-result" and "entailed-result" verbs in Thai and English: a contrastive study. Linguistics 47(3), 589-618.

Toivonen, Ida. 1999. Swedish place expressions. In Pius Tamanji, Masako Hirotani and Nancy Hall (eds.), NELS 29, Proceedings of the North East Linguistic Society, pages 367-380, University of Delaware. 
Toivonen, Ida. 2002. Verbal particles and results in Swedish and English. In Proceedings of the West Coast Conference in Formal Linguistics, volume 21, pages $457-470$.

Toivonen, Ida. 2003. Non-Projecting Words. A Case Study of Swedish Particles. Dordrecht: Kluwer.

Toivonen, Ida. 2006. On continuative on*. Studia linguistica 60(2), 181-219.

Toivonen, Ida. 2012. Between arguments and adjuncts. Paper presented at the International conference of Nordic and General Linguistics. Freiburg, Germany.

Toivonen, Ida. 2013a. English Benefactive NPs. In Miriam Butt and Tracy Holloway King (eds.), Proceedings of the LFG13 Conference.

Toivonen, Ida. 2013b. How language Represents Event Participants. Talk given at Institute of Cognitive Science Colloquium Series, Carleton University, Canada.

Tutunjian, Damon and Boland, Julie E. 2008. Do we need a distinction between arguments and adjuncts? Evidence from psycholinguistic studies of comprehension. Language and Linguistics Compass 2(4), 631-646.

van Egmond, Marie-Elaine. 2009. Two way-constructions in Dutch: motion along a path and transition to a location. VDM Verlag.

van Hout, Angeliek. 2004. Unaccusativity as Telicity Checking. In Artemis Alexiadou, Elena Anagnostopoulou and Martin Everaert (eds.), The Unaccusativity Puzzle: Explorations of the Syntax-Lexicon Interface, Chapter 2, pages 61-84, Oxford University Press. 
Van Luven, Katie. 2014. The Argument Status of Directional PPs. Undergraduate honors thesis, Carleton University.

Van Valin, Robert. 1990. Semantic parameters of split intransitivity. Language pages $221-260$.

Van Valin, Robert and LaPolla, Randy J. 1997. Syntax: form, meaning, and function. Cambridge University Press.

Vendler, Zeno. 1967. Linguistics in Philosophy. Ithaca: Cornell University Press.

Verspoor, Cornelia Maria. 1997. Contextually-Dependant Lexical Semantics. Ph. D.thesis, University of Edinburgh.

Washio, Ryuichi. 1997. Resultatives, Compositionality and Language Variation. Journal of East Asian Linguistics 6, 1-49, 10.1023/A:1008257704110.

Wechsler, S. 2000. An Analysis of English Resultatives Under the Event-Argument Homomorphism Model of Telicity. In Proceedings of the 3rd Workshop on Text Structure, pages 1-15, University of Texas, Austin.

Wechsler, S. 2005. Resultatives Under the Event-Argument Homomorphism Model of Telicity. In Nomi Erteschik-Shir and Tova Rapoport (eds.), The Syntax of AspectDeriving Thematic and Aspectual Interpretation, pages 255-273, Oxford University Press.

Wechsler, Stephen. 1991. Argument structure and linking. Ph. D.thesis, Stanford University. 
Wechsler, Stephen. 2015. Word Meaning and Syntax, volume 9. Oxford University Press.

Wechsler, Steven. 1997. Resultative Predicates and Control. In Texas Linguistics Forum, volume 38, pages 307-321.

Whelpton, Matthew. 2010. Building Resultatives in Icelandic. In Raffaella Folli and Christiane Ulbrich (eds.), Interfaces in Linguistics: New Research Perspectives, Oxford Studies in Theoretical Lingusitics, No. 31, Chapter 5, pages 96-115, Oxford University Press.

Williams, Alexander. 2015. Arguments in Syntax and Semantics. Cambridge University Press.

Zaenen, Annie and Crouch, Dick. 2009. OBLs hobble computations. In Miriam Butt and Tracy Holloway King (eds.), The Proceedings of the LFG '09 Conference, pages 644-654, Trinity College, Cambridge, UK. 